\title{
Targeting Calcium Homeostasis for the Treatment of Multiple Myeloma
}

\section{Osama M. Elzamzamy, MBBCh}

\author{
Dissertation submitted to the School of Medicine \\ at West Virginia University \\ in partial fulfillment of the requirements for the degree of \\ Doctor of Philosophy in \\ Clinical and Translational Sciences
}

\author{
Lori A. Hazlehurst, Ph.D., Mentor/ Chair \\ Scott Weed, Ph.D. \\ Michael Craig, M.D. \\ Anne Cress, Ph.D. \\ Werner Geldenhuys, Ph.D.
}

Clinical and Translational Sciences Ph.D. Program

Morgantown, West Virginia

2021

Keywords: Multiple Myeloma, calcium homeostasis, MTI-101, Store-operated calcium entry, SOCE, TRPC, Orai1, STIM1

\section{Copyright 2021 Osama Elzamzamy}




\section{ABSTRACT \\ Targeting Calcium Homeostasis for the Treatment of Multiple Myeloma}

Osama M. Elzamzamy

Multiple myeloma (MM) is a hematological malignancy characterized by the neoplastic proliferation of the plasma cells. MM is a relatively rare cancer that accounts for about $1.8 \%$ of all cancers and is the second most common hematologic malignancies, and despite the advancement from untreatable to treatable malignancy, it is yet incurable. Calcium ions $\left(\mathrm{Ca}^{2+}\right)$ play an important role as second messengers in regulating a plethora of physiological and pathological processes, hence cytoplasmic $\mathrm{Ca}^{2+}$ is tightly regulated with strict spatial and temporal control to initiate, maintain, and terminate appropriate signaling pathways and phenotypes including cellular proliferation, cell cycle control, migration, gene expression, muscle contraction, metabolism, and cell death. Multiple $\mathrm{Ca}^{2+}$ pumps and channels exist in the cell to tightly regulate cytoplasmic $\mathrm{Ca}^{2+}$ levels. The plasma membrane $\mathrm{Ca}^{2+}$ transport ATPase (PMCA), and the $\mathrm{Na}+\mathrm{Ca}^{2+}$ exchanger (NCX) are present on the plasma membrane, the mitochondrial $\mathrm{Ca}^{2+}$ uniporter (MCU) are located on the mitochondrial membrane, and the sarcoplasmic reticulum/endoplasmic reticulum $\mathrm{Ca}^{2+}$ ATPase (SERCA) pump, the 1,4,5-triphosphate receptor (IP3R) and ryanodine receptor (RyR) channels are expressed on SE/ER membranes, all these channels work seamlessly to regulate and redistribute $\mathrm{Ca}^{2+}$ levels among various cellular compartments. The major $\mathrm{Ca}^{2+}$ regulatory pathway in non-excitable cells is the Store-Operated $\mathrm{Ca}^{2+}$ Entry Pathway (SOCE) and one its major contributors is TRPC1. TRPC1 is a member of the TRP protein superfamily and a potential modulator of store-operated $\mathrm{Ca}^{2+}$ entry (SOCE) pathways. While TRPC1 is ubiquitously expressed in most tissues, its dysregulated activity may contribute to the hallmarks of various types of cancers, including breast cancer, pancreatic cancer, glioblastoma multiforme, lung cancer, hepatic cancer, multiple myeloma and thyroid cancer. Our group has developed a novel cyclic peptide referred to as MTI-101 for the treatment of MM. MTI-101 is derived from a 10 D-amino acids peptide HYD1, which was discovered to block cancer cell adhesion to extracellular matrix. It was previously reported that acquired resistance to HYD-1 correlated with repression of genes involved in store operated $\mathrm{Ca}^{2+}$ entry (SOCE): PLC $\beta$, SERCA, ITPR3, and TRPC1 expression. We sought to determine the role of TRPC1 heteromers in mediating MTI-101 induced cationic flux. Our data indicate that consistent with activation of TRPC heteromers, MTI-101 treatment induced $\mathrm{Ca}^{2+}$ and 
$\mathrm{Na}+$ influx. However, replacing extracellular $\mathrm{Na}+$ with NMDG did not reduce MTI-101-induced cell death. In contrast, decreasing extracellular $\mathrm{Ca}^{2+}$ reduced both MTI-101-induced $\mathrm{Ca}^{2+}$ influx as well as cell death. The causative role of TRPC heteromers was established by suppressing STIM1, TRPC1, TRPC4 or TRPC5 function both pharmacologically and by siRNA, resulting in a reduction in MTI-101-induced $\mathrm{Ca}^{2+}$ influx. Mechanistically MTI-101 treatment induces trafficking of TRPC1 to the membrane and co-immunoprecipitation studies indicate that MTI-101 treatment induces a TRPC1-STIM1 complex. Moreover, treatment with calpeptin inhibited MTI-101induced $\mathrm{Ca}^{2+}$ influx and cell death indicating a role of calpain in the mechanism of MTI-101induced cytotoxicity. Finally, components of the SOCE pathway were found to be poor prognostic indicators among MM patients, suggesting that this pathway is attractive for the treatment of MM. 


\section{DEDICATION}

To my father. You are the reason I kept pushing. Thank you for believing in me. I know you are in a better place.

To our darling daughter, Jumana. We will always be your biggest fans. May your smile keep brightening our lives. You are God's greatest gift.

To Dalia. The love of my life. The superhero. Thank you for being the hope when there was none left. 


\section{ACKNOWLEDGMENTS}

This project would not have been possible without the support of many people. Many thanks to my adviser, Dr. Lori Hazlehurst. I have benefited greatly from your wealth of knowledge and meticulous editing. I am extremely grateful that you took me on as a Ph.D. student and continued to have faith in me over the years.

Thank you to my committee members, Dr. Scott Weed, Dr. Michael Craig, Dr. Anne Cress, and Dr. Werner Geldenhuys your encouraging words and thoughtful, detailed feedback have been instrumental to my work.

I would also be amiss if I did not mention my lab mates, former and present, and colleagues, Wei-Chih Chen, Karen Hayes, Clark Jones, and Brennen Johnson, who were always ready to help whenever needed.

It is important to strike a balance with life outside the deep depths of the lab. As such, I cannot stress enough about the importance of game nights with my friend and colleague, Clark Jones, Marc Purazo, Rachael Rush, and Jacob Booze Thank you for your cheerful spirit and positive demeanor.

I am also indebted to my friend, Wade Bowser. You were always there, wherever and whenever that was. With every night experiment, each early morning rant, you were always there to hear me out, cheer me up and help navigate my career.

I would like to thank Mackenna Boone for her tremendous help with the project. And more importantly for giving my family an ever lasting gift, our now not a puppy anymore Zoey. You changed our lives.

My deepest gratitude to my first colleague, friend, and mentor Hannah Wilson. Thank you for teaching me everything I didn't know about lab work, for answering all my questions with a smile, and for being there for me and my family all the time. We appreciate you.

Most importantly, I am grateful for my family's unconditional, unequivocal, and loving support.

I am grateful for my parents, Mokhtar Elzamzamy and Refka Abulgebain. Your constant love and support kept me motivated and confident. My accomplishments and success are because you believed in me. Deepest thanks to my siblings, Mazin, Mohamed, Khalid and Abdelrahman, who always keep me grounded, remind me of what is important in life, and are always supportive of my decisions. Thank you to my inlaws, Ahmed Elalfy and Sawsan Massoud, for their overwhelming support, prayers and for rooting for me till the finish line.

And finally, thanks to my wife, Dalia Elsaid, for constantly listening to me vent and talk things out, for proofreading over and over and for cracking jokes when things became too serious.

Last, but not least, my warm and heartfelt thanks to my daughter, Jumana. You are the reason I kept going. I hope I made you proud! 


\section{Table of Contents}

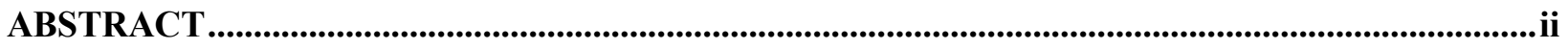

DEDICATION

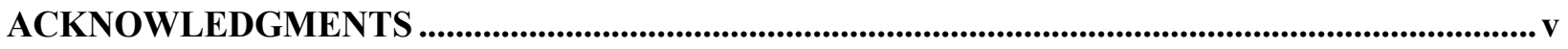

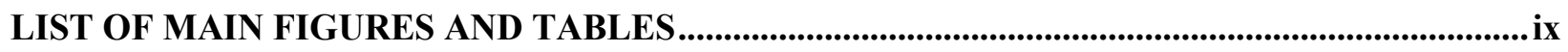

Chapter 1 Calcium Signaling in Health and Disease ........................................................................................ 1

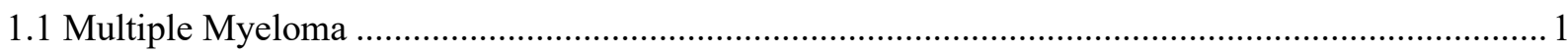

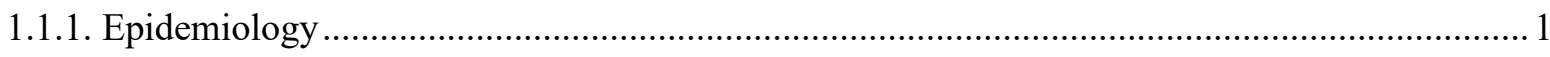

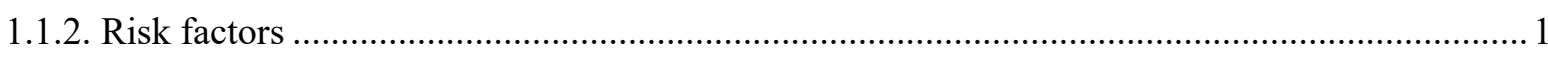

1.1.3. Clinical Presentation and Pathological Features ................................................................ 2

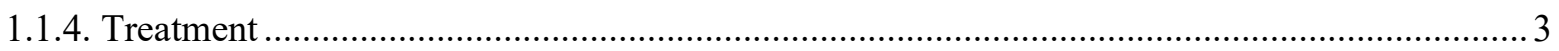

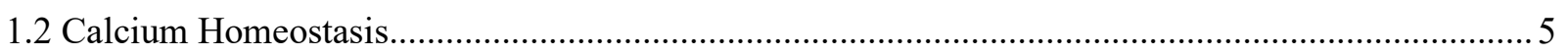

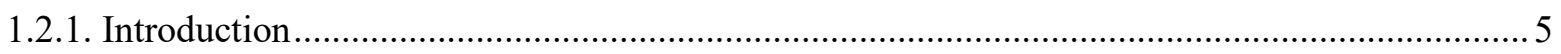

1.2.2. The Store-Operated Calcium Entry Pathway (SOCE) …..................................................... 7

1.2.3. Activation of SOCE pathway for inducing cell death in cancer ........................................... 11

1.2.4. SOCE Pathway Gene expression and their Clinical Outcomes ........................................... 12

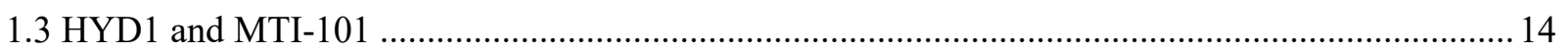

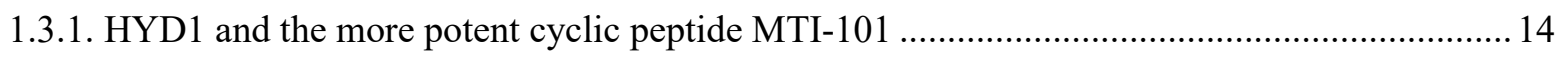

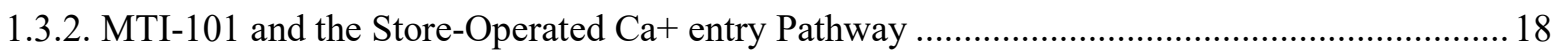

1.3.3. LOPAC $1280^{\mathrm{TM}}$ library screen identified six drugs synergizing with MTI-101 ..................... 21

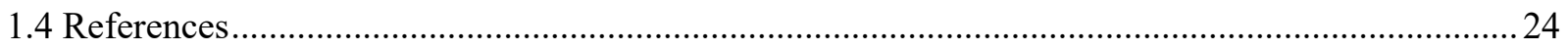

Chapter 2 The Role of TRPC1 in Modulating Cancer Progression ......................................................... 33

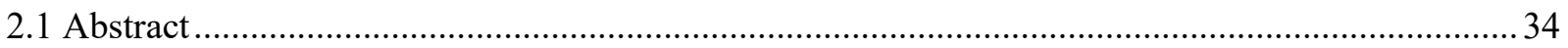

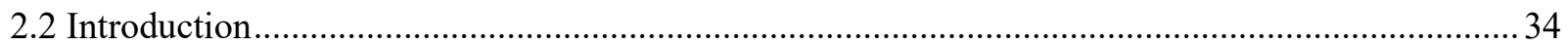

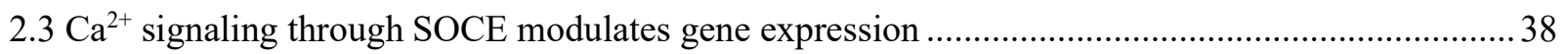

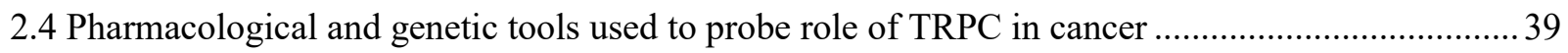

2.5 TRPC1 expression and correlation with Proliferation, EMT and migration.................................. 40

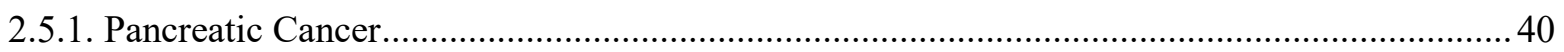

2.5.2. Breast Cancer Epithelial-Mesenchymal Transition and Proliferation..................................... 41

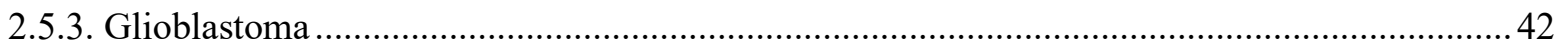

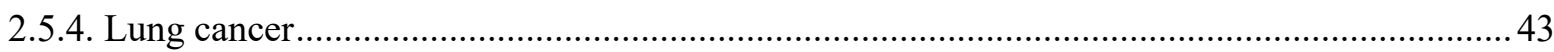

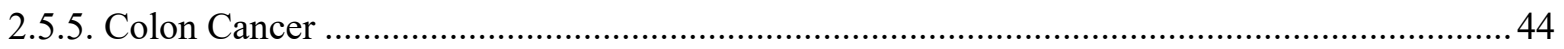

2.6 Activation of SOCE pathway for inducing cell death in cancer .................................................. 45 


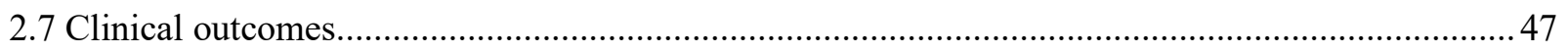

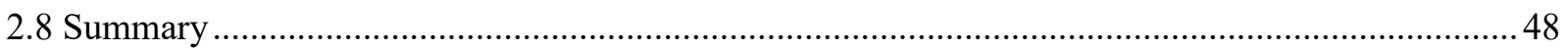

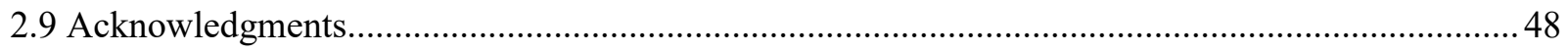

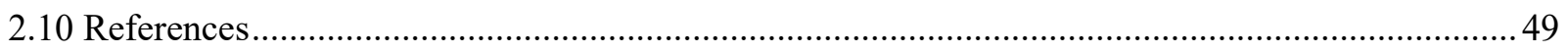

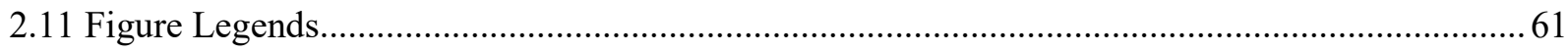

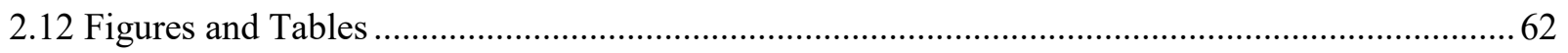

Chapter 3 Transient Receptor Potential C 1/4/5 is a Determinant of MTI-101 Induced Calcium Influx and Cell Death in Multiple Myeloma......................................................................................................65

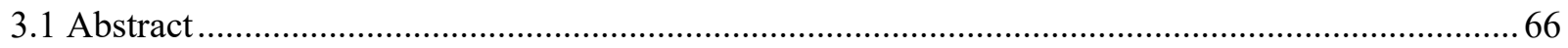

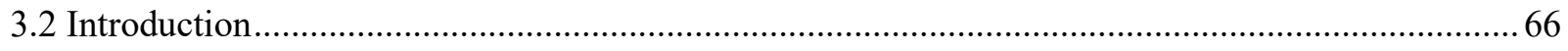

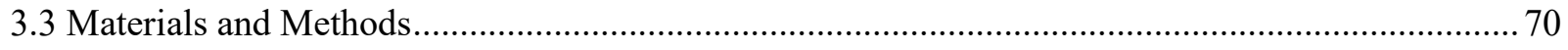

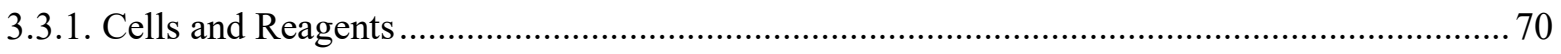

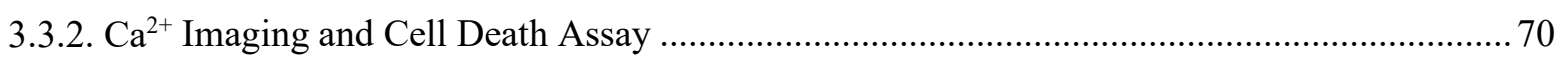

3.3.3. $\mathrm{DiBAC}_{4}(3)$ Membrane Potential Measurement .................................................................. 71

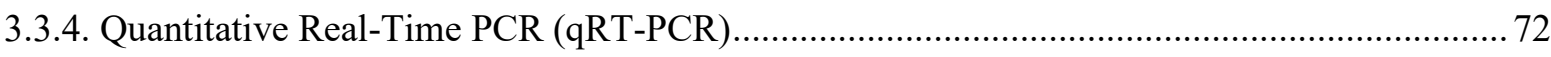

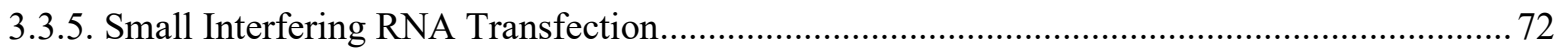

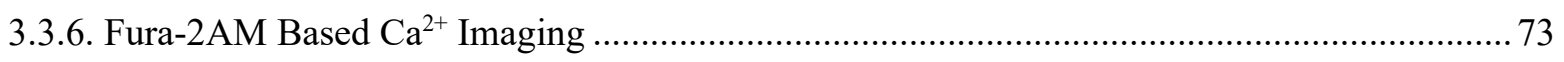

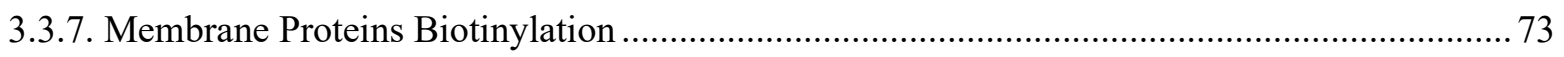

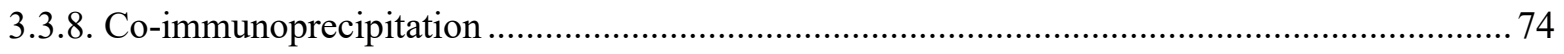

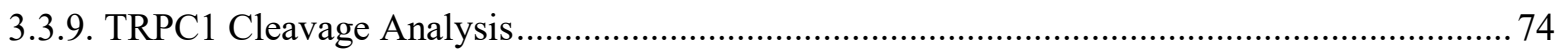

3.3.10. Survival Analysis with Multiple Myeloma Patients ......................................................... 75

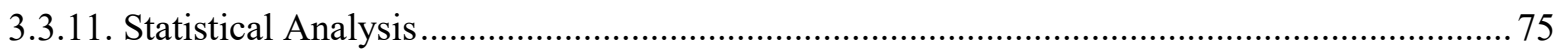

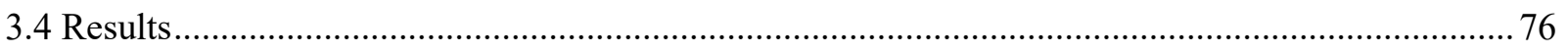

3.4.1. MTI-101 Induces Sustained $\mathrm{Ca}^{2+}$ Flux Leading to Cell Death .............................................. 76

3.4.2. Extracellular $\mathrm{Na}^{+} / \mathrm{K}^{+} / \mathrm{Ca}^{2+}$ contribution to MTI-101 activity ................................................. 77

3.4.3. Pharmacological inhibition of TRPC channels block MTI-101 induced $\mathrm{Ca}^{2+} / \mathrm{Na}^{+}$influx and cell death in MM cell lines and inhibition of CRAC channels inhibits MTI-101 induced $\mathrm{Ca}^{2+}$ influx

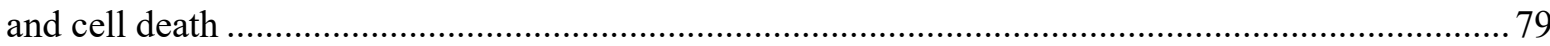

3.4.4. TRPC4/5 channel contributes to MTI-101 induced $\mathrm{Ca}^{2+} / \mathrm{Na}^{+}$influx and cell death ................ 80

3.4.5. MTI-101 activity is dependent on STIM1/TRPC1 trafficking and heteromeric assembly in the

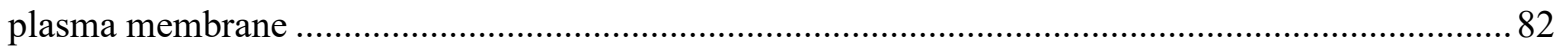

3.4.6. MTI-101 induces TRPC1 Truncation by Calpain Activation ................................................ 83

3.4.7. Members of the SOCE pathway correlates with poor patient outcomes................................. 84

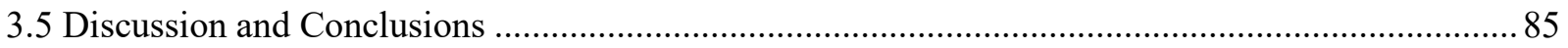

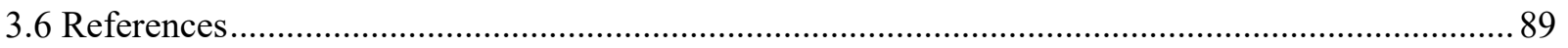

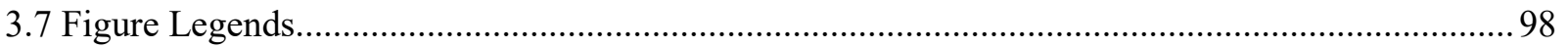


3.8 Figures

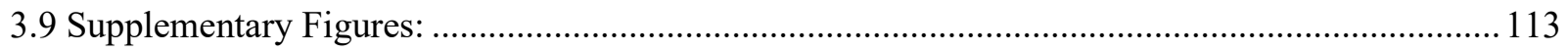

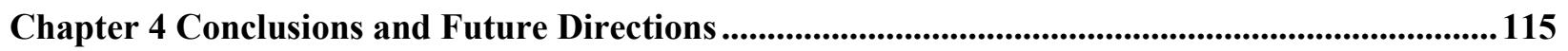

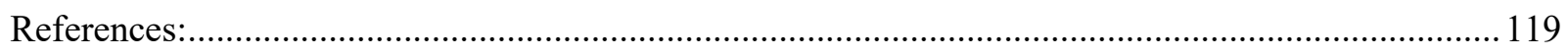

Appendix ................................................................................................................................................................. 122

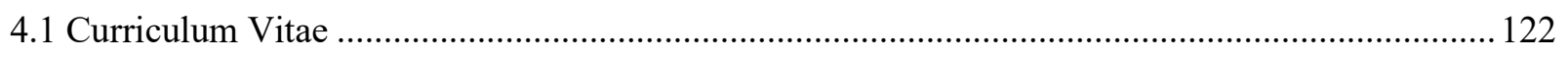

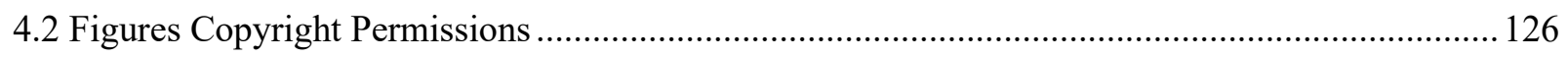




\section{LIST OF MAIN FIGURES AND TABLES}

\section{Chapter 1: Calcium Singling in Health and Disease}

Table 1. The international Staging System (ISS) and Revised-ISS for defining MM stages

Figure 1: Intracellular calcium homeostasis.

Figure 2. The Store-Operated $\mathrm{Ca}^{2+}$ Entry pathway (SOCE)

Figure 3. MTI-101 Molecular Structure NLeVVAW

Figure 4: Death Signaling By TNFR1

Figure 5. MTI-101 activates STIM1

Figure 6: LOPAC1280M library screen identified six drugs synergizing with MTI-101

\section{Chapter 2: The Role of TRPC1 in Modulating Cancer Progression}

Figure 1: The Store-Operated $\mathrm{Ca}^{2+}$ Entry pathway (SOCE)

Figure 2. $\mathrm{Ca}^{2+}$ entry through SOCE activates NFAT activation

Table 1. Role of TRPC expression or activity in augmenting proliferation and metastasis in cancer.

\section{Chapter 3: Chapter 3 Transient Receptor Potential C 1/4/5 is a Determinant of MTI-101 Induced Calcium Influx and Cell Death in Multiple Myeloma}

Figure 1: MTI-101 treatment Induces Sustained $\mathrm{Ca}^{2+}$ Flux and cell death in two independent MM cell lines

Figure 2: Extracellular $\mathrm{Na}^{+} / \mathrm{Ca}^{2+} / \mathrm{K}^{+}$contribution to MTI-101 activity

Figure 3: Pharmacological inhibition TRPC channels blocks MTI-101 induced $\mathrm{Ca}^{2+} / \mathrm{Na}^{+}$ influx and cell death in MM cell lines and inhibition of CRAC channels inhibits MTI-101 induced $\mathrm{Ca}^{2+}$ influx and cell death

Figure 4: TRPC4 channel contributes to MTI-101 induced $\mathrm{Ca}^{2+} / \mathrm{Na}^{+}$influx and cell death Figure 5: TRPC5 channel contributes to MTI-101 induced $\mathrm{Ca}^{2+} / \mathrm{Na}^{+}$influx and cell death Figure 6: MTI-101 activity is dependent on STIM1/TRPC1 trafficking and heteromeric formation in the plasma membrane

Figure 7: MTI-101 induces TRPC1 Truncation by Calpain Activation

Figure 8: Members of the SOCE pathway correlates with poor patient outcomes 


\section{Supplementary Figures}

Figure S1: Stroma cells are not sensitive to MTI-101-induced $\mathrm{Ca}^{2+}$ flux and cell death

Figure S2: MTI-101 induces TRPC1 Truncation by Calpain Activati 


\section{Chapter 1 Calcium Signaling in Health and Disease}

\subsection{Multiple Myeloma}

Multiple myeloma (MM) is a hematological malignancy characterized by the neoplastic proliferation of the plasma cells. The neoplastic proliferation of plasma cells containing monoclonal (M) protein immunoglobulin is a hallmark of multiple myeloma (MM). The plasma cells proliferate in the bone marrow, causing osteolytic lesions, osteopenia, and/or pathologic fractures.

\subsubsection{Epidemiology}

$\mathrm{MM}$ is a relatively rare cancer that accounts for about $1.8 \%$ of all cancers and slightly more than $17 \%$ of hematologic malignancies. According to the US Surveillance, Epidemiology, and End Results (SEER) registry, 34,920 new cases and 12,410 deaths from MM are expected in the United States in 2021 [1, 2]. Worldwide, MM is responsible for about 160,000 cases and 106,000 deaths per year. There has been an increased incidence of MM overtime, this is most likely due to increased use of routine laboratory testing, increased awareness of the disease, and increased availability and use of medical facilities, especially among the elderly [5].

MM is significantly prevalent in men than in women (ratio of approximately $1.4: 1$ ). It often occurs in elderly population with the median age at diagnosis of 65 to 74 years. Only $10 \%$ are younger than 50 years, and $2 \%$ are younger than 40 years old at the time of diagnosis [6, 7]. MM affects people of all races, but the incidence rate is two to three times higher in African Americans and Black populations than in White populations [7, 8].

\subsubsection{Risk factors}

The level of body fat plays a role in cancer development, a study have showed that low body mass index reduces the risk of development of eight types of cancer liver, gallbladder, pancreas, thyroid, 
ovary, gastric cardia, and multiple myeloma $[9,10]$. Historically, Agent Orange exposure has also been linked to the development of MM, where patients with monoclonal gammopathy of undetermined nature (MGUS) that have been exposed to Agent Orange have a higher chance of progressing to MM [11]. Familial history of MM also provides a risk of passing to the next generations with an estimated 3 familial cases per $1000 \mathrm{MM}$ patients [20-34], a small percentage of cases are familial. People who have a first-degree relative who has MM have a 3.7-fold increased chance of developing MM $[12,13]$. In a study of 15 families with MM clustering, ten of them had MM clustering in siblings, in 7 out of the 10 families, the same monoclonal immunoglobulin G (IgG) kappa pattern was found [14]. Furthermore, persons with a common variance at the genetic loci $3 \mathrm{p} 22.1$ or $7 \mathrm{p} 15.3$ (odds ratios of 1.32 and 1.38 , respectively) have a higher risk of developing MM as was detected by a genome-wide association analysis (GWAS) [15]. These genetic variances account for $5 \%$ of the familial risk, and have no clinical implications as indicated by a low hazard ratio.

\subsubsection{Clinical Presentation and Pathological Features}

The diagnosis of MM is suspected when the patient is presented with one of the following clinical presentations; Bone pain with lytic lesions discovered during routine radiology imaging, unexplained anemia, along with other malignancy suggestive signs and symptoms, increased total serum protein and monoclonal proteins in the serum or urine, asymptomatic or incidentally discovered hypercalcemia, and/or, nephrotic syndrome due to immunoglobulin light chain amyloidosis or acute renal failure with bland urinalysis [7].

Most MM patients are presented with increased levels of the monoclonal (M) proteins secreted by the malignant plasma cells and detected by serum FLC (Free Light Chain) analysis, or by SPEP (protein electrophoresis of the serum, or UPEP (protein electrophoresis of the urine) following a 24-hour urine collection accompanied by immunofixation of the urine and serum [7]. Depending 
on the test used, the specificity increases. The SPEP analysis detects a localized band or a peak in $80 \%$ of patients, and is increased to $90 \%$ sensitivity with serum protein immunofixation. FLC analysis or UPEP along with previous studies increase the sensitivity of M protein detection to 97\%. The absence of M protein with all these tests indicates nonsecretory myeloma [7]. The increase in the monoclonal $\mathrm{M}$ protein production by the malignant plasma cells results in suppression of uninvolved immunoglobulins ( $\operatorname{IgM}, \operatorname{IgA}$, etc.) is hypogammaglobulinemia and is named 'immunoparesis'. Immunoparesis have been reported to be associated with shorter progression free survival (PFS) in a study conducted in the Danish population [16]. Moreover, the extent of immunoparesis has been shown to be a poor prognostic indicator for Monoclonal Gammopathy of Undetermined Significance (MGUS) and Smoldering Multiple Myeloma (SMM) as they advance to MM [17].

The diagnosis of MM requires the presence of; 1) clonal plasma cells in the bone marrow $\geq 10 \%$ confirmed by kappa/lambda chain restriction by flow cytometry, immunofluorescence or immunohistochemistry, and the sample has to be from a bone marrow core specimen. 2) Tissue or organ impairment defined by increased calcium levels, renal insufficiency, anemia, and bone lesions, and are abbreviated as CRAB. 3) Detection of biomarkers associated with end-organ damage including; a) $60 \% \geq$ clonal plasma cells in the bone marrow, b) ratio of involved to uninvolved immunoglobulins FLC ration equal to or more than 100, c) more than one focal lesion detected by MTI [18-23].

\subsubsection{Treatment}

MM has advanced from untreatable to treatable malignancy, but yet incurable, with treatment options advancing over the decades. The first discovered treatment was the autologous stem cell transplant (ACST) discovered in the 1980s'[24]. ACST was followed by the discovery of novel agents including thalidomide and lenalidomide (IMID's). Later, treatment options further 
improved with the discovery of the proteasome inhibitors (PIs) lid by bortezomib. More recently, elotuzumab and daratumumab categorized as monocolonal antibodies, and Panobinostat the histone deacetylating agent has been approved by the US Food and Drug Administration [25].

The treatment decision for MM is based on the stage of the disease. The staging of MM is determined using the International Staging System (ISS) guidelines and the Revised-ISS (Table 1) $[26,27]$. Based on the National Comprehensive Cancer Network (NCCN) Multiple Myeloma Guidelines, the therapy general principals is that MM patients should undergo a triplet regimen as a standard approach, however, patients that can't tolerate the triplet regimen could be started on 2drug regimen. If a patient is undergoing hematopoietic cell transplant, they should avoid myelotoxic agents including alkylating agents and nitrosoureas to avoid compromising stem cell reserve, furthermore, harvesting peripheral blood stem cells should be considered prior to initiating the treatment on lenalidomide and/or daratumumab [27].

\section{Stage International Staging System (ISS)}

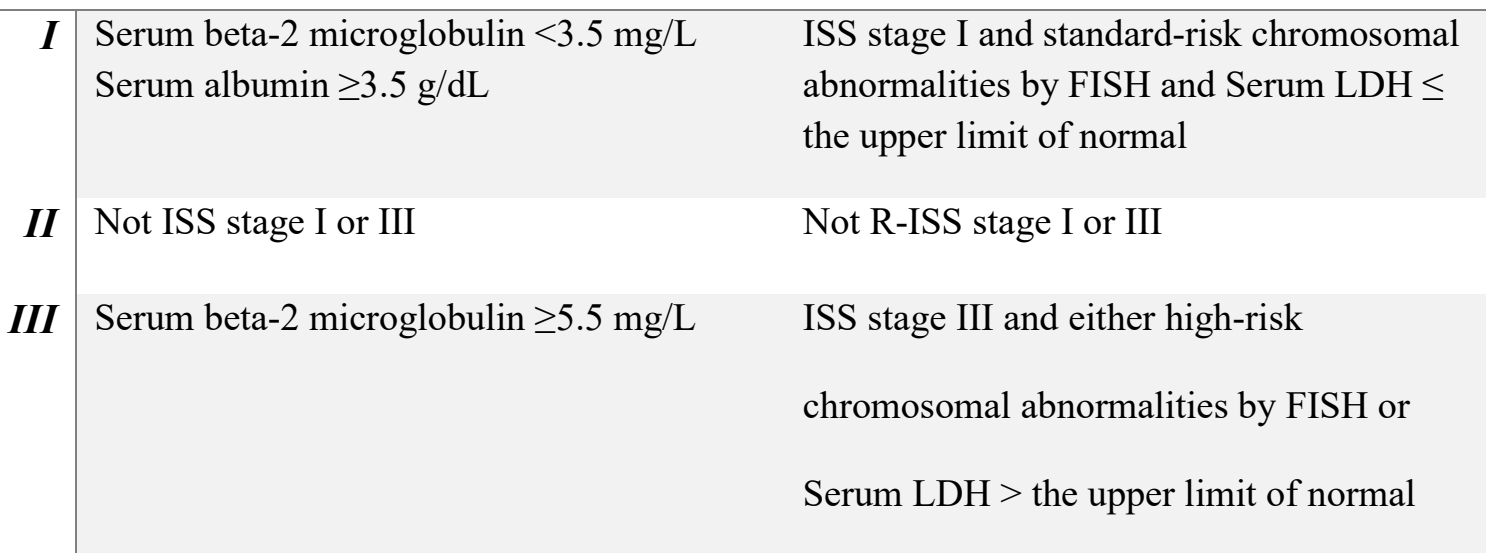

\section{Revised-ISS (R-ISS)}

ISS stage I and standard-risk chromosomal the upper limit of normal

Not R-ISS stage I or III 
maintenance therapy (4 and 3 regimens for transplant and non-transplant patient, respectively), the guidelines also include alternative combinational therapies for patients previously treated for MM [27]. Despite all the advancements in the various combinational therapies for MM, the disease remain incurable and new therapeutic strategies presents as unmet need that must be addressed.

\subsection{Calcium Homeostasis}

\subsubsection{Introduction}

Intracellular free $\mathrm{Ca}^{2+}$ concentration is extensively distributed throughout the cell, varying from one compartment to another. Under resting conditions, the cytoplasmic $\left[\mathrm{Ca}^{2+}\right]\left(\left[\mathrm{Ca}^{2+}\right] \mathrm{c}\right)$ is at 100 $\mathrm{nM}$, around 104 times lower than $\left[\mathrm{Ca}^{2+}\right]$ in the extracellular matrix. Both the nuclear and the mitochondrial compartments $\left(\mathrm{Ca}^{2+}\right)$ have similar $\left(\left[\mathrm{Ca}^{2+}\right] \mathrm{n}\right)$ levels in the cell as compared to the cytoplasm [28]. The main internal $\mathrm{Ca}^{2+}$ stores compartment inside the cell is the endoplasmic reticulum (ER), and is capable of accumulating $\mathrm{Ca}^{2+}$ and maintaining a higher $\left[\mathrm{Ca}^{2+}\right]$ concentration than the cytoplasm (about $1-5 \times 10^{-4} \mathrm{M}$ ). In muscle cells, the sarcoplasmic reticulum (SR) is the primary $\mathrm{Ca}^{2+}$ storage $[29,30]$.

Multiple $\mathrm{Ca}^{2+}$ pumps and channels exist in the cell to tightly regulate $\left[\mathrm{Ca}^{2+}\right] \mathrm{c}$ levels. The plasma membrane $\mathrm{Ca}^{2+}$ transport ATPase (PMCA), and the $\mathrm{Na}+/ \mathrm{Ca}^{2+}$ exchanger (NCX) are present on the plasma membrane [31]. The mitochondrial $\mathrm{Ca}^{2+}$ uniporter (MCU) are located on the mitochondrial membrane $[32,33]$. While, the sarcoplasmic reticulum/endoplasmic reticulum $\mathrm{Ca}^{2+}$-ATPase (SERCA) pump, the 1,4,5-triphosphate receptor (IP3R) and ryanodine receptor (RyR) channels are expressed on SE/ER membranes $[34,35]$. In a resting state, $\left[\mathrm{Ca}^{2+}\right] \mathrm{c}$ is maintained at low levels by the plasma membrane $\mathrm{Ca}^{2+}$ transport ATPase (PMCA) and the $\mathrm{Na}+/ \mathrm{Ca}^{2+}$ exchanger (NCX) [36]. When $\left[\mathrm{Ca}^{2+}\right] \mathrm{c}$ is increased, the $\mathrm{Ca}^{2+}$ is up taken into the ER and SR by SERCA pump and to a lesser extent into the mitochondria by the $\operatorname{MCU}[37,38]$. The removal of elevated $\left[\mathrm{Ca}^{2+}\right]$ results in homeostatic [Ca2]c control. $\left[\mathrm{Ca}^{2+}\right] \mathrm{c}$ levels could rise from $100 \mathrm{nM}$ to $1 \mu \mathrm{M}$ usually in a steep 
fashion followed by a decline, forming cytoplasmic $\mathrm{Ca}^{2+}$ spikes or repetitive $\mathrm{Ca}^{2+}$ oscillations, this is enhanced by the positive and negative feedback of $\mathrm{Ca}^{2+}$ effects facilitating the synchronized activation and deactivation of $\mathrm{Ca}^{2+}$ channels and the homeostatic $\mathrm{Ca}^{2+}$ removal mechanisms.

Multiple factors contribute to the increased $\left[\mathrm{Ca}^{2+}\right] \mathrm{c}$ levels including membrane depolarization, extracellular molecular binding and intracellular signals. Although the result is an increase in $\left[\mathrm{Ca}^{2+}\right] \mathrm{c}$, each stimulus activates a different pathway depending on the tissue where the cell is present, further, $\mathrm{Ca}^{2+}$ regulated channels and proteins respond to different thresholds and patterns depending on their functionality; the NCX and MCU have low affinity to $\mathrm{Ca}^{2+}$ and high conductance rate (150-300 Hz for NCX) limiting larger cytoplasmic $\mathrm{Ca}^{2+}$ transients, while SERCA and PMCA have high affinity to $\mathrm{Ca}^{2+}$ and low conductance rate $(\approx 10$ and $\approx 30 \mathrm{~Hz}$, respectively) responding to modest elevations in cytoplasmic $\mathrm{Ca}^{2+}$ levels [38]. Myriad of cellular functions are regulated by $\left[\mathrm{Ca}^{2+}\right] \mathrm{c}$, hence is tightly regulated with strict spatial and temporal control to initiate, maintain, and terminate appropriate signaling pathways and phenotypes including cellular proliferation, cell cycle control, migration, gene expression, muscle contraction, metabolism, and cell death (Figure 1) [4, 39].

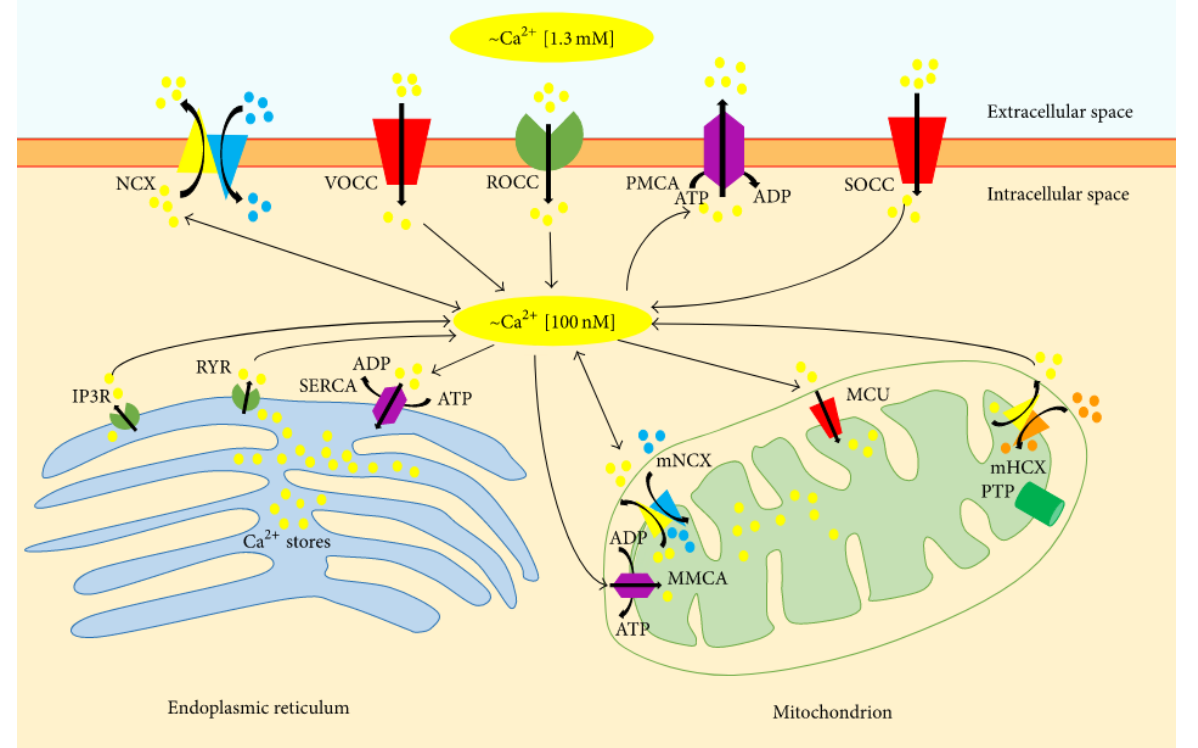


Figure 1: Intracellular calcium homeostasis. Intracellular calcium levels are tightly regulated within a narrow physiological range. Cellular calcium influx through the plasma membrane is largely mediated by receptor-operated calcium channels (ROCC), voltage-operated calcium channels (VOCC), store-operated calcium channels (SOCC) and, under exceptional circumstances, the sodium/calcium exchanger (NCX). Under physiological conditions, NCX is mainly involved in calcium efflux; however it can also reverse its mode of operation (reverse mode exchange) thereby contributing to calcium influx, especially during strong depolarization and in the presence of high intracellular sodium concentrations. Calcium may also be released into the cytoplasm from the endoplasmic reticulum, through inositol-1,4,5-trisphosphate (IP3R) and ryanodine receptors (RYR). Different systems operate within the cell to counterbalance the cytosolic calcium increase. Specifically, the plasma membrane calcium pump (PMCA), NCX, and sarcoendoplasmic reticulum calcium ATPase (SERCA) participate in restoring physiological calcium levels. The excess of intracellular calcium can also be taken up by mitochondria through the mitochondrial calcium uniporter (MCU). Calcium can be released back into the cytosol through the activity of mitochondrial NCX (mNCX), which can also reverse its mode of operation allowing the access of calcium ions into the mitochondrial matrix. Recently, the mitochondrial hydrogen/calcium exchanger (mHCX) has been proposed to be an electrogenic 1:1 mitochondrial calcium/hydrogen antiporter that drives the uptake of calcium into mitochondria at nanomolar cytosolic calcium concentrations. PTP, permeability transition pore; MMCA, mitochondrial membrane Ca2+ATPase [4] (Republished from Magi, S., et al., Intracellular Calcium Dysregulation: Implications for Alzheimer's Disease. Biomed Res Int, 2016. 2016: $p$. 6701324. This is an open access article distributed under the Creative Commons Attribution License, which permits unrestricted use, distribution, and reproduction in any medium)

\subsubsection{The Store-Operated Calcium Entry Pathway (SOCE)}

The store-operated $\mathrm{Ca}^{2+}$ entry pathway (SOCE) is a major $\mathrm{Ca}^{2+}$ entry pathway in non-excitable cells and SOCE activity is known to modulate insensitivity to antigrowth signals via multiple routes, as reviewed by Prevarskaya et al [40]. There are numerous channels and transporters that regulate $\mathrm{Ca}^{2+}$ levels and deciphering the role and interplay of individual members in facilitating tumor progression remains challenging. There is a great deal of controversy surrounding the role of TRPC1; while some reports suggest it is an ion channel, other reports suggest that TRPC1 alone is not sufficient to form an ion channel, and functions as a modulator of other TRPC channels. Additionally, the expression of TRPC1 as a prognostic marker in cancer appears to be context specific as TRPC1 expression has been reported to be associated with poor clinical outcomes for certain types of cancers, while in other indications it is reported to be associated with improved 
outcomes. This review will focus on the role of TRPC1 expression as a determinant of SOCE and cancer progression.

The transient receptor potential (TRP) ion channels were first discovered in Drosophila melanogasler by studying photo-transduction [41]. The TRP protein superfamily shares similarities in structure to the parent Dorsophila TRP and were initially classified into 3 subfamilies TRP-Canonical, TRP-Vanilloid, and TRP-Melastatin (TRPC, TRPV, and TRPM respectively) [42]. Later, the TRP superfamily was classified into 7 subfamilies; TRPClassical/Canonical (TRPC), TRP-Vanilliod (TRPV), TRP-Melastatin (TRPM), TRP-Ankyrin (TRPA), TRP-Polycystin (TRPP), TRP-Mucolipin (TRPML). The non-mechanoreceptor potential C-TRP (TRPN), is comprised of approximately 30 members [43]. Except for TRPM4 and TRPM5, which are $\mathrm{Ca}^{2+}$-activated monovalent-selective cation channels $[44,45]$, TRP family members are non-selective channels that are permeable to $\mathrm{Ca}^{2+}$ to varying degrees [43]. TRP channels generally share structural similarities that include six-transmembrane domains and the proteins typically assemble as homotetrameric or in some cases heterotetrameric channels summarized by Strubing and colleagues [46].

In addition to TRP channels, the SOCE mechanism of action is dependent on the depletion of the endoplasmic reticulum (ER) $\mathrm{Ca}^{2+}$ stores through ryanodine receptors (RyR) or inositol 1,4,5trisphosphate receptors $\left(\mathrm{IP}_{3} \mathrm{R}\right)[47,48]$. SOCE is regulated by agonist binding surface receptors, including G-protein coupled receptors (GPCR) or receptor tyrosine-kinases (RTK), activating phospholipase C $\beta$ (PLC $\beta$ ) via Gq/11 and PLC $\gamma$ via RTK mediated signaling $[30,49]$. This results in the enzymatic cleavage of plasma-membrane phosphatidylinositol 4,5-bisphosphate ( $\left.\mathrm{PIP}_{2}\right)$ into $\mathrm{IP}_{3}$ and diacylglycerol (DAG). The depletion of $\mathrm{Ca}^{2+}$ stores from the ER is sensed by the transmembrane protein stromal interaction molecules (STIM1 and STIM2), as $\mathrm{Ca}^{2+}$ dissociates from the EF domain of STIM1 and/or STIM2[50]. STIM molecules multimerize and translocate 
to ER-PM junction to form puncta that co-assemble with any or all of three Calcium-ReleaseActivated Calcium (CRAC) channel subunits Orai1/2/3. This protein-protein interaction between STIM and Orai results in the sustained opening of the highly $\mathrm{Ca}^{2+}$-selective CRAC channels that allow for both cytosolic $\mathrm{Ca}^{2+}$ signaling and replenishing of ER stores [30]. Additionally, in some cell types, STIM1 may intersect with Orail and members of TRPC subfamily by its reported capability to directly interact with TRPC1, TRPC4, and TRPC5, and indirectly with TRPC3 and TRPC6 (Figure 2 A) [51-54].

A

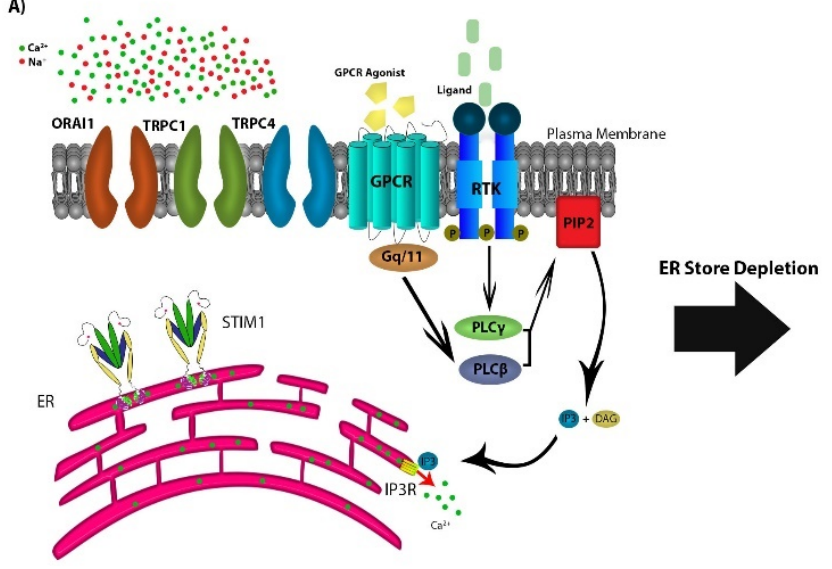

B)

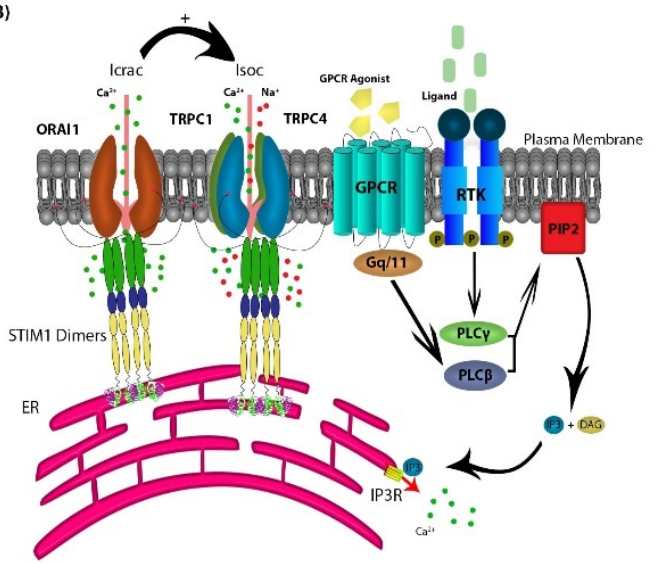

Figure 2. The Store-Operated $\mathrm{Ca}^{2+}$ Entry pathway (SOCE): A) SOCE is regulated by agonist binding to G-protein coupled receptors (GPCR) or receptor tyrosine-kinases (RTK), activating phospholipase $C \beta$ (PLC $\beta$ ) via Gq/11 and PLC $\gamma$ via RTK mediated signaling, resulting in the production of IP3 and DAG from the cleavage of plasma-membrane PIP2. IP3 depletes $\mathrm{Ca}^{2+}$ stores from the ER through the IP3R which is sensed by STIM1. B) STIM molecules multimerize forming puncta and translocate to ER-PM junction co-assembling with the CRAC channel subunits Orail activating the $\mathrm{Ca}^{2+}$ selective Icrac currents. Further, STIM1 forms STIM1/Orai1/TRPC1 complex activating cation nonselective Isoc currents [3].

The TRPC subfamily consists of seven members (TRPC1-7), and they are known to function as non-selective cation channels, with permeability to $\mathrm{Ca}^{2+}, \mathrm{Na}^{+}$, and $\mathrm{K}^{+}$[55]. The role of TRPC1 in SOCE activity has been discussed in a recent report by Dyrda and colleagues, where they reported that TRPC1 activation is dependent on activation of the Icrac current activated by STIM1 and comprised of Orai1/2/3 [56]. However, activation of STIM1 doesn't necessarily activate TRPC1, 
as there are two proposed mechanisms for the store-operated channels activation. The transmembrane protein STIM1 interacts with Orail activating the CRAC channels, with $\mathrm{Ca}^{2+}$ selective Icrac currents [57-60]. STIM1 interacts with TRPC1, forming STIM1/Orai1/TRPC1 complex and activating the SOC channels conducting a cation non-selective Isoc currents [60, 61]. This experimental evidence supports a model in which, following the activation of the SOC channels, the non-selective cation channels TRPC1, TRPC4, and TRPC5 form heterotetramers as TRPC1/TRPC4, TRPC1/TRPC5, or TRPC1/TRPC4/TRPC5 become operative to facilitate further $\mathrm{Ca}^{2+}$ entry (Figure $2 \mathrm{~B}$ ) [62-64]. TRPC1 has been under study in recent years as a $\mathrm{Ca}^{2+}$ channel in the SOCE pathway, on the other hand, recent reports have suggested that TRPC1 when expressed on it is own is not sufficient to form a channel. The role of TRPC1 has been studied extensively in recent years to investigate its function as a calcium channel or a modulator for other TRPC channels. Despite all data and studies into TRPC proteins, their mechanism of action remains poorly understood. Some members of the TRPC subfamily are capable of forming channels when expressed alone by forming homomers (TRPC4/TRPC4, and TRPC5/TRPC5) [65]. However, Storch et al. reported that TRPC1 is incapable of forming $\mathrm{Ca}^{2+}$ permeable channel by itself but is essential in forming heteromers with all other members of the TRPC subfamily [66]. Further, they reported a decrease in $\mathrm{Ca}^{2+}$ permeability in heteromeric complexes containing TRPC1, but the effect of TRPC1 in $\mathrm{Ca}^{2+}$ entry and as a member of the SOCE pathway is tissue dependent.

The role of $\mathrm{Ca}^{2+}$ signaling through the SOCE pathway involving STIM1 and Orail has been reported previously to affect prognosis of cervical, colorectal, breast, esophageal, multiple myeloma, and lung cancers by affecting tumor growth, proliferation, metastasis, and survival [6770]. 


\subsubsection{Activation of SOCE pathway for inducing cell death in cancer}

Cancer requires robust $\mathrm{Ca}^{2+}$ signaling to support proliferation, invasion and metastasis, whereas excessive $\mathrm{Ca}^{2+}$ levels lead to apoptosis and cell death, Both the suppression and enhancement of the SOCE pathways may be exploited for treatment of cancer. In Triple negative breast cancer (TNBC), Grant et al. reported that TRPC1 and TRPC4 were overexpressed in some TNBC cell lines. For example, the Hs578T TNBC cell line showed high expression levels of TRPC1 and TRPC4 compared to the MD-MB-231 TNBC cell line, and the BT-549 TNBC cell line had high levels of TRPC4 when compared to MD-MB-231 cell line [71]. The higher TRPC expression levels in these cancer cells may render these cells more vulnerable to therapeutic strategies aimed at eliciting $\mathrm{Ca}^{2+}$ overload and cell death through channel agonists rather than pharmacological inhibition to reverse hallmarks of cancer.

Support of $\mathrm{Ca}^{2+}$ overload being a vulnerability for cancer is that TNBC cell lines with increased TRPC4 and TRPC5 showed increased sensitivity to the TRPC4 and TRPC5 activator englerin A (EA) compared to cell lines with reduced expression [71]. Interestingly, the expression of TRPC4 and TRPC5 alone did not yield sensitivity to EA-induced and $\mathrm{Ca}^{2+}$-dependent cell death, indicating the importance of the heteromeric formation of TRPC members. Although TRPC1 levels in BT549 cells were comparable to the EA-resistant cell line HCC1806, BT-549 cells showed increased sensitivity to EA-induced $\mathrm{Ca}^{2+}$ entry and cell death when compared to Hs578T, when TRPC4 alone is predominantly and highly expressed. A possible explanation for this is the shift of the heteromeric TRPC1/TRPC4 channel towards more Na+ flux [66]. In renal cell carcinoma (RCC), A498 RCC cell lines responded to englerin A by elevation of intracellular $\mathrm{Ca}^{2+}$ levels and followed by cell death The $\mathrm{Ca}^{2+}$ entry was due to activation of TRPC4 channels as was demonstrated by patch-clamp studies. Further, while the expression of only TRPC1 did not contribute as a $\mathrm{Ca}^{2+}$ channel to the englerin A-induced $\mathrm{Ca}^{2+}$ overload and cell death, the co-expression of TRPC1 and 
TRPC4 and their heteromeric formation reproduced the same $\mathrm{Ca}^{2+}$ entry currents in HEK293 cells [72].

These findings corroborate the importance of TRPC1 expression for the overall functionality of the SOCE pathway. Our laboratory has shown that the novel cyclic peptide referred to as MTI-101 induces a robust and sustained increase in intracellular $\mathrm{Ca}^{2+}$ levels in multiple myeloma cells lines $[73,74]$. Emergence of resistance to chronic exposure of increasing concentrations of MTI-101 in the multiple myeloma $\mathrm{H} 929$ cell line correlated with decreased expression of the $\mathrm{IP}_{3}$ receptor, SERCA pump, PLC $\beta$, TRPC1 and TRPM7. Treatment with the pharmacological inhibitor 2-ABP attenuated MTI-101-induced $\mathrm{Ca}^{2+}$ influx, a finding that correlated with decreased cell death. U266 and MM1.s myeloma cells with reduced expression of TRPC1 using shRNA strategies showed a reduction in MTI-101 induced cell death [73]. Further studies are required to determine the role of TRPC1 in mediating MTI-101 induced $\mathrm{Ca}^{2+}$ entry and whether MTI-101-induced activity is dependent on activation of TRPC1 heteromers and regulation of the SOCE pathway, thereby allowing for sustained $\mathrm{Ca}^{2+}$ influx and leading to caspase-independent cell death [74]. Interestingly, MTI-101 was found to be more active in primary specimens obtained from myeloma patients relapsing on standard of care agents. Together, these data suggest that stimulating $\mathrm{Ca}^{2+}$ overload maybe a unique vulnerability to cancer cells, as experimental evidence indicates that cancer cells remodel $\mathrm{Ca}^{2+}$ handling pathways to favor $\mathrm{Ca}^{2+}$ influx required to facilitate the hallmarks of cancer.

\subsubsection{SOCE Pathway Gene expression and their Clinical Outcomes}

As outlined above, several TRPC members have been studied and implicated in the promotion of cancer through tumor cell proliferation, migration, invasion, and survival, as observed in lung cancer, malignant glioma, neuroblastoma, renal cell carcinoma, hepatoma, thyroid cancer, colon cancer, and breast cancer [75-82]. With respect to TRPC1, the screening of patient specimens as 
well as the mining of large data sets have yielded several clinically relevant insights in patients with tumors expressing TRPC1. Faouzi et al. reported TRPC1 to be expressed in all examined 17 data sets of breast cancer specimens, with no specific clinical significance [82]. Azimi et al. reported the TRPC1 expression levels in a data set from the University of North Carolina of 855 breast cancer patients, classified and reported based on the 50-signature genes subtype classification known as PAM50 [83, 84]. The claudin-low breast cancer subtype exhibited the highest TRPC1 expression levels compared to other subtypes. Further, in TNBC, the mesenchymal subtype showed the highest expression level of TRPC1, and the basal subtype with lymph-node metastasis showed worsened prognoses associated with high TRPC1 expression levels [84]. In lung cancer, SOCE components including STIM1, Orai1 and TRPC channels have been examined in a dataset of more than 2,000 cases. While TRPC1 had no effect on the risk of lung cancer, two variants of TRPC4 namely (rs9547991 and rs978156), and one variant of TRPC7 (rs11748198) were associated with increased risk of lung cancer compared to control subjects [75]. TRPC1 plasma membrane levels have been reported to be low when in inactive status, being located in close proximity to the plasma membrane. Transfer to the plasma membrane is dependent on $\mathrm{Ca}^{2+}$ signals generated by STIM1-Orail activation [85]. Thus, membrane localization may be an important factor linking SOCE and TRPC1 functions, even if expression levels may not change. Considering the function of TRPC1, it is feasible that quantification of membrane staining of TRPC1 may lead to increased sensitivity as a prognostic indicator in cancer. Taken together, targeting the increased expression of TRPC1 and other SOCE pathway proteins could aid in discovering novel cancer therapeutics, especially for relapsed patients on currently available treatment regimens. 


\subsection{HYD1 and MTI-101}

\subsubsection{HYD1 and the more potent cyclic peptide MTI-101}

HYD1 is a peptide that was discovered to block cancer cell adhesion to extracellular matrix in epithelial carcinoma cells $[86,87]$. It is 10 D-amino acid with the sequence KIKMVISWKG, further, it has been reported to induce cell death in U266, 8226, and H929 MM cell lines, but not in the hematopoietic CD34+ progenitor cells or PBMCs (peripheral blood mononuclear cells), the HYD1-induced cell death is associated with loss of mitochondrial membrane potential, ATP depletion, and ROS production, and not apoptotic or autophagic in nature, being caspaseindependent $[86,87]$. Following the discovery of HYD1-induced caspase independent cell death, Gebhard and colleagues discovered the minimally active truncated core region in HYD1 to be (MVISW). The active core was transformed into a cyclic peptide using a $\beta$ turn promoter scaffold backbone with the addition of 3 lysines, creating a water soluble, more potent drug named MTI101 [74]. The newly formed cyclic peptide MTI-101 had the optimized sequence NLeVVAW (Figure 3). MTI-101 showed to be more potent than HYD1 in multiple myeloma cell lines U266 and NCI-H929, with $87 \%$ percent reduction in the IC50 $(63.9 \mu \mathrm{mol} / \mathrm{L} \pm 6.0 \mathrm{vs} .8 .38 \mu \mathrm{mol} / \mathrm{L} \pm 0.9$ for HYD1 and MTI-101, respectively) in NCI-H929, and 75\% reduction in the IC50 in U266 (89.03 $\mu \mathrm{mol} / \mathrm{L} \pm 18.6$ vs. $22.10 \mu \mathrm{mol} / \mathrm{L} \pm 4.24$ for HYD1 and MTI-101, respectively). Furthermore, MTI-101 showed cross-resistance to the in-house created HYD1-resistant H929-60 cell line, along with a similar caspase-independent cell death. MTI-101 treatment resulted in reduction in ATP levels, and increased ROS production, going along the lines with what was previously reported with HYD1 [74, 88]. 


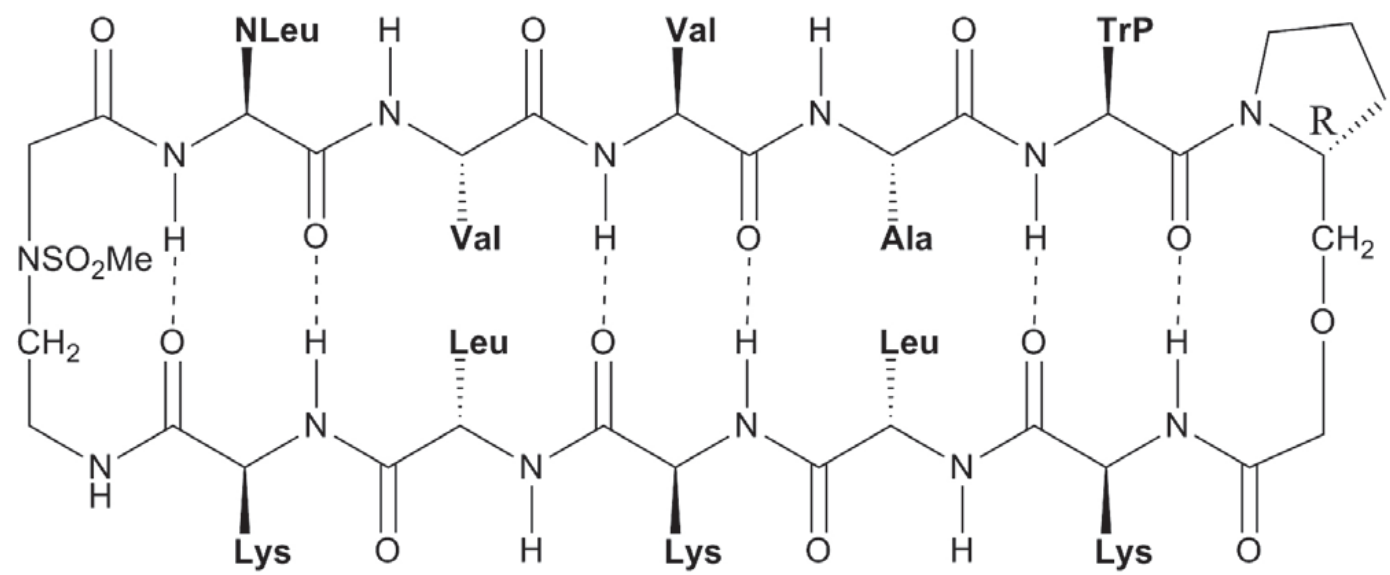

Figure 3. MTI-101 Molecular Structure NLeVVAW [74] (Reprinted from Molecular Cancer Therapeutics, 2013,volume 12, issue 11, 2446-58, Anthony W. Gebhard,Priyesh Jain,Rajesh R. Nair,Michael F.Emmons,Raul F. Argilagos,John M. Koomen,Mark L.McLaughlin,Lori A. Hazlehurst, MTI-101 (Cyclized HYD1) Binds a CD44 Containing Complexand Induces Necrotic Cell Death in Multiple Myeloma, with permission from $A A C R)$

To further define binding partners to HYD1 and MTI-101, Biotin-conjugated HYD1 and MTI101, CD44 was found in complex associated to Biotin-HYD1 and Biotin-MTI-101 analyzed by LC/MS-MS and Western Blot. To further assess the role of CD44 as a binding target and as an initiator of the death signal by HYD1, a concentration-dependent increase in binding to NeutraAvidin-coated plates with Biotin-HYD1 to recombinant CD44. It was also reported that overexpressing CD44 in the cell line RPMI-8266, where there is a minimal basal expression level of CD44, resulted in increased binging to FAM-HYD1, albeit, there was no significant increase in cell death [74]. These date indicated that while CD44 is not a rate-limiting step in the HYD1/MTI-101 induced cell death, it could play a role in the lateral or downstream cell death signaling. Furthermore, reducing CD44 expression by siRNA contributed to caspase-3 cleavage and apoptotic cell death when compared the non-silencing siControl, indicative of CD44 role in multiple myeloma cell survival, which positions CD44 as a valid target for MM targeting treatment [74]. To address whether MTI-101 treatment activates a CD44-dependant signaling cascade. 
Gebhard and colleagues examined the binding partners to CD44 following MTI-101 treatment in U266 and NCI-H929 cell lines, using co-immunoprecipitation studies. They reported an increased binding of the focal adhesion tyrosine kinase protein Pyk2 to CD44, in both cell lines, moreover, there was an increased activation of Erk/Map kinase pathways, in U266 and NCI-H929.

Historically, apoptosis is regarded as homeostatic and developmental programmed cell death and is characterized by a set of morphological characteristics that include chromatin condensation and nuclear fragmentation, cell shrinkage, plasma membrane blebbing, and the development of apoptotic bodies. While necrosis has been considered an unregulated, nonspecific kind of cell death which occurs as a result of nonspecific and nonphysiological stress [89]. However, Yuan and colleagues reported a form of a complex programmed necrotic cell death, and they named it necropotosis $[90,91]$. Programmed necrosis could be initiated through multiple events; necrotic cell death may be caused by binding ligands to specific membrane receptors, necrosis can be regulated by genetic, epigenetic and pharmacological mechanisms, and may contribute to an embryonic development and adult tissue homeostasis [92]. Necroptosis death signaling cascade is initiated by the ligand-bound tumor necrosis factor (TNF) receptor 1 (TNFR1), allowing the formation of a complex (TNFR1 complex 1) containing TRADD (TNFR-associated death domain), cIAP1 (cellular inhibitor of apoptosis 1), cIAP2, and RIP1 (receptor-interacting protein kinase 1 (RIP1). Once activated ,RIP1 interacts with RIP3 physically and functionally, inducing necroptotic signaling complex known as necrosome (Figure 4) [93]. Consequently, activated RIP3 phosphorylates and activates DRP1 (Dynamin-related protein 1), Mfn1 (Mitofusin 1), and Mfn 2. DRP1 is a cytoplasmic protein that interacts with mitochondrial outer membrane (MOM) causing mitochondrial fission, loss of membrane integrity, and fragmentation, playing a role in the process of necroptosis [94, 95]. 


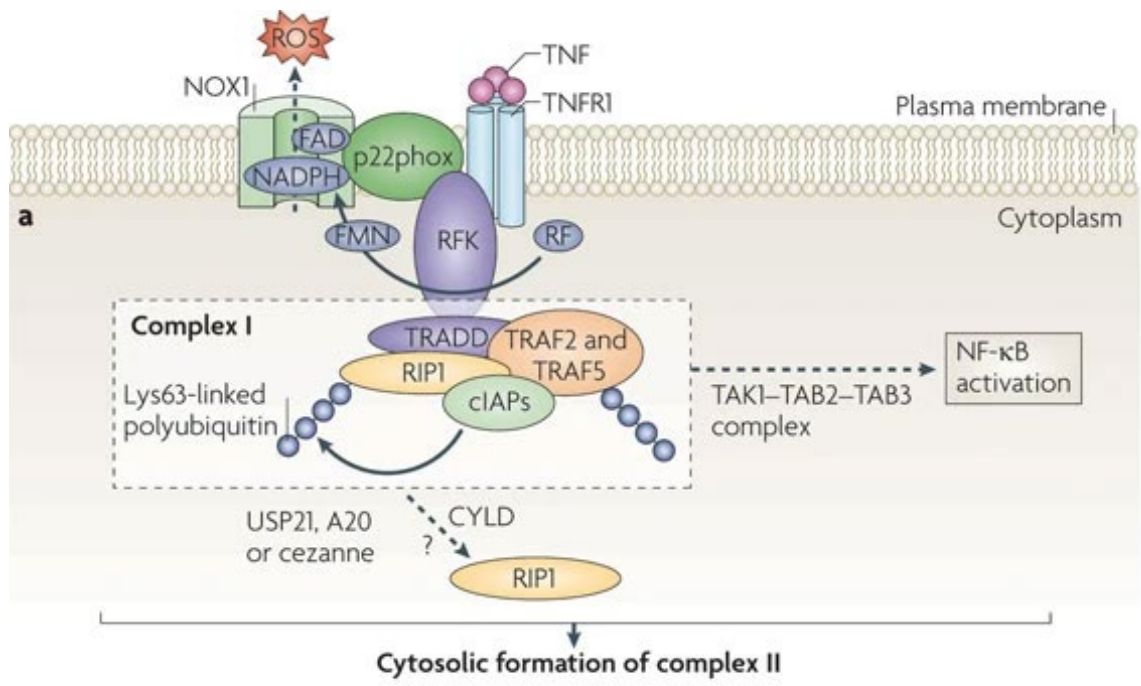

b

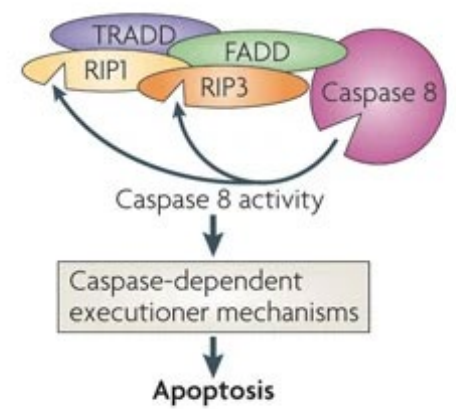

c

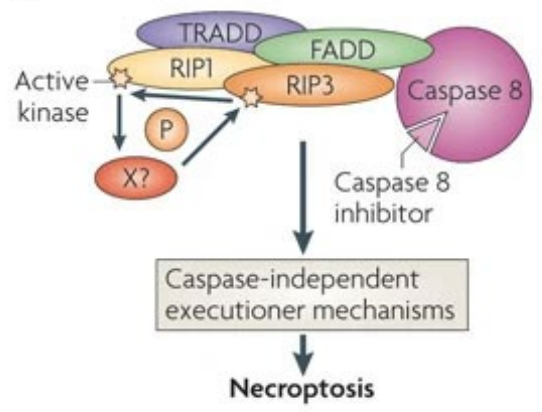

Nature Reviews | Molecular Cell Biology

Figure 4: Death Signaling By TNFR1: TNF binding TNFR1 allows the formation of TNFR complex 1 , downstream of which the necroptotic death pathway is activated through the activity of RIP1 and RIP3 [93] (Reprinted by permission from SPRINGER NATURE, Nature Reviews Molecular Cell Biology, Vandenabeele, P., et al., Molecular mechanisms of necroptosis: an ordered cellular explosion. Nat Rev Mol Cell Biol, 2010)

To address whether MTI-101-induced cell death is dependent on the activation of the necroptotic cell death pathway. Reducing the expression of RIP1, RIP3 and DRP1 by siRNA or pharmacologically inhibiting DRP1 using mdivi-1 (a known DRP1 inhibitor) significantly increased the survival of U266 cells when treated with MTI-101 [74]. However, The same results were not carried over to the cell line NCI-H929, where there was no increased survival with 
inhibition of DRP1, or reducing the expression of RIP1, RIP3, and DRP1. These data suggest that other pathways contribute to MTI-101 induced cytotoxicity [74]. Lastly, the effect of MTI-101 as an effective anti-tumor agent against MM. MTI-101 was tested in vivo by injecting 5TGM1 cells in C57BL/KaLwRijHsd mice. MTI-101 treated mice showed increased survival, along with a significant reduction in serum $\kappa$ levels as a single agent, similar to bortezomib, versus control. Furthermore, the SCID-Hu myeloma mouse model was used to test the effect of MTI-101 on myeloma without the confounding effect of the systematic disease by engrafting cadaveric fetal bone into the mammary mouse pad. MTI-101 showed significant increased survival along with reduction in $\kappa$ levels versus controls, and no signs of toxicity from MTI-101 was reported [74].

\subsubsection{MTI-101 and the Store-Operated Ca+ entry Pathway}

To further determine the mechanism of MTI-101 induced cell death. Emmons and colleagues sought to conduct a comparative gene expression profiling for the HYD1/MTI-101 resistant cell line H929-60 and its parent cell line NCI-H929 to delineate gene expression differences in pathways conferring sensitivity and resistance to both compounds [73]. PLC $\beta$, ITPR3, TRPC1, TRPM7, SERCA, ATP2A3 were downregulated in the resistance cell lines as confirmed by RTPCR. As mentioned earlier, the SOCE pathway is the major $\mathrm{Ca}^{2+}$ entry pathway in non-excitable cells, and the resistant cell line H929-60 showed downregulation of genes encoding for components of the SOCE pathway. Interestingly, TRPM7 apart from being a $\mathrm{Ca}^{2+}$ entry channel, aids in the necroptotic pathway by being a substrate of MLKL, downstream of TNF $\alpha$ and Ripk3 signaling (Figure 5). Consequently, MTI-101 and HYD1 were tested to see if they had an affect on $\left[\mathrm{Ca}^{2+}\right] \mathrm{c}$ levels in NCI-H929 and H929-60, and data showed that HYD1 and MTI-101 caused increased $\left[\mathrm{Ca}^{2+}\right] \mathrm{c}$ levels in both cell lines detected by the ratiometric dye fura2-AM, however, there was a significant reduction in $\mathrm{Ca}^{2+}$ influx by MTI-101 in H929-60 cells vs. NCI-H929. The 
data also showed that $\left[\mathrm{Ca}^{2+}\right] \mathrm{c}$ increase is higher with MTI-101 compared to HYD1, suggesting that MTI-101 induces MM cell death through $\mathrm{Ca}^{2+}$ overload [73].

As we mentioned previously, IP3R is the calcium channel on the ER membrane allowing $\mathrm{Ca}^{2+}$ release from the ER through IP3 activation. IP3 is a product of plasma membrane PIP2 hydrolysis by phospholipase C $\beta$ (PLC $\beta$ ) [49]. The test whether PLC $\beta$ is produced downstream of MTI-101 binding and facilitates MTI-101 induced increased $\left[\mathrm{Ca}^{2+}\right] \mathrm{c}$, the group used PLC $\beta$ inhibitor U73122 on NCI-H929 and U266 and were able to decreases MTI-101-induced increased $\left[\mathrm{Ca}^{2+}\right] \mathrm{c}$ levels in the absence of extracellular $\mathrm{Ca}^{2+}$ [96]. Furthermore, the IP3R blocker 2-APB attenuated MTI-101 induced cell death in U266 and NCI-H929, taken together, these data implicate the ER and SOCE pathway on MTI-101-induced $\mathrm{Ca}^{2+}$ and cell death $[73,97]$. When $\left[\mathrm{Ca}^{2+}\right] \mathrm{c}$ is increased, the $\mathrm{Ca}^{2+}$ is up taken into the ER and SR by SERCA pump and to a lesser extent into the mitochondria by the MCU. The removal of elevated $\left[\mathrm{Ca}^{2+}\right]$ results in homeostatic $\left[\mathrm{Ca}^{2+}\right] \mathrm{c}$ control. The role of the mitochondria and $\mathrm{MCU}$ was addressed by blocking mitochondrial $\mathrm{Ca}^{2+}$ uptake through $\mathrm{MCU}$ by using RU360 [98]. RU360 pretreated MM cells showed significantly increased survival with MTI101 indicating that MTI-101's induced cell death is partially dependent on the mitochondrial uptake of increased $\left[\mathrm{Ca}^{2+}\right] \mathrm{c}[73]$.

The role of STIM1 activation downstream of MTI-101 binding was addressed using Total Internal Reflection Fluorescence (TIRF) microscopy. When ER $\mathrm{Ca}^{2+}$ stores are depleted, $\mathrm{Ca}^{2+}$ is dissociated from the EF domain in STIM1, allowing it to undergo conformational changes, and trafficking to the ER/PM membrane space to bind Orai1/2/3 (CRAC channels), leading to $\mathrm{Ca}^{2+}$ influx [30]. In a confined specimen region immediately proximal to the interface between two media with differing refractive indications, TIRF microscopy exploits the uniqueness of an evanescent wave or field generated allowing the imaging of fluorophores within $100 \mathrm{~nm}$ distance from the plasma membrane [99]. Following MTI-101 treatment, U266 cells overexpressing STIM1 
mCherry tagged protein were imaged using TIRF, interestingly, STIM1-mCherry fluorescence intensity increased following 10 minutes treatment of MTI-101 when compared to control (Figure 6). Furthermore, reducing TRPC1 expression using shRNA significantly attenuated MTI-101induced cell death. Taken together, these strongly suggest that the SOCE pathway plays a major role in the $\mathrm{Ca}^{2+}$ influx induced cell death following MTI-101 treatment.
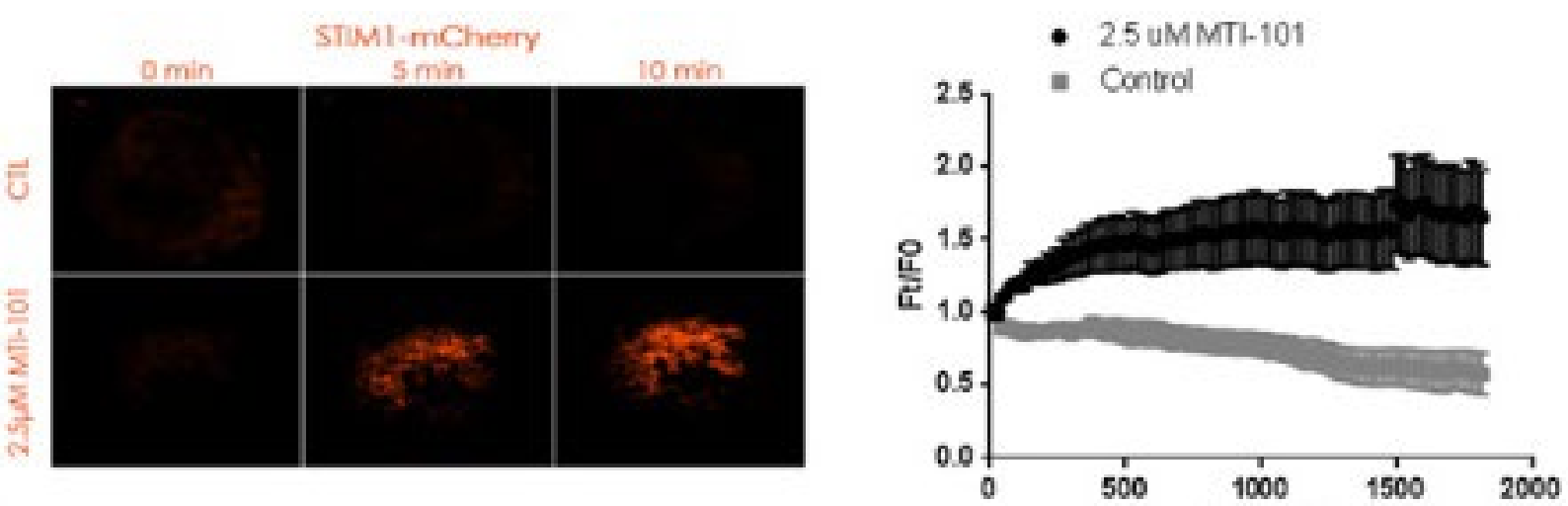

Figure 5. MTI-101 activates STIM1. (A) U226 cells over expressing Stim1 m-cherry show increased trafficking to the plasma membrane following treatment with MTI-101 compared to control cells. Using TIRF microscopy, images of individual cells $(n=7)$ at each time point were visualized, analyzed, and linked through time. TIRF images were collected every 15 seconds over 30 minutes with the experimental group receiving a single $2.5 \mu \mathrm{M}$ treatment of MTI-101 at 30 seconds. Ft/F0 is the pixel intensity at the indicated time as denoted on the $\mathrm{X}$ axis divided by the average pixel density prior to drug treatment. Mean intensity data for STIM1 mCherry at each time point were extracted for comparisons. A representative cell from the control group and treatment group is shown before treatment $(0 \mathrm{~min})$ and after treatment ( 5 and $10 \mathrm{~min})$. Shown is the mean and standard error of 7 cells for a representative experiment $(p<0.05$, Two Way ANOVA). The experiment was repeated 3 independent times and similar data was obtained [73].

Emmons and colleagues sought to determine the effect of combining MTI-101 and the standard of care for the treatment of MM bortezomib in vitro and in vivo. In vitro, using the murine cell line 5TGM1, the combination of MTI-101 and bortezomib showed a combination indexes (CI) of less than 1 in the 30 hours and up to 72 hours, indicating a synergy between both drugs. The 
combination index value is calculated using the CompuSyn software and the values are $<1,=1$, or $>1 . \mathrm{CI}<1$ indicates synergism, $\mathrm{CI}=1$ indicates additive effect, and $\mathrm{CI}>1$ indicate antagonism [100]. Additionally, MTI-101, bortezomib, and the combination were tested in C57BL/KaLwRijHsd mice injected with 5TGM1 syngeneic MM cells, the outcomes of this study showed improved anti-myeloma activity in the form of increased mean survival in the combination treated group vs single agents or vehicle control. However, there was no significant reduction in IgG2B levels in the combination compared to the single agent treated mice [73].

Clinically, the effect of MTI-101 was tested on MM patients' specimens. The group compared the effect of MTI-101 on newly diagnosed vs relapsed MM patients' specimens by isolating the CD138+ cells, as reported previously, MTI-101 was significantly more potent in relapsed patients than in the newly diagnosed. Furthermore, to test whether $\mathrm{Ca}^{2+}$ overload plays a role in MTI-101induced cell death in patients' specimen, cells were pre-treated with 2-APB, and similar to MM cell lines, 2-APB significantly inhibited MTI-101 induced cell death, indicative of the role of $\mathrm{Ca}^{2+}$ overload in the mechanism of action. Lastly, combining MTI-101 with bortezomib showed synergistic effect in patients' specimens. These findings support further development for MTI-101 as prospective treatment for MM in combination with other treatments [73].

\subsubsection{LOPAC1280 ${ }^{\mathrm{TM}}$ library screen identified six drugs synergizing with MTI-101}

The LOPAC $1280^{\mathrm{TM}}$ is an annotated library formed of 1280 pharmacologically known and active drugs. By screening the drugs with MTI-101 we aimed at identifying agents synergistic with MTI101. In the primary screen, we defined positive hits as drugs that in combination with MTI-101 would induce two folds increase in cell death. The primary screening hit rate was $5.94 \%$ ( 76 drugs out the 1280 screened drugs) (figure 6 A). The secondary screen was for hit confirmation and was defined as any hit that would cause two-fold increase in cell death in combination with MTI-101 compared to the hit or MTI- 101 alone. The secondary screen hit rate was 7.89\% (6 drugs out of 
the 76 drugs from the primary screen hits) identified; Ebastine (histamine H1 receptor antagonist), JNJ-40418677 (gamma-secretase modulator), SB-216763 (GSK3- $\beta$ inhibitor), Tamoxifen citrate (PKC inhibitor), $\mathrm{R}(+)$-DIOA (potent $[\mathrm{K}+, \mathrm{Cl}-]$-cotransport inhibitor), and 7-Cyclopentyl-5- (4phenoxy) phenyl-7H-pyrrolo[2,3-d]pyrimidin-4-ylamine (Selective inhibitor of GLS1) (figure 6 $\mathrm{B}$ and $\mathrm{C}$ ). The outcomes from this screening would allow us to further understand and determine the mechanism of action of MTI-101, and to find possible FDA approved candidates that could used down the road in clinical studies. This could attained by determination of the combination index and the specificity of the combination to multiple myeloma cells, to correlate the combination induced cell death with $\mathrm{Ca}^{2+}$ influx in in-vitro and in-vivo models, and to test the combination in an in-vivo syngeneic mouse model (Figure 6 D).

A)

LOPAC ${ }^{\circledR 1280}$ Library Primary Screening

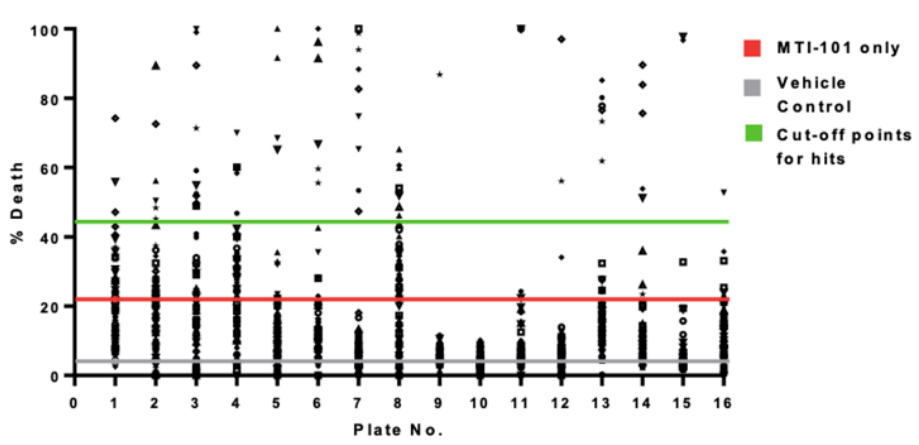

B)

\section{LOPAC ${ }^{\circledR 1280}$ Library Secondary Screening}

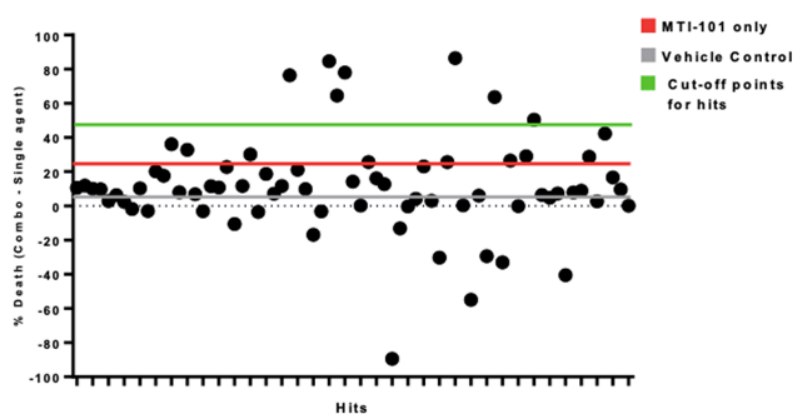




\section{C)}

Enhancers to MTI-101 Induced Cell Death

\begin{tabular}{|c|c|c|c|}
\hline Drug name & $\begin{array}{l}\text { Single \% } \\
\text { Death }\end{array}$ & $\begin{array}{c}\text { Combo \% } \\
\text { Death }\end{array}$ & Pathway \\
\hline Ebastine & 17.06 & 93.43 & Second-generation $\mathrm{H} 1$ receptor antagonist \\
\hline $\begin{array}{l}\text { 7-Cyclopentyl-5-(4- } \\
\text { phenoxy)phenyl-7H- } \\
\text { pyrrolo[2,3-d]pyrimidin-4- } \\
\text { ylamine }\end{array}$ & 18.39 & 82.87 & $\begin{array}{l}\text { Lymphocyte-specific protein tyrosine kinase (Lck) } \\
\text { inhibitor; selective inhibitor of glutaminase GLS1 }\end{array}$ \\
\hline $\begin{array}{l}\mathbf{R}(+)-\text { Butylindazone ('R(+)- } \\
\text { DIOA) }\end{array}$ & 14.69 & 92.66 & $\begin{array}{l}\text { Potent }[\mathrm{K}+, \mathrm{Cl}-] \text {-cotransport inhibitor that shows no } \\
\text { side effects on the bumetanimide-sensitive }[\mathrm{Na}+, \mathrm{K}+\text {, } \\
\mathrm{Cl}-] \text {-cotransport system }\end{array}$ \\
\hline JNJ-40418677 & 11.27 & 97.6 & Gamma-secretase modulator \\
\hline SB-216763 & 28.42 & 92.03 & $\begin{array}{l}\text { Potent, selective, cell permeable inhibitor of glycogen } \\
\text { synthetase kinase-3 (GSK-3) }\end{array}$ \\
\hline Tamoxifen citrate & 10.38 & 52.6 & $\begin{array}{l}\text { Anti-estrogen; relatively selective protein kinase C } \\
\text { inhibitor }\end{array}$ \\
\hline
\end{tabular}

D)

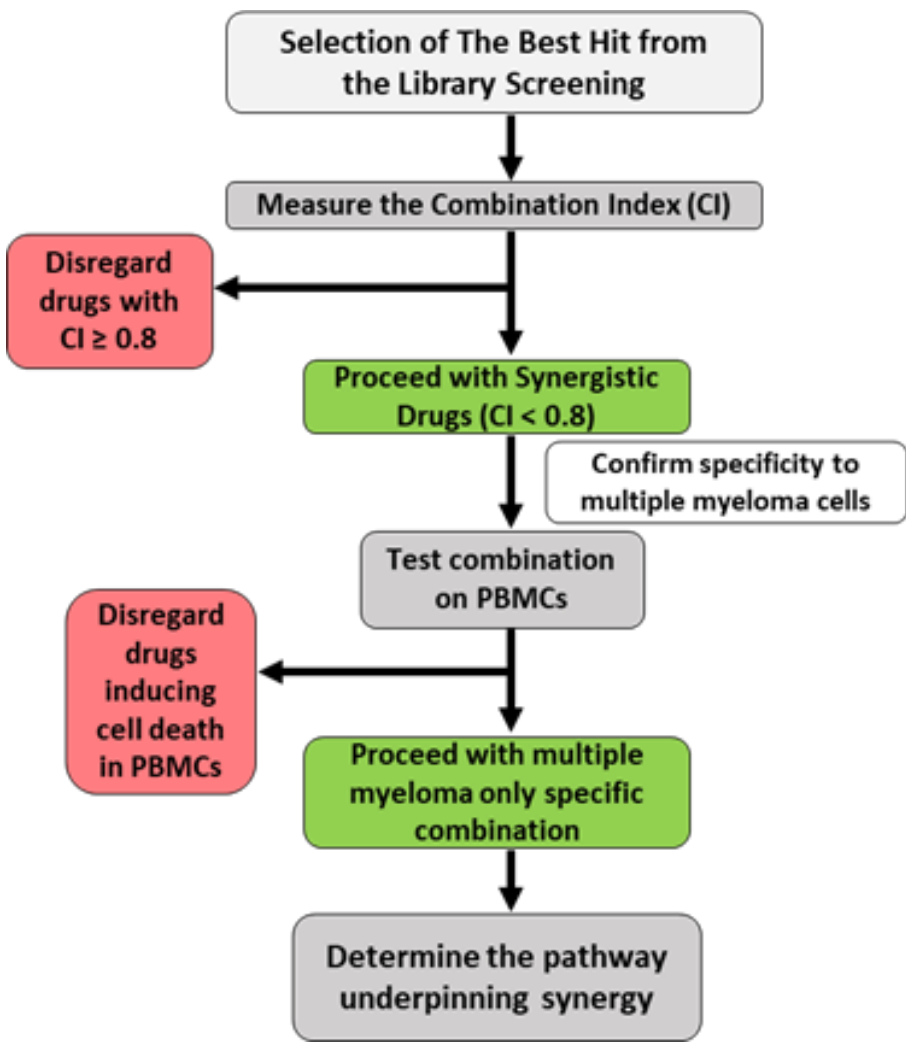


Figure 6: LOPAC1280TM library screen identified six drugs synergizing with MTI-101: A) Plot for the percent death in U266 cells following primary screen of the LOPAC1280 ${ }^{\mathrm{TM}}$ library. Cells were plated and treated with 10uM MTI-101 with 10uM of the each library drug for 3 hours. Death was measured by DAPI. B) Secondary screen percent death of U266 cells treated with combination of 76 hits and 10uM MTI-101 for 3 hours. Death measured by DAPI. C) The six hits from the secondary screen along with the pathway they target. D) Workflow for determining the best candidate to proceed with from the LOPAC1280 ${ }^{\mathrm{TM}}$ library screen.

\subsection{References}

1. SEER Cancer Stat Facts: Myeloma. 2021; Available from: https://seer.cancer.gov/statfacts/html/mulmy.html.

2. Siegel, R.L., et al., Cancer Statistics, 2021. CA Cancer J Clin, 2021. 71(1): p. 7-33.

3. Elzamzamy, O.M., R. Penner, and L.A. Hazlehurst, The Role of TRPC1 in Modulating Cancer Progression. Cells, 2020.9(2).

4. Magi, S., et al., Intracellular Calcium Dysregulation: Implications for Alzheimer's Disease. Biomed Res Int, 2016. 2016: p. 6701324.

5. Kyle, R.A., et al., Incidence of multiple myeloma in Olmsted County, Minnesota: Trend over 6 decades. Cancer, 2004. 101(11): p. 2667-74.

6. Blade, J. and R.A. Kyle, Multiple myeloma in young patients: clinical presentation and treatment approach. Leuk Lymphoma, 1998. 30(5-6): p. 493-501.

7. Kyle, R.A., et al., Review of 1027 patients with newly diagnosed multiple myeloma. Mayo Clin Proc, 2003. 78(1): p. 21-33.

8. Waxman, A.J., et al., Racial disparities in incidence and outcome in multiple myeloma: a population-based study. Blood, 2010. 116(25): p. 5501-6.

9. Lauby-Secretan, B., et al., Body Fatness and Cancer--Viewpoint of the IARC Working Group. N Engl J Med, 2016. 375(8): p. 794-8. 
10. Islami, F., et al., Proportion of Cancer Cases Attributable to Excess Body Weight by US State, 2011-2015. JAMA Oncol, 2019. 5(3): p. 384-392.

11. Naresh Bumma, M.N., Griffin Hemingway, Hirotaka Miyashita, Tahmida Chowdhury, Seongho Kim, Hema M Vankayala, Shabbir Ahmed, Pallavi Jasti, Effect of Exposure to Agent Orange on the Risk of Monoclonal Gammopathy and Subsequent Transformation to Multiple Myeloma: A Single-Center Experience From the Veterans Affairs Hospital, Detroit. Clin Lymphoma Myeloma Leuk, 2020: p. 305-311.

12. Lynch, H.T., et al., Familial multiple myeloma: a family study and review of the literature. J Natl Cancer Inst, 2001. 93(19): p. 1479-83.

13. Camp, N.J., T.L. Werner, and L.A. Cannon-Albright, Familial myeloma. N Engl J Med, 2008. 359(16): p. 1734-5; author reply 1735.

14. Grosbois, B., et al., Familial multiple myeloma: report of fifteen families. Br J Haematol, 1999. 105(3): p. 768-70.

15. Broderick, P., et al., Common variation at 3p22.1 and $7 p 15.3$ influences multiple myeloma risk. Nat Genet, 2011. 44(1): p. 58-61.

16. Sorrig, R., et al., Immunoparesis in newly diagnosed Multiple Myeloma patients: Effects on overall survival and progression free survival in the Danish population. PLoS One, 2017. 12(12): p. e0188988.

17. Perez-Persona, E., et al., New criteria to identify risk of progression in monoclonal gammopathy of uncertain significance and smoldering multiple myeloma based on multiparameter flow cytometry analysis of bone marrow plasma cells. Blood, 2007. 110(7): p. 2586-92.

18. Mikhael, J.R., et al., Management of newly diagnosed symptomatic multiple myeloma: updated Mayo Stratification of Myeloma and Risk-Adapted Therapy (mSMART) consensus guidelines 2013. Mayo Clin Proc, 2013. 88(4): p. 360-76. 
19. Kastritis, E., et al., The prognostic importance of the presence of more than one focal lesion in spine MRI of patients with asymptomatic (smoldering) multiple myeloma. Leukemia, 2014. 28(12): p. 2402-3.

20. Hillengass, J., et al., Prognostic significance of focal lesions in whole-body magnetic resonance imaging in patients with asymptomatic multiple myeloma. J Clin Oncol, 2010. 28(9): p. 1606-10.

21. Rajkumar, S.V., G. Merlini, and J.F. San Miguel, Haematological cancer: Redefining myeloma. Nat Rev Clin Oncol, 2012.9(9): p. 494-6.

22. Larsen, J.T., et al., Serum free light chain ratio as a biomarker for high-risk smoldering multiple myeloma. Leukemia, 2013. 27(4): p. 941-6.

23. Dispenzieri, A., et al., Immunoglobulin free light chain ratio is an independent risk factor for progression of smoldering (asymptomatic) multiple myeloma. Blood, 2008. 111(2): p. 785-9.

24. Kazandjian, D. and O. Landgren, A look backward and forward in the regulatory and treatment history of multiple myeloma: Approval of novel-novel agents, new drug development, and longer patient survival. Semin Oncol, 2016. 43(6): p. 682-689.

25. Raju, G.K., et al., A Benefit-Risk Analysis Approach to Capture Regulatory Decision-Making: Multiple Myeloma. Clin Pharmacol Ther, 2018. 103(1): p. 67-76.

26. Palumbo, A., et al., Revised International Staging System for Multiple Myeloma: A Report From International Myeloma Working Group. J Clin Oncol, 2015. 33(26): p. 2863-9.

27. (NCCN), N.C.C.N. NCCN Guidelines - Multiple Myeloma. 2021; Available from: https://www.nccn.org/professionals/physician_gls/pdf/myeloma.pdf.

28. Demaurex, N. and P. Nunes, The role of STIM and ORAI proteins in phagocytic immune cells. Am J Physiol Cell Physiol, 2016. 310(7): p. C496-508.

29. Lytton, J., et al., Functional comparisons between isoforms of the sarcoplasmic or endoplasmic reticulum family of calcium pumps. J Biol Chem, 1992. 267(20): p. 14483-9.

30. Clapham, D.E., Calcium signaling. Cell, 2007. 131(6): p. 1047-58. 
31. Brini, M. and E. Carafoli, Calcium pumps in health and disease. Physiol Rev, 2009. 89(4): p. 134178.

32. Csordas, G., et al., MICU1 controls both the threshold and cooperative activation of the mitochondrial Ca(2)(+) uniporter. Cell Metab, 2013. 17(6): p. 976-987.

33. Hajnoczky, G., et al., Mitochondrial calcium signalling and cell death: approaches for assessing the role of mitochondrial $\mathrm{Ca}^{2+}$ uptake in apoptosis. Cell Calcium, 2006. 40(5-6): p. 553-60.

34. Fan, G., et al., Gating machinery of InsP3R channels revealed by electron cryomicroscopy. Nature, 2015. 527(7578): p. 336-41.

35. des Georges, A., et al., Structural Basis for Gating and Activation of RyR1. Cell, 2016. 167(1): p. $145-157$ e17.

36. Brini, M. and E. Carafoli, The plasma membrane Ca(2)+ ATPase and the plasma membrane sodium calcium exchanger cooperate in the regulation of cell calcium. Cold Spring Harb Perspect Biol, 2011. 3(2).

37. Fan, M., et al., Structure and mechanism of the mitochondrial $\mathrm{Ca}^{2+}\left(^{2+}\right.$ uniporter holocomplex. Nature, 2020. 582(7810): p. 129-133.

38. Boyman, L., et al., Kinetic and equilibrium properties of regulatory calcium sensors of NCX1 protein. J Biol Chem, 2009. 284(10): p. 6185-93.

39. Zhang, S.J., et al., Nuclear calcium signaling controls expression of a large gene pool: identification of a gene program for acquired neuroprotection induced by synaptic activity. PLoS Genet, 2009. 5(8): p. e1000604.

40. Prevarskaya, N., R. Skryma, and Y. Shuba, Ion channels and the hallmarks of cancer. Trends Mol Med, 2010. 16(3): p. 107-21.

41. Minke, B., C. Wu, and W.L. Pak, Induction of photoreceptor voltage noise in the dark in Drosophila mutant. Nature, 1975. 258(5530): p. 84-7.

42. Montell, C., et al., A unified nomenclature for the superfamily of TRP cation channels. Mol Cell, 2002. 9(2): p. 229-31. 
43. Montell, C., The TRP superfamily of cation channels. Sci STKE, 2005. 2005(272): p. re3.

44. Launay, P., et al., TRPM4 is a $\mathrm{Ca}^{2+}$-activated nonselective cation channel mediating cell membrane depolarization. Cell, 2002. 109(3): p. 397-407.

45. Hofmann, T., et al., TRPM5 Is a Voltage-Modulated and $\mathrm{Ca}^{2+}$-Activated Monovalent Selective Cation Channel. Current Biology, 2003. 13(13): p. 1153-1158.

46. Strubing, C., et al., Formation of novel TRPC channels by complex subunit interactions in embryonic brain. J Biol Chem, 2003. 278(40): p. 39014-9.

47. Lewis, R.S., Calcium signaling mechanisms in T lymphocytes. Annu Rev Immunol, 2001. 19: p. 497-521.

48. Thakur, P., S. Dadsetan, and A.F. Fomina, Bidirectional coupling between ryanodine receptors and $\mathrm{Ca}^{2+}$ release-activated $\mathrm{Ca}^{2+}$ (CRAC) channel machinery sustains store-operated $\mathrm{Ca}^{2+}$ entry in human T lymphocytes. J Biol Chem, 2012. 287(44): p. 37233-44.

49. Berridge, M.J., M.D. Bootman, and H.L. Roderick, Calcium signalling: dynamics, homeostasis and remodelling. Nat Rev Mol Cell Biol, 2003. 4(7): p. 517-29.

50. Zhang, S.L., et al., STIM1 is a $\mathrm{Ca}^{2+}$ sensor that activates CRAC channels and migrates from the $\mathrm{Ca}^{2+}$ store to the plasma membrane. Nature, 2005. 437(7060): p. 902-5.

51. Cheng, K.T., et al., Contribution and regulation of TRPC channels in store-operated $\mathrm{Ca}^{2+}$ entry. Curr Top Membr, 2013. 71: p. 149-79.

52. Jia, S., et al., Homer binds to Orail and TRPC channels in the neointima and regulates vascular smooth muscle cell migration and proliferation. Sci Rep, 2017. 7(1): p. 5075.

53. $\mathrm{Xu}, \mathrm{S} . Z$., et al., TRPC channel activation by extracellular thioredoxin. Nature, 2008. 451(7174): $\mathrm{p}$. 69-72.

54. Hofmann, T., et al., Direct activation of human TRPC6 and TRPC3 channels by diacylglycerol. Nature, 1999. 397(6716): p. 259-63.

55. Bon, R.S. and D.J. Beech, In pursuit of small molecule chemistry for calcium-permeable nonselective TRPC channels -- mirage or pot of gold? Br J Pharmacol, 2013. 170(3): p. 459-74. 
56. Dyrda, A., S. Koenig, and M. Frieden, STIM1 long and STIM1 gate differently TRPC1 during storeoperated calcium entry. Cell Calcium, 2019. 86: p. 102134.

57. Yuan, J.P., et al., SOAR and the polybasic STIMI domains gate and regulate Orai channels. Nat Cell Biol, 2009. 11(3): p. 337-43.

58. Derler, I., et al., The extended transmembrane Orail $N$-terminal (ETON) region combines binding interface and gate for Orail activation by STIM1. J Biol Chem, 2013. 288(40): p. 29025-34.

59. Stathopulos, P.B., et al., STIM1/Orail coiled-coil interplay in the regulation of store-operated calcium entry. Nat Commun, 2013. 4: p. 2963.

60. Lopez, J.J., et al., Molecular Basis and Regulation of Store-Operated Calcium Entry. Adv Exp Med Biol, 2020. 1131: p. 445-469.

61. Lee, K.P., et al., Molecular determinants mediating gating of Transient Receptor Potential Canonical (TRPC) channels by stromal interaction molecule 1 (STIM1). J Biol Chem, 2014. 289(10): p. 6372-82.

62. Broker-Lai, J., et al., Heteromeric channels formed by TRPC1, TRPC4 and TRPC5 define hippocampal synaptic transmission and working memory. EMBO J, 2017. 36(18): p. 2770-2789.

63. Zhang, Z., et al., TRPC channels underlie cholinergic plateau potentials and persistent activity in entorhinal cortex. Hippocampus, 2011. 21(4): p. 386-97.

64. Obukhov, A.G. and M.C. Nowycky, TRPC5 channels undergo changes in gating properties during the activation-deactivation cycle. J Cell Physiol, 2008. 216(1): p. 162-71.

65. Beech, D.J., Characteristics of transient receptor potential canonical calcium-permeable channels and their relevance to vascular physiology and disease. Circ J, 2013. 77(3): p. 570-9.

66. Storch, U., et al., Transient receptor potential channel 1 (TRPC1) reduces calcium permeability in heteromeric channel complexes. J Biol Chem, 2012. 287(5): p. 3530-40.

67. Chen, Y.F., et al., Store-Operated $\mathrm{Ca}\left({ }^{2+}\right)$ Entry in Tumor Progression: From Molecular Mechanisms to Clinical Implications. Cancers (Basel), 2019. 11(7). 
68. Fiorio Pla, A., K. Kondratska, and N. Prevarskaya, STIM and ORAI proteins: crucial roles in hallmarks of cancer. Am J Physiol Cell Physiol, 2016. 310(7): p. C509-19.

69. Chen, Y.F., et al., Remodeling of calcium signaling in tumor progression. J Biomed Sci, 2013. 20 : p. 23.

70. Chen, Y.F., K.F. Hsu, and M.R. Shen, The store-operated $\mathrm{Ca}\left({ }^{2+}\right)$ entry-mediated signaling is important for cancer spread. Biochim Biophys Acta, 2016. 1863(6 Pt B): p. 1427-35.

71. Grant, C.V., et al., Triple-negative breast cancer cell line sensitivity to englerin A identifies a new, targetable subtype. Breast Cancer Res Treat, 2019. 177(2): p. 345-355.

72. Akbulut, Y., et al., (-)-Englerin A is a potent and selective activator of TRPC4 and TRPC5 calcium channels. Angew Chem Int Ed Engl, 2015. 54(12): p. 3787-91.

73. Emmons, M.F., et al., MTI-101 treatment inducing activation of Stim1 and TRPC1 expression is a determinant of response in multiple myeloma. Sci Rep, 2017. 7(1): p. 2685.

74. Gebhard, A.W., et al., MTI-101 (cyclized HYD1) binds a CD44 containing complex and induces necrotic cell death in multiple myeloma. Mol Cancer Ther, 2013. 12(11): p. 2446-58.

75. Zhang, Z., et al., Identification of TRPCs genetic variants that modify risk for lung cancer based on the pathway and two-stage study. Meta Gene, 2016. 9: p. 191-6.

76. Alptekin, M., et al., Gene expressions of TRP channels in glioblastoma multiforme and relation with survival. Tumour Biol, 2015. 36(12): p. 9209-13.

77. Lepannetier, S., et al., Sphingosine-1-phosphate-activated TRPC1 channel controls chemotaxis of glioblastoma cells. Cell Calcium, 2016. 60(6): p. 373-383.

78. Nasman, J., et al., The orexin OX1 receptor regulates $\mathrm{Ca}^{2+}$ entry via diacylglycerol-activated channels in differentiated neuroblastoma cells. J Neurosci, 2006. 26(42): p. 10658-66.

79. Asghar, M.Y., et al., Transient Receptor Potential Canonical 1 (TRPC1) Channels as Regulators of Sphingolipid and VEGF Receptor Expression: IMPLICATIONS FOR THYROID CANCER CELL MIGRATION AND PROLIFERATION. J Biol Chem, 2015. 290(26): p. 16116-31. 
80. Selli, C., et al., Differential expression of store-operated calcium- and proliferation-related genes in hepatocellular carcinoma cells following TRPC1 ion channel silencing. Mol Cell Biochem, 2016. 420(1-2): p. 129-40.

81. Gueguinou, M., et al., SK3/TRPC1/Orail complex regulates SOCE-dependent colon cancer cell migration: a novel opportunity to modulate anti-EGFR mAb action by the alkyl-lipid Ohmline. Oncotarget, 2016. 7(24): p. 36168-36184.

82. Faouzi, M., et al., Functional cooperation between KCa3.1 and TRPC1 channels in human breast cancer: Role in cell proliferation and patient prognosis. Oncotarget, 2016. 7(24): p. 36419-36435.

83. Cancer Genome Atlas, N., Comprehensive molecular portraits of human breast tumours. Nature, 2012. 490(7418): p. 61-70.

84. Azimi, I., et al., TRPC1 is a differential regulator of hypoxia-mediated events and Akt signalling in PTEN-deficient breast cancer cells. J Cell Sci, 2017. 130(14): p. 2292-2305.

85. Ambudkar, I.S., L.B. de Souza, and H.L. Ong, TRPC1, Orail, and STIM1 in SOCE: Friends in tight spaces. Cell Calcium, 2017. 63: p. 33-39.

86. DeRoock, I.B., et al., Synthetic peptides inhibit adhesion of human tumor cells to extracellular matrix proteins. Cancer Res, 2001. 61(8): p. 3308-13.

87. Sroka, T.C., M.E. Pennington, and A.E. Cress, Synthetic D-amino acid peptide inhibits tumor cell motility on laminin-5. Carcinogenesis, 2006. 27(9): p. 1748-57.

88. Nair, R.R., et al., HYD1-induced increase in reactive oxygen species leads to autophagy and necrotic cell death in multiple myeloma cells. Mol Cancer Ther, 2009. 8(8): p. 2441-51.

89. Kroemer, G., et al., Classification of cell death: recommendations of the Nomenclature Committee on Cell Death 2009. Cell Death Differ, 2009. 16(1): p. 3-11.

90. Galluzzi, L. and G. Kroemer, Necroptosis: a specialized pathway of programmed necrosis. Cell, 2008. 135(7): p. 1161-3.

91. Degterev, A., et al., Chemical inhibitor of nonapoptotic cell death with therapeutic potential for ischemic brain injury. Nat Chem Biol, 2005. 1(2): p. 112-9. 
92. Golstein, P. and G. Kroemer, Cell death by necrosis: towards a molecular definition. Trends Biochem Sci, 2007. 32(1): p. 37-43.

93. Vandenabeele, P., et al., Molecular mechanisms of necroptosis: an ordered cellular explosion. Nat Rev Mol Cell Biol, 2010. 11(10): p. 700-14.

94. Wang, H., et al., Mixed lineage kinase domain-like protein MLKL causes necrotic membrane disruption upon phosphorylation by RIP3. Mol Cell, 2014. 54(1): p. 133-146.

95. Zhang, S., et al., Drpl and RB interaction to mediate mitochondria-dependent necroptosis induced by cadmium in hepatocytes. Cell Death Dis, 2019. 10(7): p. 523.

96. Bleasdale, J.E., et al., Selective inhibition of receptor-coupled phospholipase C-dependent processes in human platelets and polymorphonuclear neutrophils. J Pharmacol Exp Ther, 1990. 255(2): p. 756-68.

97. Diver, J.M., S.O. Sage, and J.A. Rosado, The inositol trisphosphate receptor antagonist 2aminoethoxydiphenylborate (2-APB) blocks $\mathrm{Ca}^{2+}$ entry channels in human platelets: cautions for its use in studying $\mathrm{Ca}^{2+}$ influx. Cell Calcium, 2001. 30(5): p. 323-9.

98. Ying, W.L., et al., Inhibition of mitochondrial calcium ion transport by an oxo-bridged dinuclear ruthenium ammine complex. Biochemistry, 1991. 30(20): p. 4949-52.

99. Axelrod, D., Cell-substrate contacts illuminated by total internal reflection fluorescence. J Cell Biol, 1981. 89(1): p. 141-5.

100. Chou, T.C., Theoretical basis, experimental design, and computerized simulation of synergism and antagonism in drug combination studies. Pharmacol Rev, 2006. 58(3): p. 621-81. 


\section{Chapter 2 The Role of TRPC1 in Modulating Cancer Progression}

(Published in Cells February 2020)

\section{Osama M Elzamzamy 1, Reinhold Penner 2 and Lori A Hazlehurst 3,*}

1 Clinical and Translational Sciences Institute, School of Medicine, West Virginia University, Morgantown, WV 26506, USA; omelzamzamy@mix.wvu.edu

2 The Queen's Medical Center and University of Hawaii, Honolulu, HI 96813, USA;

rpenner@hawaii.edu

3 Pharmaceutical Sciences, School of Pharmacy and WVU Cancer Institute, West Virginia University,

Morganton, WV 26506, USA

*Correspondence: lahazlehurst@hsc.wvu.edu; Tel: +1-304-293-3398

Received: 07 January 2020; Accepted: 03 February 2020; Published: 07 February 2020

Keywords: TRPC1; SOCE; cancer progression; EMT 


\subsection{Abstract}

Calcium ions $\left(\mathrm{Ca}^{2+}\right)$ play an important role as second messengers in regulating a plethora of physiological and pathological processes, including the progression of cancer. Several selective and non-selective $\mathrm{Ca}^{2+}$-permeable ion channels are implicated in mediating $\mathrm{Ca}^{2+}$ signaling in cancer cells. In this review, we are focusing on TRPC1, a member of the TRP protein superfamily and a potential modulator of store-operated $\mathrm{Ca}^{2+}$ entry (SOCE) pathways. While TRPC1 is ubiquitously expressed in most tissues, its dysregulated activity may contribute to the hallmarks of various types of cancers, including breast cancer, pancreatic cancer, glioblastoma multiforme, lung cancer, hepatic cancer, multiple myeloma and thyroid cancer. A range of pharmacological and genetic tools have been developed to address the functional role of TRPC1 in cancer. Interestingly, the unique role of TRPC1 has elevated this channel as a promising target for modulation both in terms of pharmacological inhibition leading to suppression of tumor growth and metastasis as well as for agonistic strategies eliciting $\mathrm{Ca}^{2+}$ overload and cell death in aggressive metastatic tumor cells.

\subsection{Introduction}

Calcium is a ubiquitous second messenger that is known to regulate a myriad of physiological cellular functions in normal cells [1]. Levels of intracellular free concentration of $\mathrm{Ca}^{2+}$ is tightly regulated with strict spatial and temporal control to initiate, maintain, and terminate appropriate signaling pathways and phenotypes. Changes in intracellular $\mathrm{Ca}^{2+}$ concentration include fast processes that require milliseconds of intracellular $\mathrm{Ca}^{2+}$ spikes necessary for exocytosis and muscle contraction to processes requiring minutes to hours of $\mathrm{Ca}^{2+}$ flux that affect cellular proliferation, cell cycle control, migration, gene expression, and cell death $[2,3]$. Ion channels play a fundamental role in defining regulatory signaling pathways in the progression of cancer. Further, 
numerous studies indicate that $\mathrm{Ca}^{2+}$-dependent signaling pathways are involved in augmenting tumor proliferation, differentiation, migration, invasion, metastasis, and apoptosis, thus tumor cells often exhibit increased expression of $\mathrm{Ca}^{2+}$ regulatory networks [2-4]. Morever, given the importance of $\mathrm{Ca}^{2+}$ signaling, it is not surprising that cells tightly and precisely regulate proteins handling $\mathrm{Ca}^{2+}$ signals, including receptors, channels, and transporters [5]. Regulation of $\mathrm{Ca}^{2+}$ homeostasis includes transient $\mathrm{Ca}^{2+}$ release from intracellular stores (ER/SR, mitochondria, lysosomes) as well as more sustained influx of extracellular $\mathrm{Ca}^{2+}[6]$. The store-operated $\mathrm{Ca}^{2+}$ entry pathway (SOCE) is a major $\mathrm{Ca}^{2+}$ entry pathway in non-excitable cells and SOCE activity is known to modulate insensitivity to antigrowth signals via multiple routes, as reviewed by Prevarskaya et al [4]. There are numerous channels and transporters that regulate $\mathrm{Ca}^{2+}$ levels and deciphering the role and interplay of individual members in facilitating tumor progression remains challenging. There is a great deal of controversy surrounding the role of TRPC1; while some reports suggest it is an ion channel, other reports suggest that TRPC1 alone is not sufficient to form an ion channel, and functions as a modulator of other TRPC channels. Additionally, the expression of TRPC1 as a prognostic marker in cancer appears to be context specific as TRPC1 expression has been reported to be associated with poor clinical outcomes for certain types of cancers, while in other indications it is reported to be associated with improved outcomes. This review will focus on the role of TRPC1 expression as a determinant of SOCE and cancer progression.

The transient receptor potential (TRP) ion channels were first discovered in Drosophila melanogasler by studying photo-transduction [7]. The TRP protein superfamily shares similarities in structure to the parent Dorsophila TRP and were initially classified into 3 subfamilies TRPCanonical, TRP-Vanilloid, and TRP-Melastatin (TRPC, TRPV, and TRPM respectively) [8]. Later, the TRP superfamily was classified into 7 subfamilies; TRP-Classical/Canonical (TRPC), 
TRP-Vanilliod (TRPV), TRP-Melastatin (TRPM), TRP-Ankyrin (TRPA), TRP-Polycystin (TRPP), TRP-Mucolipin (TRPML). The non-mechanoreceptor potential C-TRP (TRPN), is comprised of approximately 30 members [9]. Except for TRPM4 and TRPM5, which are Ca ${ }^{2+}$ activated monovalent-selective cation channels [10,11], TRP family members are non-selective channels that are permeable to $\mathrm{Ca}^{2+}$ to varying degrees [9]. TRP channels generally share structural similarities that include six-transmembrane domains and the proteins typically assemble as homotetrameric or in some cases heterotetrameric channels summarized by Strubing and colleagues [12].

In addition to TRP channels, the SOCE mechanism of action is dependent on the depletion of the endoplasmic reticulum (ER) $\mathrm{Ca}^{2+}$ stores through ryanodine receptors (RyR) or inositol 1,4,5trisphosphate receptors $\left(\mathrm{IP}_{3} \mathrm{R}\right)[13,14]$. SOCE is regulated by agonist binding surface receptors, including G-protein coupled receptors (GPCR) or receptor tyrosine-kinases (RTK), activating phospholipase $\mathrm{C} \beta$ (PLC $\beta$ ) via Gq/11 and PLC $\gamma$ via RTK mediated signaling $[2,6]$. This results in the enzymatic cleavage of plasma-membrane phosphatidylinositol 4,5-bisphosphate $\left(\mathrm{PIP}_{2}\right)$ into $\mathrm{IP}_{3}$ and diacylglycerol (DAG). The depletion of $\mathrm{Ca}^{2+}$ stores from the ER is sensed by the transmembrane protein stromal interaction molecules (STIM1 and STIM2), as $\mathrm{Ca}^{2+}$ dissociates from the EF domain of STIM1 and/or STIM2[15]. STIM molecules multimerize and translocate to ER-PM junction to form puncta that co-assemble with any or all of three Calcium-ReleaseActivated Calcium (CRAC) channel subunits Orai1/2/3. This protein-protein interaction between STIM and Orai results in the sustained opening of the highly $\mathrm{Ca}^{2+}$-selective CRAC channels that allow for both cytosolic $\mathrm{Ca}^{2+}$ signaling and replenishing of ER stores [6]. Additionally, in some cell types, STIM1 may intersect with Orail and members of TRPC subfamily by its reported 
capability to directly interact with TRPC1, TRPC4, and TRPC5, and indirectly with TRPC3 and TRPC6 (Figure 1A) [16-19].

The TRPC subfamily consists of seven members (TRPC1-7), and they are known to function as non-selective cation channels, with permeability to $\mathrm{Ca}^{2+}, \mathrm{Na}^{+}$, and $\mathrm{K}^{+}$[20]. The role of TRPC1 in SOCE activity has been discussed in a recent report by Dyrda and colleagues, where they reported that TRPC1 activation is dependent on activation of the Icrac current activated by STIM1 and comprised of Orai1/2/3 [21]. However, activation of STIM1 doesn't necessarily activate TRPC1, as there are two proposed mechanisms for the store-operated channels activation. The transmembrane protein STIM1 interacts with Orail activating the CRAC channels, with $\mathrm{Ca}^{2+}$ selective Icrac currents [22-25]. STIM1 interacts with TRPC1, forming STIM1/Orai1/TRPC1 complex and activating the SOC channels conducting a cation non-selective Isoc currents [25,26]. This experimental evidence supports a model in which, following the activation of the SOC channels, the non-selective cation channels TRPC1, TRPC4, and TRPC5 form heterotetramers as TRPC1/TRPC4, TRPC1/TRPC5, or TRPC1/TRPC4/TRPC5 become operative to facilitate further $\mathrm{Ca}^{2+}$ entry (Figure 1B) [27-29]. TRPC1 has been under study in recent years as a $\mathrm{Ca}^{2+}$ channel in the SOCE pathway, on the other hand, recent reports have suggested that TRPC1 when expressed on it is own is not sufficient to form a channel. The role of TRPC1 has been studied extensively in recent years to investigate its function as a calcium channel or a modulator for other TRPC channels. Despite all data and studies into TRPC proteins, their mechanism of action remains poorly understood. Some members of the TRPC subfamily are capable of forming channels when expressed alone by forming homomers (TRPC4/TRPC4, and TRPC5/TRPC5) [30]. However, Storch et al. reported that TRPC1 is incapable of forming $\mathrm{Ca}^{2+}$ permeable channel by itself but is essential in forming heteromers with all other members of the TRPC subfamily [31]. Further, they 
reported a decrease in $\mathrm{Ca}^{2+}$ permeability in heteromeric complexes containing TRPC1, but the effect of TRPC1 in $\mathrm{Ca}^{2+}$ entry and as a member of the SOCE pathway is tissue dependent.

The role of $\mathrm{Ca}^{2+}$ signaling through the SOCE pathway involving STIM1 and Orail has been reported previously to affect prognosis of cervical, colorectal, breast, esophageal, multiple myeloma, and lung cancers by affecting tumor growth, proliferation, metastasis, and survival $[3,32-34]$. In this review we aim to address the role of TRPC1 as a member of the SOCE pathway in promoting the advancement of the hallmarks of cancer and consider their potential as therapeutic targets for developing novel cancer treatments.

\section{3 $\mathrm{Ca}^{2+}$ signaling through SOCE modulates gene expression}

Considering the numerous pathways that $\mathrm{Ca}^{2+}$ signaling modulates, including kinases, phosphatases, proteases and metabolic enzymes, the role of $\mathrm{Ca}^{2+}$ signaling in progression of cancer is likely multi-factorial. However, one attractive $\mathrm{Ca}^{2+}$ dependent candidate pathway is activation of NFAT (reviewed by Putney[35]). Increased intracellular $\mathrm{Ca}^{2+}$ levels occurs via multiple channels, but the increased oscillatory $\mathrm{Ca}^{2+}$ currents through emptying of intracellular stores, and extracellular $\mathrm{Ca}^{2+}$ flux through the SOCE is the major contributor to $\mathrm{Ca}^{2+}$ regulated gene expressions[36]. $\mathrm{Ca}^{2+}$ binding to its receptor calmodulin activates the phosphatase protein calcineurin, which in turn dephosphorylates NFAT, leading to its translocation to the nucleus. NFAT is a transcription factor known to regulate the expression of genes encoding cytokines and receptors mandatory for T-cell survival. Multiple reports indicate that tumor cells have hijacked the calcium dependent NFAT pathway to support cytokine dependent survival and homing. For example, in diffuse large B-cell lymphoma (DLCBCL) Bucher et al., reported that NFAT activity is chronically elevated in tumor cells; a finding that correlated with elevated $\mathrm{Ca}^{2+}$ levels. In addition, inhibition of calcineurin with cyclosproin A or FK506 treatment reduced NFAT target 
genes including EGR2, IL10, NFKB1A and Jun and induced cell death in DLCBCL cell lines [37]. Similarly, Urso et al., showed that NFATc3 is a critical determinant of proliferation and migration of U251 glioblastoma cell lines[38]. The authors demonstrated that reducing the expression of NFAT3c inhibited expression of TNF-alpha, GM-CSF, IL-2 and CXCR-3 when U251 cells were treated with an ionophore. Finally, the authors demonstrated that a reduction of NFAT3c inhibited growth of U251 cells in vivo. The role of NFAT in cancer progression has been comprehensively reviewed by Mancini et al. where they reported that NFAT overexpression in solid and hematological tumors plays a role in tumor survival, migration, and invasion[39](Figure 2).

\subsection{Pharmacological and genetic tools used to probe role of TRPC in cancer}

Numerous studies have addressed the role of TRPC1 as a $\mathrm{Ca}^{2+}$ channel using siRNA or shRNA strategies to reduce the expression of TRPC1 [31,40-53]. The outcomes of silencing TRPC1 in cancer cells are addressed below in detail in context to disease indication and contribution to growth and metastasis. Other studies have employed various pharmacological tools to determine the role of TRPC1 along with TRPC4 and TRPC5 as contributors to the SOCE pathways and $\mathrm{Ca}^{2+}$ entry. Some of these tools are inhibitors that suppress SOCE and cell proliferation, including 2APB [40,43,44,48,49,51-56], SKF96365 [31,51,53,55,57], and MRS1845 [51,53], whereas the plant-derived sesquiterpenoid englerin A can be used as an agonist for TRPC4 and TRPC5 to promote $\mathrm{Ca}^{2+}$ overload and cell death $[41,58]$. 2-APB was originally discovered as an IP3R inhibitor, but has since been recognized as a fairly non-selective inhibitor of a large number TRP channels that lack specificity for TRPC1 [59,60]. Similarly, SKF96365 was originally discovered

as an inhibitor of the receptor-mediated $\mathrm{Ca}^{2+}$ entry in platelets and endothelial cells. The compound is also pleiotropic and found to inhibit SOCE via STIM1, to block various TRPC channels, as well 
as voltage-gated $\mathrm{K}^{+}$and $\mathrm{Ca}^{2+}$ channels [61,62]. Finally, the dihydropyridine MRS1845 has been reported as an inhibitor for the SOCE pathway in HL-60 leukemia cell line [63], but its potential direct effects on TRPC1 have not yet been established in electrophysiological studies. Thus, these inhibitors cannot be considered as specific reagents for TRPC1, and genetic confirmation is required when using these pharmacological tools. Other more specific antagonists for TRPC1, TRPC4, and TRPC5 have been discussed by Rubaiy, and include PICO 145, Clemizole, M084, AC1903, Galangin and AM12. These tools could facilitate future studies aimed at better understanding the role of TRPC1 in cancer [64].

\subsection{TRPC1 expression and correlation with Proliferation, EMT and migration}

\subsubsection{Pancreatic Cancer}

Epithelial-mesenchymal transition (EMT) is a known modulator and a key step into tumor invasion and metastasis. One of the key modulators of EMT is TGF- $\beta$, which has been reported previously to induce EMT in mammary epithelial cells [65]. The role of TRPC1 as a $\mathrm{Ca}^{2+}$ channel in pancreatic cancer cell proliferation and its development was proposed as being a downstream effector of TGF $\beta$ signaling $[52,56]$. In SMAD4-null pancreatic cancer cells, TGF $\beta$ is reported to induce a cytosolic $\mathrm{Ca}^{2+}$ increase, leading to the activation of the $\mathrm{Ca}^{2+}$-dependent protein kinase $\mathrm{C}$ $\alpha(\mathrm{PKC} \alpha)$ and its translocation to the plasma membrane. Further, TGF $\beta$ activated PKC $\alpha$-dependent cellular motility and migration, by inhibiting the tumor suppressor PTEN [56]. Later, TRPC1 4 and 6 levels were shown to be high in pancreatic cancer cells, indicating their function as TGF $\beta$ mediators for $\mathrm{Ca}^{2+}$ entry [52]. Pharmacologically inhibiting SOCE pathways using 2-APB and $\mathrm{La}^{3+}$ abrogated the TGF $\beta$-dependent increase in cytosolic $\mathrm{Ca}^{2+}$ levels. Blocking PKC $\alpha$ by the selective PKC $\alpha$ inhibitor Gö-6976 also inhibited TGF $\beta$ induced $\mathrm{Ca}^{2+}$ flux [52]. Further, siRNA knockdown of TRPC1 or treatment with 2-APB significantly inhibited pancreatic cancer cell 
motility induced by TGF $\beta$, although interestingly, siRNA knockdown of TRPC4 and 6 had no effect on TGF $\beta$-induced pancreatic cell motility [52].

\subsubsection{Breast Cancer Epithelial-Mesenchymal Transition and Proliferation}

It has previously been reported that epithelial-mesenchymal transition (EMT) is associated with upregulation of SOCE via increased levels of STIM1 and Orai1 in MCF7 and MDA-MB-231 cell lines, promoting invasion and proliferation of breast cancer cells [54]. However, the role of the SOCE pathway in EMT may be dependent on the stimulus inducing the transition and/or cell context specific. For example, in MDA-MB-468 cell lines undergoing EGF-induced EMT correlates with a reduction of SOCE activity, and the reduction in $\mathrm{Ca}^{2+}$ flux was associated with Orail downregulation, while TRPC1 expression was not altered [50]. Interestingly, hypoxiainduced EMT increased the expression of TRPC1 in MDA-MB-468, MDA-MB-231, and HCC1569 cell lines, an effect that requiredHIF $1 \alpha$ expression, indicating that TRPC1 is a HIF $1 \alpha$ target . Reducing TRPC1 expression inhibited hypoxia-induced increased Snail, Vimentin and Twist expression. Reducing the expression of TRPC1 in hypoxia resulted in decreased basal $\mathrm{Ca}^{2+}$ levels but increased SOCE activity was noted by depleting intracellular stores using the Sarco/Endoplasmic Reticulum $\mathrm{Ca}^{2+}$ ATPase (SERCA) inhibitor cyclopiazonic acid [42]. Reducing the expression of TRPC1 in MDA-MB-468 cells decreased the proliferation rate and was associated with reduction of cells in the S-phase, while Orail had no effect [50].

MCF7 breast cancer cells proliferate in response to activation of the $\mathrm{Ca}^{2+}$-sensing receptor $(\mathrm{CaR})$ by extracellular $\mathrm{Ca}^{2+}$ or its agonist spermine [66]. El Hiani and colleagues reported that $\mathrm{Ca}^{2+}$-mediated CaR activation in MCF7 cells results in activation of PLC and PKC [55].They further reported that proliferation is dependent on activation of ERK1/2 which was shown to be activated downstream of PLC and PKC. Reducing the expression of TRPC1 attenuated ERK1/2 phosphorylation mediated by $\mathrm{CaR}$ activation, which is necessary for $\mathrm{CaR}$-induced cell 
proliferation of MCF7 cells. In addition, reducing TRPC1 expression inhibited MCF7 proliferation by halting the cell cycle progression at the G1 phase [45]. Cell cycle progression was dependent on TRPC1 mediating the activity of $\mathrm{Ca}^{2+}$-activated $\mathrm{K}^{+}$channels (KCa3.1) [45,55]. Interestingly, a feed-forward loop was described where TRPC1 expression was dependent on activation of EGFR and ERK activity in MCF7 cells [67]. In human breast ductal adenocarcinoma primary patient samples, TRPC1, TRPC6, TRPM7, and TRPM8 were reported to be overexpressed in cancer cells compared to normal adjacent tissue. Importantly, increased TRPC1 expression correlated with expression and increased proliferative and invasive capacity of small grade I breast cancer tumors [68]. Taken together, these data suggest that TRPC1 expression may play a role in facilitating EMT and proliferation and further studies are required to carefully delineate the mechanism underpinning the role of TRPC1 in mediating EMT and proliferation in breast cancer.

\subsubsection{Glioblastoma}

In D54MG cells, a model for malignant gliomas or glioblastoma multiforme (GBM), the pharmacological inhibition of SOCE with 2-APB, SKF96365, and MRS1845 significantly reduced both $\mathrm{Ca}^{2+}$ influx and proliferation as well as the formation of multinucleated cells, a characteristic of GBM [53]. To define the role of TRPC1 as a $\mathrm{Ca}^{2+}$ channel involved in SOCE, its function was blocked using a polyclonal-TRPC1 antibody, which reduced the $\mathrm{Ca}^{2+}$ entry by $25 \%$, whereas no effect was seen with TRPC5 inhibition [53]. Similarly, $\mathrm{Ca}^{2+}$ entry was significantly decreased following the reduction of TRPC1 expression using shRNA [53]. The knockdown of TRPC1 also significantly reduced proliferation and resulted in enlarged multinucleated cells. Moreover, TRPC1 expression levels were reportedly down-regulated in patients with giant cell glioblastoma [53]. 
It has been reported that lipid rafts microdomains (LRD) and plasma membrane caveolin-1 are critical for TRPC1 insertion into the plasma membrane and its activity as $\mathrm{Ca}^{2+}$ channel, as TRPC channels contain a caveolin-1 binding domain [69-71]. Indeed, TRPC1 was implicated in chemotaxis and directional migration of D54MG cells towards epidermal growth factor (EGF) by co-localizing with caveolin-1 and lipid rafts in the cells' leading edge, which was abrogated with inducible TRPC1 shRNA knockdown [51]. Consistent with the importance of $\mathrm{Ca}^{2+}$ signaling, the use of SOCE inhibitors MRS1845 and SKF96365 disrupted glioma migration [51]. Evidence that TRPC1 expression is essential for growth in vivo was assessed by injecting nude mice glioma cells ectopically expressing doxycycline-inducible shRNA targeting TRPC1. Mice with inducible knockdown of TRPC1 had a shallow, significantly smaller tumor size compared to wild-type TRPC1 expression, However, propensity for metastasis was not evaluated in these mice [53].

\subsubsection{Lung cancer}

Lung cancer is the leading cause of death from cancer in men and women and thus clinical data continue to indicate the need for new treatment strategies to improve patient outcomes [72]. Levels of TRPC protein expression and their relation to tumor prognosis have been reported previously and identified as a potential target for treatment. TRPC1, TRPC3, TRPC4, and TRPC6 levels have been found to be highly expressed in patient specimens compared to other TRPC channels $[49,73]$. Moreover, overexpressing TRPC1 and TRPC6 in A549 NSCLC cell line was sufficient to increase proliferation, while blocking TRPC channels by the $\mathrm{IP}_{3}$ receptor inhibitor and SOCE modulator 2-APB or the specific TRPC1, TRPC3/TRPC6 antibodies T1E3 and T3667E3 inhibited A549 cells proliferation [49].

As mentioned earlier, TRPC1 levels in breast cancer were dependent on HIF-1 $\alpha$ following hypoxia-induced EMT. Wang et al. reported similar results in lung cancer by exposing A549 cells to high nicotine levels, which in turn resulted in increased HIF-1 $\alpha$ levels (as shown previously by 
Guo et al. [74]), leading to the upregulation of SOCE components, namely Orai1, TRPC1, and TRPC6 [75]. Further, the nicotine exposure was associated with increased basal intracellular $\mathrm{Ca}^{2+}$ levels in A549 cells related to constitutive SOCE activity. Downregulating HIF-1 $\alpha$ was associated with low expression of Orai1, TRPC1, and TRPC6, and resulted in decreased proliferation of A549 cells. Silencing TRPC1 decreased hypoxia-induced autophagy [75]. Autophagy is known to promote survival in hypoxic environments [76] albeit no data was reported on survival with respect to exposure to hypoxia and TRPC1 expression. More recently, STIM1 and TRPC1 were shown to mediate cisplatin cytotoxicity in NSCLC by facilitating DNA Damage Response (DDR) and reactive-oxygen species (ROS) production leading to apoptosis. While these effects were discovered mostly by silencing STIM1, and thus do not rule out Orai1 or other SOCE components, the overall effect was mainly mediated by inhibition of $\mathrm{Ca}^{2+}$ influx through the SOCE pathway $[40]$.

\subsubsection{Colon Cancer}

In colon cancer, the role of SOCE members, mainly TRPC1 and Orai1 has been discussed thoroughly by Villalobos et al [77]. Basal $\mathrm{Ca}^{2+}$ levels have been shown to be higher in HT29 colon carcinoma cell lines with higher increase in cytosolic $\mathrm{Ca}^{2+}$ in response to agonists like ATP and carbachol compared to the normal human mucosa cell line NCM460 [48]. Although TRPC1 mRNA levels were similar to other SOCE members in HT29 cells, there was an increase in protein expression levels compared to others, and TRPC1 silencing was associated with decreased storeoperated (Isoc) currents. As previously mentioned, TRPC1 facilitates the migration of GBM cells towards EGF. Guéguinou et al. investigated the mechanism by which TRPC1 contributes to colon cancer cell migration. They demonstrate that reducing the expression of TRPC1 inhibits migration of HCT-116 colon cancer cell line by disrupting the complex formation of $\mathrm{Ca}^{2+}$-activated $\mathrm{K}^{+}$ channels (SK3), Orai1, and TRPC1 in the lipid rafts [44]. Further, colon cancer cell migration was 
shown to be dependent on EGFR activation, leading to downstream activation of the PI3K/Akt pathway. This promotes the phosphorylation activation of STIM1 and SOCE, leading to the translocation of TRPC1 and Orai1 in the lipid rafts to form a complex with SK3, which allows a loop formation of further Akt activation and TRPC1/ORA1/SK3-dependent migration. Taken together, TRPC1 expression appears to have a role in the migration of multiple cancer types and more studies are required to determine whether inhibition of this pathway will block metastasis of primary tumors.

\subsection{Activation of SOCE pathway for inducing cell death in cancer}

Cancer requires robust $\mathrm{Ca}^{2+}$ signaling to support proliferation, invasion and metastasis, whereas excessive $\mathrm{Ca}^{2+}$ levels lead to apoptosis and cell death, Both the suppression and enhancement of the SOCE pathways may be exploited for treatment of cancer. In Triple negative breast cancer (TNBC), Grant et al. reported that TRPC1 and TRPC4 were overexpressed in some TNBC cell lines. For example, the Hs578T TNBC cell line showed high expression levels of TRPC1 and TRPC4 compared to the MD-MB-231 TNBC cell line, and the BT-549 TNBC cell line had high levels of TRPC4 when compared to MD-MB-231 cell line [41]. The higher TRPC expression levels in these cancer cells may render these cells more vulnerable to therapeutic strategies aimed at eliciting $\mathrm{Ca}^{2+}$ overload and cell death through channel agonists rather than pharmacological inhibition to reverse hallmarks of cancer.

Support of $\mathrm{Ca}^{2+}$ overload being a vulnerability for cancer is that TNBC cell lines with increased TRPC4 and TRPC5 showed increased sensitivity to the TRPC4 and TRPC5 activator englerin A (EA) compared to cell lines with reduced expression [41]. Interestingly, the expression of TRPC4 and TRPC5 alone did not yield sensitivity to EA-induced and $\mathrm{Ca}^{2+}$-dependent cell death, indicating the importance of the heteromeric formation of TRPC members. Although TRPC1 levels in BT-549 cells were comparable to the EA-resistant cell line HCC1806, BT-549 cells 
showed increased sensitivity to EA-induced $\mathrm{Ca}^{2+}$ entry and cell death when compared to Hs578T, when TRPC4 alone is predominantly and highly expressed. A possible explanation for this is the shift of the heteromeric TRPC1/TRPC4 channel towards more Na+ flux [31]. In renal cell carcinoma (RCC), A498 RCC cell lines responded to englerin A by elevation of intracellular $\mathrm{Ca}^{2+}$ levels and followed by cell death The $\mathrm{Ca}^{2+}$ entry was due to activation of TRPC4 channels as was demonstrated by patch-clamp studies. Further, while the expression of only TRPC1 did not contribute as a $\mathrm{Ca}^{2+}$ channel to the englerin A-induced $\mathrm{Ca}^{2+}$ overload and cell death, the coexpression of TRPC1 and TRPC4 and their heteromeric formation reproduced the same $\mathrm{Ca}^{2+}$ entry currents in HEK293 cells [58].

These findings corroborate the importance of TRPC1 expression for the overall functionality of the SOCE pathway. Our laboratory has shown that the novel cyclic peptide referred to as MTI101 induces a robust and sustained increase in intracellular $\mathrm{Ca}^{2+}$ levels in multiple myeloma cells lines [78,79]. Emergence of resistance to chronic exposure of increasing concentrations of MTI101 in the multiple myeloma $\mathrm{H} 929$ cell line correlated with decreased expression of the $\mathrm{IP}_{3}$ receptor, SERCA pump, PLC $\beta$, TRPC1 and TRPM7. Treatment with the pharmacological inhibitor 2-ABP attenuated MTI-101-induced $\mathrm{Ca}^{2+}$ influx, a finding that correlated with decreased cell death. U266 and MM1.s myeloma cells with reduced expression of TRPC1 using shRNA strategies showed a reduction in MTI-101 induced cell death [78]. Further studies are required to determine the role of TRPC1 in mediating MTI-101 induced $\mathrm{Ca}^{2+}$ entry and whether MTI-101induced activity is dependent on activation of TRPC1 heteromers and regulation of the SOCE pathway, thereby allowing for sustained $\mathrm{Ca}^{2+}$ influx and leading to caspase-independent cell death [79]. Interestingly, MTI-101 was found to be more active in primary specimens obtained from myeloma patients relapsing on standard of care agents. Together, these data suggest that stimulating $\mathrm{Ca}^{2+}$ overload maybe a unique vulnerability to cancer cells, as experimental evidence 
indicates that cancer cells remodel $\mathrm{Ca}^{2+}$ handling pathways to favor $\mathrm{Ca}^{2+}$ influx required to facilitate the hallmarks of cancer.

\subsection{Clinical outcomes}

As outlined above, several TRPC members have been studied and implicated in the promotion of cancer through tumor cell proliferation, migration, invasion, and survival, as observed in lung cancer, malignant glioma, neuroblastoma, renal cell carcinoma, hepatoma, thyroid cancer, colon cancer, and breast cancer $[43-47,57,80,81]$. With respect to TRPC1, the screening of patient specimens as well as the mining of large data sets have yielded several clinically relevant insights in patients with tumors expressing TRPC1. Faouzi et al. reported TRPC1 to be expressed in all examined 17 data sets of breast cancer specimens, with no specific clinical significance [45]. Azimi et al. reported the TRPC1 expression levels in a data set from the University of North Carolina of 855 breast cancer patients, classified and reported based on the 50-signature genes subtype classification known as PAM50 [42,82]. The claudin-low breast cancer subtype exhibited the highest TRPC1 expression levels compared to other subtypes. Further, in TNBC, the mesenchymal subtype showed the highest expression level of TRPC1, and the basal subtype with lymph-node metastasis showed worsened prognoses associated with high TRPC1 expression levels [42]. In lung cancer, SOCE components including STIM1, Orai1 and TRPC channels have been examined in a dataset of more than 2,000 cases. While TRPC1 had no effect on the risk of lung cancer, two variants of TRPC4 namely (rs9547991 and rs978156), and one variant of TRPC7 (rs11748198) were associated with increased risk of lung cancer compared to control subjects [57]. TRPC1 plasma membrane levels have been reported to be low when in inactive status, being located in close proximity to the plasma membrane. Transfer to the plasma membrane is dependent on $\mathrm{Ca}^{2+}$ signals generated by STIM1-Orail activation [83]. Thus, membrane localization may be an important factor linking SOCE and TRPC1 functions, even if expression levels may not change. 
Considering the function of TRPC1, it is feasible that quantification of membrane staining of TRPC1 may lead to increased sensitivity as a prognostic indicator in cancer.

\subsection{Summary}

Experimental evidence indicates that although TRPC1 may not represent a driver of cancer, the expression of TRPC1 contributes to the hallmarks of cancer. To further the understanding of TRPC1 functionality in vivo, various TRPC knockout mice were created and used in different settings. A Hepta-KO cell line was created by combining cell lines with 5 TRPC knockout alleles, with TRPC2 KO, along with TRPC4 knockout, formulating a null cell line devoid of all 7 TRPC members. Surprisingly, the Hepta-KO model has a functional SOCE system regardless of TRPC expression [84]. These data suggest that the SOCE can function independent of TRPC expression. However, it is feasible that TRPC1 function requires activation such as hypoxia or a reprogramming switch to EMT in order to modify the SOCE pathway. It is also possible that TRPC1 acts as a modulator in only a subset of cell types and/or under specific (patho)physiological circumstances. Thus more studies are required to inform the role of TRPC1 in the context of cancer in genetically engineered mouse models. Finally, the development of more specific pharmacological tools for inhibiting or activating TRPC1 function are needed to fully validate TRPC1 as a potential target for the treatment of cancer.

\subsection{Acknowledgments}

Research reported in this publication was supported by the National Institute of General Medical Sciences of the National Institutes of Health under Award Number 5U54GM104942-04, R44CA221554 Hazlehurst PI NCI, and NCI 1R01CA195727-01_LAH. The content is solely the responsibility of the authors and does not necessarily represent the official views of the National 
Institutes of Health. Dr. Hazlehurst is a co-founder of Modulation Therapeutics which has a license to MTI-101 for treatment of cancer.

\subsection{References}

1. Berridge, M.J.; Lipp, P.; Bootman, M.D. The versatility and universality of calcium signalling. Nat Rev Mol Cell Biol 2000, 1, 11-21, doi:10.1038/35036035.

2. Berridge, M.J.; Bootman, M.D.; Roderick, H.L. Calcium signalling: dynamics, homeostasis and remodelling. Nat Rev Mol Cell Biol 2003, 4, 517-529, doi:10.1038/nrm1155.

3. Chen, Y.F.; Chen, Y.T.; Chiu, W.T.; Shen, M.R. Remodeling of calcium signaling in tumor progression. J Biomed Sci 2013, 20, 23, doi:10.1186/1423-0127-20-23.

4. Prevarskaya, N.; Skryma, R.; Shuba, Y. Ion channels and the hallmarks of cancer. Trends Mol Med 2010, 16, 107-121, doi:10.1016/j.molmed.2010.01.005.

5. Rizzuto, R.; Pozzan, T. When calcium goes wrong: genetic alterations of a ubiquitous signaling route. Nature genetics 2003, 34, 135-141, doi:10.1038/ng0603-135.

6. Clapham, D.E. Calcium signaling. Cell 2007, 131, 1047-1058, doi:10.1016/j.cell.2007.11.028.

7. Minke, B.; Wu, C.; Pak, W.L. Induction of photoreceptor voltage noise in the dark in Drosophila mutant. Nature 1975, 258, 84-87, doi:10.1038/258084a0.

8. Montell, C.; Birnbaumer, L.; Flockerzi, V.; Bindels, R.J.; Bruford, E.A.; Caterina, M.J.; Clapham, D.E.; Harteneck, C.; Heller, S.; Julius, D., et al. A unified nomenclature for the superfamily of TRP cation channels. Mol Cell 2002, 9, 229-231, doi:10.1016/s10972765(02)00448-3.

9. Montell, C. The TRP superfamily of cation channels. Sci STKE 2005, 2005, re3, doi:10.1126/stke.2722005re3. 
10. Launay, P.; Fleig, A.; Perraud, A.L.; Scharenberg, A.M.; Penner, R.; Kinet, J.P. TRPM4 is a $\mathrm{Ca}^{2+}$-activated nonselective cation channel mediating cell membrane depolarization. Cell 2002, 109, 397-407, doi:10.1016/s0092-8674(02)00719-5.

11. Hofmann, T.; Chubanov, V.; Gudermann, T.; Montell, C. TRPM5 Is a VoltageModulated and $\mathrm{Ca}^{2+}$-Activated Monovalent Selective Cation Channel. Current Biology 2003, 13, 1153-1158, doi:10.1016/s0960-9822(03)00431-7.

12. Strubing, C.; Krapivinsky, G.; Krapivinsky, L.; Clapham, D.E. Formation of novel TRPC channels by complex subunit interactions in embryonic brain. J Biol Chem 2003, 278, 39014-39019, doi:10.1074/jbc.M306705200.

13. Lewis, R.S. Calcium signaling mechanisms in T lymphocytes. Annu Rev Immunol 2001, 19, 497-521, doi:10.1146/annurev.immunol.19.1.497.

14. Thakur, P.; Dadsetan, S.; Fomina, A.F. Bidirectional coupling between ryanodine receptors and $\mathrm{Ca}^{2+}$ release-activated $\mathrm{Ca}^{2+}(\mathrm{CRAC})$ channel machinery sustains storeoperated $\mathrm{Ca}^{2+}$ entry in human T lymphocytes. J Biol Chem 2012, 287, 37233-37244, doi:10.1074/jbc.M112.398974.

15. Zhang, S.L.; Yu, Y.; Roos, J.; Kozak, J.A.; Deerinck, T.J.; Ellisman, M.H.; Stauderman, K.A.; Cahalan, M.D. STIM1 is a $\mathrm{Ca}^{2+}$ sensor that activates CRAC channels and migrates from the $\mathrm{Ca}^{2+}$ store to the plasma membrane. Nature 2005, 437, 902-905, doi:10.1038/nature04147.

16. Cheng, K.T.; Ong, H.L.; Liu, X.; Ambudkar, I.S. Contribution and regulation of TRPC channels in store-operated $\mathrm{Ca}^{2+}$ entry. Curr Top Membr 2013, 71, 149-179, doi:10.1016/B978-0-12-407870-3.00007-X. 
17. Jia, S.; Rodriguez, M.; Williams, A.G.; Yuan, J.P. Homer binds to Orai1 and TRPC channels in the neointima and regulates vascular smooth muscle cell migration and proliferation. Sci Rep 2017, 7, 5075, doi:10.1038/s41598-017-04747-w.

18. Xu, S.Z.; Sukumar, P.; Zeng, F.; Li, J.; Jairaman, A.; English, A.; Naylor, J.; Ciurtin, C.; Majeed, Y.; Milligan, C.J., et al. TRPC channel activation by extracellular thioredoxin. Nature 2008, 451, 69-72, doi:10.1038/nature06414.

19. Hofmann, T.; Obukhov, A.G.; Schaefer, M.; Harteneck, C.; Gudermann, T.; Schultz, G. Direct activation of human TRPC6 and TRPC3 channels by diacylglycerol. Nature 1999, 397, 259-263, doi:10.1038/16711.

20. Bon, R.S.; Beech, D.J. In pursuit of small molecule chemistry for calcium-permeable non-selective TRPC channels -- mirage or pot of gold? Br J Pharmacol 2013, 170, 459474, doi:10.1111/bph.12274.

21. Dyrda, A.; Koenig, S.; Frieden, M. STIM1 long and STIM1 gate differently TRPC1 during store-operated calcium entry. Cell Calcium 2019, 86, 102134, doi:10.1016/j.ceca.2019.102134.

22. Yuan, J.P.; Zeng, W.; Dorwart, M.R.; Choi, Y.J.; Worley, P.F.; Muallem, S. SOAR and the polybasic STIM1 domains gate and regulate Orai channels. Nat Cell Biol 2009, 11, 337-343, doi:10.1038/ncb1842.

23. Derler, I.; Plenk, P.; Fahrner, M.; Muik, M.; Jardin, I.; Schindl, R.; Gruber, H.J.; Groschner, K.; Romanin, C. The extended transmembrane Orai1 N-terminal (ETON) region combines binding interface and gate for Orail activation by STIM1. J Biol Chem 2013, 288, 29025-29034, doi:10.1074/jbc.M113.501510. 
24. Stathopulos, P.B.; Schindl, R.; Fahrner, M.; Zheng, L.; Gasmi-Seabrook, G.M.; Muik, M.; Romanin, C.; Ikura, M. STIM1/Orail coiled-coil interplay in the regulation of storeoperated calcium entry. Nat Commun 2013, 4, 2963, doi:10.1038/ncomms3963.

25. Lopez, J.J.; Jardin, I.; Albarran, L.; Sanchez-Collado, J.; Cantonero, C.; Salido, G.M.; Smani, T.; Rosado, J.A. Molecular Basis and Regulation of Store-Operated Calcium Entry. Adv Exp Med Biol 2020, 1131, 445-469, doi:10.1007/978-3-030-12457-1_17.

26. Lee, K.P.; Choi, S.; Hong, J.H.; Ahuja, M.; Graham, S.; Ma, R.; So, I.; Shin, D.M.; Muallem, S.; Yuan, J.P. Molecular determinants mediating gating of Transient Receptor Potential Canonical (TRPC) channels by stromal interaction molecule 1 (STIM1). J Biol Chem 2014, 289, 6372-6382, doi:10.1074/jbc.M113.546556.

27. Broker-Lai, J.; Kollewe, A.; Schindeldecker, B.; Pohle, J.; Nguyen Chi, V.; Mathar, I.; Guzman, R.; Schwarz, Y.; Lai, A.; Weissgerber, P., et al. Heteromeric channels formed by TRPC1, TRPC4 and TRPC5 define hippocampal synaptic transmission and working memory. EMBO J 2017, 36, 2770-2789, doi:10.15252/embj.201696369.

28. Zhang, Z.; Reboreda, A.; Alonso, A.; Barker, P.A.; Seguela, P. TRPC channels underlie cholinergic plateau potentials and persistent activity in entorhinal cortex. Hippocampus 2011, 21, 386-397, doi:10.1002/hipo.20755.

29. Obukhov, A.G.; Nowycky, M.C. TRPC5 channels undergo changes in gating properties during the activation-deactivation cycle. J Cell Physiol 2008, 216, 162-171, doi:10.1002/jcp.21388.

30. Beech, D.J. Characteristics of transient receptor potential canonical calcium-permeable channels and their relevance to vascular physiology and disease. Circ J 2013, 77, 570579, doi:10.1253/circj.cj-13-0154. 
31. Storch, U.; Forst, A.L.; Philipp, M.; Gudermann, T.; Mederos y Schnitzler, M. Transient receptor potential channel 1 (TRPC1) reduces calcium permeability in heteromeric channel complexes. J Biol Chem 2012, 287, 3530-3540, doi:10.1074/jbc.M111.283218.

32. Chen, Y.F.; Lin, P.C.; Yeh, Y.M.; Chen, L.H.; Shen, M.R. Store-Operated Ca $\left({ }^{2+}\right)$ Entry in Tumor Progression: From Molecular Mechanisms to Clinical Implications. Cancers (Basel) 2019, 11, doi:10.3390/cancers11070899.

33. Fiorio Pla, A.; Kondratska, K.; Prevarskaya, N. STIM and ORAI proteins: crucial roles in hallmarks of cancer. Am J Physiol Cell Physiol 2016, 310, C509-519, doi:10.1152/ajpcell.00364.2015.

34. Chen, Y.F.; Hsu, K.F.; Shen, M.R. The store-operated $\mathrm{Ca}\left({ }^{2+}\right)$ entry-mediated signaling is important for cancer spread. Biochim Biophys Acta 2016, 1863, 1427-1435, doi:10.1016/j.bbamcr.2015.11.030.

35. Putney, J.W. Calcium signaling: deciphering the calcium-NFAT pathway. Curr Biol 2012, 22, R87-89, doi:10.1016/j.cub.2011.12.030.

36. Di Capite, J.; Ng, S.W.; Parekh, A.B. Decoding of cytoplasmic $\mathrm{Ca}\left({ }^{2+}\right)$ oscillations through the spatial signature drives gene expression. Curr Biol 2009, 19, 853-858, doi:10.1016/j.cub.2009.03.063.

37. Bucher, P.; Erdmann, T.; Grondona, P.; Xu, W.; Schmitt, A.; Schurch, C.; Zapukhlyak, M.; Schonfeld, C.; Serfling, E.; Kramer, D., et al. Targeting chronic NFAT activation with calcineurin inhibitors in diffuse large B-cell lymphoma. Blood 2020, 135, 121-132, doi:10.1182/blood.2019001866.

38. Urso, K.; Fernandez, A.; Velasco, P.; Cotrina, J.; de Andres, B.; Sanchez-Gomez, P.; Hernandez-Lain, A.; Hortelano, S.; Redondo, J.M.; Cano, E. NFATc3 controls tumour 
growth by regulating proliferation and migration of human astroglioma cells. Sci Rep 2019, 9, 9361, doi:10.1038/s41598-019-45731-w.

39. Mancini, M.; Toker, A. NFAT proteins: emerging roles in cancer progression. Nat Rev Cancer 2009, 9, 810-820, doi:10.1038/nrc2735.

40. Gualdani, R.; de Clippele, M.; Ratbi, I.; Gailly, P.; Tajeddine, N. Store-Operated Calcium Entry Contributes to Cisplatin-Induced Cell Death in Non-Small Cell Lung Carcinoma. Cancers (Basel) 2019, 11, doi:10.3390/cancers11030430.

41. Grant, C.V.; Carver, C.M.; Hastings, S.D.; Ramachandran, K.; Muniswamy, M.; Risinger, A.L.; Beutler, J.A.; Mooberry, S.L. Triple-negative breast cancer cell line sensitivity to englerin A identifies a new, targetable subtype. Breast Cancer Res Treat 2019, 177, 345-355, doi:10.1007/s10549-019-05324-7.

42. Azimi, I.; Milevskiy, M.J.G.; Kaemmerer, E.; Turner, D.; Yapa, K.; Brown, M.A.; Thompson, E.W.; Roberts-Thomson, S.J.; Monteith, G.R. TRPC1 is a differential regulator of hypoxia-mediated events and Akt signalling in PTEN-deficient breast cancer cells. J Cell Sci 2017, 130, 2292-2305, doi:10.1242/jcs.196659.

43. Lepannetier, S.; Zanou, N.; Yerna, X.; Emeriau, N.; Dufour, I.; Masquelier, J.; Muccioli, G.; Tajeddine, N.; Gailly, P. Sphingosine-1-phosphate-activated TRPC1 channel controls chemotaxis of glioblastoma cells. Cell Calcium 2016, 60, 373-383, doi:10.1016/j.ceca.2016.09.002.

44. Gueguinou, M.; Harnois, T.; Crottes, D.; Uguen, A.; Deliot, N.; Gambade, A.; Chantome, A.; Haelters, J.P.; Jaffres, P.A.; Jourdan, M.L., et al. SK3/TRPC1/Orai1 complex regulates SOCE-dependent colon cancer cell migration: a novel opportunity to modulate anti-EGFR mAb action by the alkyl-lipid Ohmline. Oncotarget 2016, 7, 36168-36184, doi:10.18632/oncotarget.8786. 
45. Faouzi, M.; Hague, F.; Geerts, D.; Ay, A.S.; Potier-Cartereau, M.; Ahidouch, A.; OuadidAhidouch, H. Functional cooperation between KCa3.1 and TRPC1 channels in human breast cancer: Role in cell proliferation and patient prognosis. Oncotarget 2016, 7, 36419-36435, doi:10.18632/oncotarget.9261.

46. Asghar, M.Y.; Magnusson, M.; Kemppainen, K.; Sukumaran, P.; Lof, C.; Pulli, I.; Kalhori, V.; Tornquist, K. Transient Receptor Potential Canonical 1 (TRPC1) Channels as Regulators of Sphingolipid and VEGF Receptor Expression: IMPLICATIONS FOR THYROID CANCER CELL MIGRATION AND PROLIFERATION. J Biol Chem 2015, 290, 16116-16131, doi:10.1074/jbc.M115.643668.

47. Alptekin, M.; Eroglu, S.; Tutar, E.; Sencan, S.; Geyik, M.A.; Ulasli, M.; Demiryurek, A.T.; Camci, C. Gene expressions of TRP channels in glioblastoma multiforme and relation with survival. Tumour Biol 2015, 36, 9209-9213, doi:10.1007/s13277-015-3577-

$\mathrm{x}$.

48. Sobradillo, D.; Hernandez-Morales, M.; Ubierna, D.; Moyer, M.P.; Nunez, L.; Villalobos, C. A reciprocal shift in transient receptor potential channel 1 (TRPC1) and stromal interaction molecule 2 (STIM2) contributes to $\mathrm{Ca}^{2+}$ remodeling and cancer hallmarks in colorectal carcinoma cells. J Biol Chem 2014, 289, 28765-28782, doi:10.1074/jbc.M114.581678.

49. Jiang, H.N.; Zeng, B.; Zhang, Y.; Daskoulidou, N.; Fan, H.; Qu, J.M.; Xu, S.Z. Involvement of TRPC channels in lung cancer cell differentiation and the correlation analysis in human non-small cell lung cancer. PLoS One 2013, 8, e67637, doi:10.1371/journal.pone.0067637.

50. Davis, F.M.; Peters, A.A.; Grice, D.M.; Cabot, P.J.; Parat, M.O.; Roberts-Thomson, S.J.; Monteith, G.R. Non-stimulated, agonist-stimulated and store-operated $\mathrm{Ca}^{2+}$ influx in 
MDA-MB-468 breast cancer cells and the effect of EGF-induced EMT on calcium entry. PLoS One 2012, 7, e36923, doi:10.1371/journal.pone.0036923.

51. Bomben, V.C.; Turner, K.L.; Barclay, T.T.; Sontheimer, H. Transient receptor potential canonical channels are essential for chemotactic migration of human malignant gliomas. J Cell Physiol 2011, 226, 1879-1888, doi:10.1002/jcp.22518.

52. Dong, H.; Shim, K.N.; Li, J.M.; Estrema, C.; Ornelas, T.A.; Nguyen, F.; Liu, S.; Ramamoorthy, S.L.; Ho, S.; Carethers, J.M., et al. Molecular mechanisms underlying $\mathrm{Ca}^{2+}$-mediated motility of human pancreatic duct cells. Am J Physiol Cell Physiol 2010, 299, C1493-1503, doi:10.1152/ajpcell.00242.2010.

53. Bomben, V.C.; Sontheimer, H. Disruption of transient receptor potential canonical channel 1 causes incomplete cytokinesis and slows the growth of human malignant gliomas. Glia 2010, 58, 1145-1156, doi:10.1002/glia.20994.

54. Hu, J.; Qin, K.; Zhang, Y.; Gong, J.; Li, N.; Lv, D.; Xiang, R.; Tan, X. Downregulation of transcription factor Oct4 induces an epithelial-to-mesenchymal transition via enhancement of $\mathrm{Ca}^{2+}$ influx in breast cancer cells. Biochem Biophys Res Commun 2011, 411, 786-791, doi:10.1016/j.bbrc.2011.07.025.

55. El Hiani, Y.; Ahidouch, A.; Lehen'kyi, V.; Hague, F.; Gouilleux, F.; Mentaverri, R.; Kamel, S.; Lassoued, K.; Brule, G.; Ouadid-Ahidouch, H. Extracellular signal-regulated kinases 1 and 2 and TRPC1 channels are required for calcium-sensing receptorstimulated MCF-7 breast cancer cell proliferation. Cell Physiol Biochem 2009, 23, 335346, doi:10.1159/000218179.

56. Chow, J.Y.; Dong, H.; Quach, K.T.; Van Nguyen, P.N.; Chen, K.; Carethers, J.M. TGFbeta mediates PTEN suppression and cell motility through calcium-dependent PKC-alpha 
activation in pancreatic cancer cells. Am J Physiol Gastrointest Liver Physiol 2008, 294, G899-905, doi:10.1152/ajpgi.00411.2007.

57. Zhang, Z.; Wang, J.; He, J.; Zeng, X.; Chen, X.; Xiong, M.; Zhou, Q.; Guo, M.; Li, D.; $\mathrm{Lu}, \mathrm{W}$. Identification of TRPCs genetic variants that modify risk for lung cancer based on the pathway and two-stage study. Meta Gene 2016, 9, 191-196, doi:10.1016/j.mgene.2016.07.005.

58. Akbulut, Y.; Gaunt, H.J.; Muraki, K.; Ludlow, M.J.; Amer, M.S.; Bruns, A.; Vasudev, N.S.; Radtke, L.; Willot, M.; Hahn, S., et al. (-)-Englerin A is a potent and selective activator of TRPC4 and TRPC5 calcium channels. Angew Chem Int Ed Engl 2015, 54, 3787-3791, doi:10.1002/anie.201411511.

59. Diver, J.M.; Sage, S.O.; Rosado, J.A. The inositol trisphosphate receptor antagonist 2aminoethoxydiphenylborate (2-APB) blocks $\mathrm{Ca}^{2+}$ entry channels in human platelets: cautions for its use in studying $\mathrm{Ca}^{2+}$ influx. Cell Calcium 2001, 30, 323-329, doi:10.1054/ceca.2001.0239.

60. Xu, S.Z.; Zeng, F.; Boulay, G.; Grimm, C.; Harteneck, C.; Beech, D.J. Block of TRPC5 channels by 2-aminoethoxydiphenyl borate: a differential, extracellular and voltagedependent effect. Br J Pharmacol 2005, 145, 405-414, doi:10.1038/sj.bjp.0706197.

61. Merritt, J.E.; Armstrong, W.P.; Benham, C.D.; Hallam, T.J.; Jacob, R.; Jaxa-Chamiec, A.; Leigh, B.K.; McCarthy, S.A.; Moores, K.E.; Rink, T.J. SK\&F 96365, a novel inhibitor of receptor-mediated calcium entry. Biochem $J$ 1990, 271, 515-522, doi:10.1042/bj2710515.

62. Rychkov, G.; Barritt, G.J. TRPC1 Ca $\left({ }^{2+}\right)$-permeable channels in animal cells. Handb Exp Pharmacol 2007, 10.1007/978-3-540-34891-7_2, 23-52, doi:10.1007/978-3-540-34891$7 \_2$. 
63. Harper, J.L.; Camerini-Otero, C.S.; Li, A.H.; Kim, S.A.; Jacobson, K.A.; Daly, J.W. Dihydropyridines as inhibitors of capacitative calcium entry in leukemic HL-60 cells. Biochem Pharmacol 2003, 65, 329-338, doi:10.1016/s0006-2952(02)01488-0.

64. Rubaiy, H.N. Treasure troves of pharmacological tools to study transient receptor potential canonical 1/4/5 channels. Br J Pharmacol 2019, 176, 832-846, doi:10.1111/bph.14578.

65. Radisky, D.C.; LaBarge, M.A. Epithelial-mesenchymal transition and the stem cell phenotype. Cell Stem Cell 2008, 2, 511-512, doi:10.1016/j.stem.2008.05.007.

66. El Hiani, Y.; Ahidouch, A.; Roudbaraki, M.; Guenin, S.; Brule, G.; Ouadid-Ahidouch, H. Calcium-sensing receptor stimulation induces nonselective cation channel activation in breast cancer cells. J Membr Biol 2006, 211, 127-137, doi:10.1007/s00232-006-0017-2.

67. El Hiani, Y.; Lehen'kyi, V.; Ouadid-Ahidouch, H.; Ahidouch, A. Activation of the calcium-sensing receptor by high calcium induced breast cancer cell proliferation and TRPC1 cation channel over-expression potentially through EGFR pathways. Arch Biochem Biophys 2009, 486, 58-63, doi:10.1016/j.abb.2009.03.010.

68. Dhennin-Duthille, I.; Gautier, M.; Faouzi, M.; Guilbert, A.; Brevet, M.; Vaudry, D.; Ahidouch, A.; Sevestre, H.; Ouadid-Ahidouch, H. High expression of transient receptor potential channels in human breast cancer epithelial cells and tissues: correlation with pathological parameters. Cell Physiol Biochem 2011, 28, 813-822, doi:10.1159/000335795.

69. Brazer, S.C.; Singh, B.B.; Liu, X.; Swaim, W.; Ambudkar, I.S. Caveolin-1 contributes to assembly of store-operated $\mathrm{Ca}^{2+}$ influx channels by regulating plasma membrane localization of TRPC1. J Biol Chem 2003, 278, 27208-27215, doi:10.1074/jbc.M301118200. 
70. Ambudkar, I.S.; Brazer, S.C.; Liu, X.; Lockwich, T.; Singh, B. Plasma membrane localization of TRPC channels: role of caveolar lipid rafts. Novartis Found Symp 2004, 258, 63-70; discussion 70-64, 98-102, 263-106.

71. Pani, B.; Singh, B.B. Lipid rafts/caveolae as microdomains of calcium signaling. Cell Calcium 2009, 45, 625-633, doi:10.1016/j.ceca.2009.02.009.

72. Howlader N, N.A., Krapcho M, Miller D, Brest A, Yu M, Ruhl J, Tatalovich Z, Mariotto A, Lewis DR, Chen HS, Feuer EJ, Cronin KA (eds). SEER Cancer Statistics Review, 1975-2016, National Cancer Institute. Bethesda, MD, https://seer.cancer.gov/csr/1975_2016/, based on November 2018 SEER data submission, posted to the SEER web site, April 2019. Availabe online: (accessed on 02/01/2020).

73. Zhang, Q.; He, J.; Lu, W.; Yin, W.; Yang, H.; Xu, X.; Wang, D. [Expression of transient receptor potential canonical channel proteins in human non-small cell lung cancer]. Zhongguo Fei Ai Za Zhi 2010, 13, 612-616, doi:10.3779/j.issn.1009-3419.2010.06.009.

74. Guo, L.; Li, L.; Wang, W.; Pan, Z.; Zhou, Q.; Wu, Z. Mitochondrial reactive oxygen species mediates nicotine-induced hypoxia-inducible factor-1alpha expression in human non-small cell lung cancer cells. Biochim Biophys Acta 2012, 1822, 852-861, doi:10.1016/j.bbadis.2012.02.004.

75. Wang, Y.; He, J.; Jiang, H.; Zhang, Q.; Yang, H.; Xu, X.; Zhang, C.; Xu, C.; Wang, J.; Lu, W. Nicotine enhances storeoperated calcium entry by upregulating HIF1alpha and SOCC components in nonsmall cell lung cancer cells. Oncol Rep 2018, 40, 2097-2104, doi:10.3892/or.2018.6580.

76. Tan, Q.; Wang, M.; Yu, M.; Zhang, J.; Bristow, R.G.; Hill, R.P.; Tannock, I.F. Role of Autophagy as a Survival Mechanism for Hypoxic Cells in Tumors. Neoplasia 2016, 18, 347-355, doi:10.1016/j.neo.2016.04.003. 
77. Villalobos, C.; Hernandez-Morales, M.; Gutierrez, L.G.; Nunez, L. TRPC1 and ORAI1 channels in colon cancer. Cell Calcium 2019, 81, 59-66, doi:10.1016/j.ceca.2019.06.003.

78. Emmons, M.F.; Anreddy, N.; Cuevas, J.; Steinberger, K.; Yang, S.; McLaughlin, M.; Silva, A.; Hazlehurst, L.A. MTI-101 treatment inducing activation of Stim1 and TRPC1 expression is a determinant of response in multiple myeloma. Sci Rep 2017, 7, 2685, doi:10.1038/s41598-017-02713-0.

79. Gebhard, A.W.; Jain, P.; Nair, R.R.; Emmons, M.F.; Argilagos, R.F.; Koomen, J.M.; McLaughlin, M.L.; Hazlehurst, L.A. MTI-101 (cyclized HYD1) binds a CD44 containing complex and induces necrotic cell death in multiple myeloma. Mol Cancer Ther 2013, 12, 2446-2458, doi:10.1158/1535-7163.MCT-13-0310.

80. Nasman, J.; Bart, G.; Larsson, K.; Louhivuori, L.; Peltonen, H.; Akerman, K.E. The orexin OX1 receptor regulates $\mathrm{Ca}^{2+}$ entry via diacylglycerol-activated channels in differentiated neuroblastoma cells. J Neurosci 2006, 26, 10658-10666, doi:10.1523/JNEUROSCI.2609-06.2006.

81. Selli, C.; Pearce, D.A.; Sims, A.H.; Tosun, M. Differential expression of store-operated calcium- and proliferation-related genes in hepatocellular carcinoma cells following TRPC1 ion channel silencing. Mol Cell Biochem 2016, 420, 129-140, doi:10.1007/s11010-016-2776-0.

82. Cancer Genome Atlas, N. Comprehensive molecular portraits of human breast tumours. Nature 2012, 490, 61-70, doi:10.1038/nature11412.

83. Ambudkar, I.S.; de Souza, L.B.; Ong, H.L. TRPC1, Orai1, and STIM1 in SOCE: Friends in tight spaces. Cell Calcium 2017, 63, 33-39, doi:10.1016/j.ceca.2016.12.009.

84. Birnbaumer, L. From GTP and G proteins to TRPC channels: a personal account. J Mol Med (Berl) 2015, 93, 941-953, doi:10.1007/s00109-015-1328-5. 


\subsection{Figure Legends}

Figure 1. The Store-Operated $\mathrm{Ca}^{2+}$ Entry pathway (SOCE): A) SOCE is regulated by agonist binding to G-protein coupled receptors (GPCR) or receptor tyrosine-kinases (RTK), activating phospholipase $\mathrm{C} \beta$ (PLC $\beta$ ) via Gq/11 and PLC $\gamma$ via RTK mediated signaling, resulting in the production of IP3 and DAG from the cleavage of plasma-membrane PIP2. IP3 depletes $\mathrm{Ca}^{2+}$ stores from the ER through the IP3R which is sensed by STIM1. B) STIM molecules multimerize forming puncta and translocate to ER-PM junction co-assembling with the CRAC channel subunits Orail activating the $\mathrm{Ca}^{2+}$ selective Icrac currents. Further, STIM1 forms STIM1/Orai1/TRPC1 complex activating cation non-selective Isoc currents.

Figure 2. $\mathrm{Ca}^{2+}$ entry through SOCE activates NFAT activation: $\mathrm{Ca}^{2+}$ entry through Icrac channel binds calmodulin, leading to the activation of the phosphatase protein calcineurin, activating the transcription factor NFAT. Active NFAT is translocated to the nucleus regulating the expression of genes promoting proliferation, migration, and survival.

Table 1. Role of TRPC expression or activity in augmenting proliferation and metastasis in cancer. 


\subsection{Figures and Tables}

\section{Figure 1:}

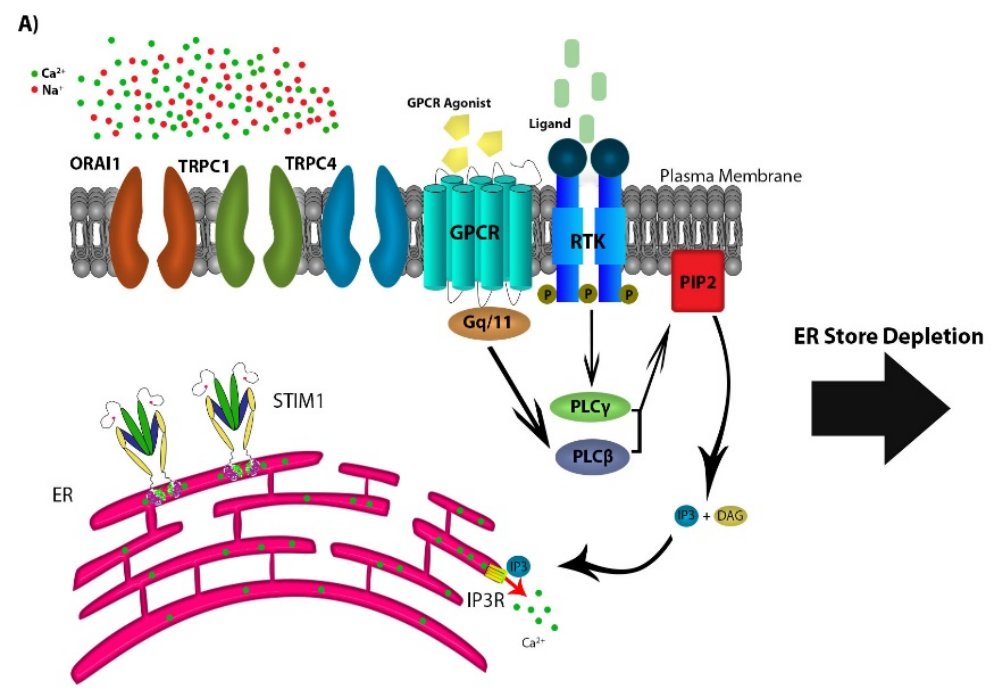

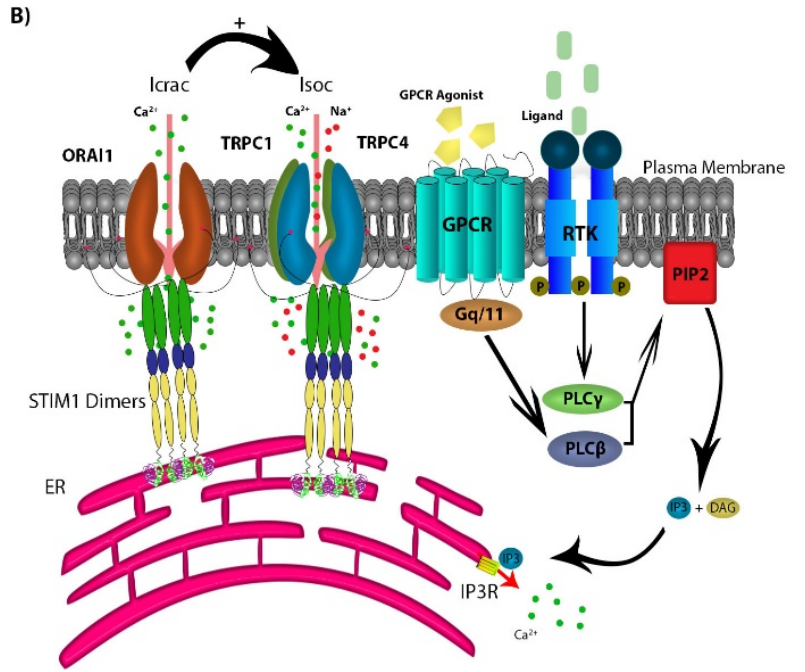


Figure 2:

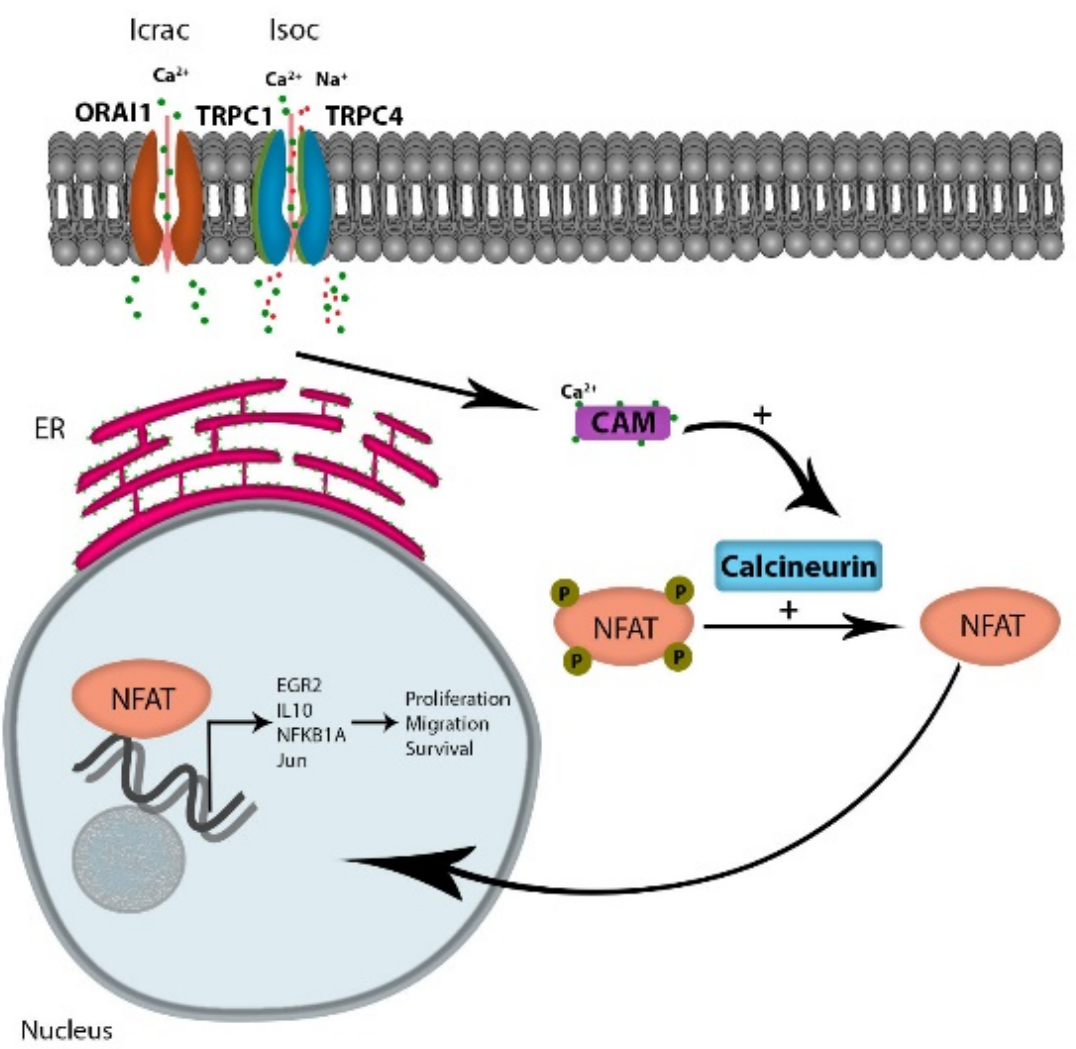


Table 1:

\begin{tabular}{|c|c|c|c|c|c|}
\hline Cancer Type & Cell Type & $\begin{array}{c}\text { Native } \\
\text { TRPC } \\
\text { expression } \\
\end{array}$ & $\begin{array}{l}\text { Silenced proteins / } \\
\text { Tools used }\end{array}$ & $\begin{array}{l}\text { Native expression } \\
\text { effect / Silencing effect }\end{array}$ & $\begin{array}{c}\text { Referenc } \\
\text { e }\end{array}$ \\
\hline Pancreatic & $\begin{array}{c}\text { BxPc3 (Human } \\
\text { ductal } \\
\text { adenocarcinoma) } \\
\end{array}$ & $\uparrow \mathrm{TRPC} 1$ & $\begin{array}{ll}\text { - } & \mathrm{SOC} / 2-\mathrm{APB} \\
\text { - } & \mathrm{TRPC} 1 \text { / siRNA } \\
\end{array}$ & $\begin{array}{l}\text { Motility / } \downarrow \text { Motility } \\
\text { (TGF } \beta \text {-dependent } \\
\text { motility) }\end{array}$ & {$[52]$} \\
\hline \multirow{5}{*}{ Breast } & $\begin{array}{c}\text { MDA-MB-468 } \\
\text { (EGF-mediated } \\
\text { EMT cells) (Human } \\
\text { breast } \\
\text { adenocarcinoma) }\end{array}$ & $\begin{array}{l}\text { Comparable } \\
\text { to MDA- } \\
\text { MB-231 - } \\
\text { EMT }\end{array}$ & TRPC1 / siRNA & $\begin{array}{l}\text { - } \quad / \downarrow \text { Cell } \\
\text { proliferation }(\downarrow S- \\
\text { phase) }\end{array}$ & {$[50]$} \\
\hline & $\begin{array}{l}\text { MDA-MB-468 } \\
\text { Hypoxia-mediated } \\
\text { EMT cells) }\end{array}$ & $\begin{array}{l}\uparrow \text { TRPC1 \& } \\
\text { TRPC3 }\end{array}$ & TRPC1 / siRNA & $\begin{array}{l}-\quad / \uparrow \mathrm{Ca}^{2+} \text { influx in } \\
\text { SOCE \& } \downarrow \\
\text { autophagy } \\
\text { marker LC3BIII }\end{array}$ & {$[42]$} \\
\hline & $\begin{array}{c}\text { MCF7 } \\
\text { (adenocarcinoma) }\end{array}$ & $\uparrow \mathrm{TRPC} 1$ & TRPC1 / siRNA & $\begin{array}{l}\text { Proliferation / } \downarrow \\
\text { Proliferation } \\
\text { ( } \downarrow \text { G1-phase) }\end{array}$ & {$[45,55]$} \\
\hline & $\begin{array}{l}\text { Primary patient } \\
\text { TNBC cells } \\
\text { (mesenchymal } \\
\text { subtype) }\end{array}$ & $\uparrow \mathrm{TRPC} 1$ & - & Worsened prognosis / - & {$[42]$} \\
\hline & $\begin{array}{l}\text { Primary human } \\
\text { breast ductal } \\
\text { adenocarcinoma }\end{array}$ & $\begin{array}{l}\uparrow \mathrm{TRPC} 1 \\
\uparrow \mathrm{TRPC6}\end{array}$ & - & $\begin{array}{l}\uparrow \text { proliferation \& } \\
\text { invasion / - }\end{array}$ & {$[68]$} \\
\hline $\begin{array}{l}\text { Glioblastoma } \\
\text { Multiforme }\end{array}$ & $\begin{array}{l}\text { D54MG (GMB Cell } \\
\text { line) }\end{array}$ & - & $\begin{array}{l}\text { TRPC1 / 2-APB, } \\
\text { SKF96365, } \\
\text { MRS1845, } \\
\text { polyclonal TRPC1 ab } \\
\text {, and shRNA }\end{array}$ & $\begin{array}{l}\text { Proliferation, migration } \\
/ \downarrow \mathrm{Ca}^{2+} \text { influx in } \\
\text { SOCE, } \downarrow \text { proliferation }\end{array}$ & {$[51,53]$} \\
\hline \multirow{3}{*}{ Lung } & $\begin{array}{l}\text { Primary patient cells } \\
\text { (NSCLC) }\end{array}$ & $\begin{array}{l}\uparrow \mathrm{TRPC} 1 \\
3,4,6\end{array}$ & - & $\begin{array}{l}\text { High expression with } \\
\text { well differentiated } \\
\text { tumor }\end{array}$ & {$[49,73]$} \\
\hline & $\begin{array}{c}\text { A549 (NSCLC cell } \\
\text { line) }\end{array}$ & $\begin{array}{l}\uparrow \mathrm{TRPC} 1 \\
\uparrow \mathrm{TRPC6}\end{array}$ & $\begin{array}{ll}\bullet & \mathrm{SOC} / 2-\mathrm{APB} \\
\text { - } & \mathrm{TRPC} 1, \\
\text { TRPC3-TRPC6 } \\
\text { / T1E3, and } \\
\text { T3667E3 ab }\end{array}$ & $\begin{array}{l}\uparrow \text { Proliferation } / \downarrow \\
\text { Proliferation }\end{array}$ & [49] \\
\hline & $\begin{array}{l}\text { A549 (hypoxia- } \\
\text { mediated EMT by } \\
\text { Nicotine treatment) }\end{array}$ & $\begin{array}{c}\uparrow \text { TRPC1 } \\
\uparrow \mathrm{TRPC6}, \\
\text { and } \uparrow \text { Orail }\end{array}$ & $\begin{array}{l}\downarrow \text { TRPC1 / siRNA } \\
\text { HIF- } 1 \alpha\end{array}$ & $\begin{array}{l}\uparrow \text { SOCE activity / } \downarrow \\
\text { Proliferation, } \downarrow \text { hypoxia- } \\
\text { induced autophagy }\end{array}$ & {$[75]$} \\
\hline \multirow[t]{2}{*}{ Colon } & $\begin{array}{l}\text { HT29 (human colon } \\
\text { carcinoma) }\end{array}$ & $\begin{array}{l}\uparrow \mathrm{TRPC1} \\
\text { (protein) }\end{array}$ & $\begin{array}{ll}\text { - } & \mathrm{SOC} / 2-\mathrm{APB} \\
\text { - } & \mathrm{TRPC} 1 \text { / siRNA }\end{array}$ & $\begin{array}{l}\uparrow \text { SOCE, } \uparrow \text { Proliferation } \\
/ \downarrow \text { Isoc currents, } \downarrow \\
\text { Invasion }\end{array}$ & {$[48]$} \\
\hline & HCT116 & - & TRPC / siRNA & Migration / $\downarrow$ Migration & [44] \\
\hline
\end{tabular}

( - ) INDICATES NO AVAILABLE DATA 


\section{Chapter 3 Transient Receptor Potential C 1/4/5 is a Determinant of MTI-101 Induced Calcium Influx and Cell Death in Multiple Myeloma}

(Published in Cells June 2021)

Osama M. Elzamzamy ${ }^{1}$, Brandon E. Johnson ${ }^{2}$, Wei-Chih Chen ${ }^{3}$, Gangqing Hu ${ }^{4}$, Reinhold Penner ${ }^{5}$, and Lori A. Hazlehurst ${ }^{6, *}$

${ }^{1}$ Clinical and Translational Sciences Institute, School of Medicine, and WVU Cancer Institute, West Virginia University, Morgantown, WV 26506, USA; omelzamzamy@mix.wvu.edu

${ }^{2}$ Center for Biomedical Research, The Queen's Medical Center., Honolulu, HI, 96813, USA; brajohnson@queens.org

3 Department of Pharmaceutical Sciences, School of Pharmacy. West Virginia University, Morganton, WV 26506, USA; weichih.chen@hsc.wvu.edu

4 WVU Cancer Institute, and Department of Microbiology, Immunology and Cell Biology, School of Medicine, West Virginia University, Morgantown, WV 26506 USA; michael.hu@hsc.wvu.edu

5 Department of Cell and Molecular Biology, The Queen's Medical Center and University of Hawaii, Honolulu, HI 96813, USA; rpenner@hawaii.edu

6 Pharmaceutical Sciences, School of Pharmacy and WVU Cancer Institute, West Virginia University, Morganton, WV 26506, USA ; lahazlehurst@hsc.wvu.edu

*Ｃorrespondence: 1ahazlehurst@hsc.wvu.edu; Tel.: +1-304-293-3398 


\subsection{Abstract}

Multiple Myeloma (MM) is a currently incurable hematologic cancer. Patients that initially respond to therapeutic intervention eventually relapse with drug resistant disease. Thus, novel treatment strategies are critically needed to improve patient outcomes. Our group has developed a novel cyclic peptide referred to as MTI-101 for the treatment of MM. We previously reported that acquired resistance to HYD-1, the linear form of MTI-101, correlated with repression of genes involved in store operated $\mathrm{Ca}^{2+}$ entry (SOCE): PLC $\beta$, SERCA, ITPR3, and TRPC1 expression. In this study, we sought to determine the role of TRPC1 heteromers in mediating MTI-101 induced cationic flux. Our data indicate that consistent with activation of TRPC heteromers MTI-101 treatment induced $\mathrm{Ca}^{2+}$ and $\mathrm{Na}+$ influx. However, replacing extracellular $\mathrm{Na}+$ with NMDG did not reduce MTI-101-induced cell death. In contrast, decreasing extracellular $\mathrm{Ca}^{2+}$ reduced both MTI-101-induced $\mathrm{Ca}^{2+}$ influx as well as cell death. The causative role of TRPC heteromers was established by suppressing STIM1, TRPC1, TRPC4 or TRPC5 function both pharmacologically and by siRNA, resulting in a reduction in MTI-101-induced $\mathrm{Ca}^{2+}$ influx. Mechanistically MTI-101 treatment induces trafficking of TRPC1 to the membrane and co-immunoprecipitation studies indicate that MTI-101 treatment induces a TRPC1-STIM1 complex. Moreover, treatment with calpeptin inhibited MTI-101-induced $\mathrm{Ca}^{2+}$ influx and cell death indicating a role of calpain in the mechanism of MTI-101-induced cytotoxicity. Finally, components of the SOCE pathway were found to be poor prognostic in-dicators among MM patients, suggesting that this pathway is attractive for the treatment of MM.

Keywords: Multiple Myeloma, SOCE, Calcium, TRPC

\subsection{Introduction}

Multiple myeloma (MM) is a malignancy arising from neoplastic proliferation of plasma cells in the bone marrow. MM is the second-most common form of blood cancer accounting for $17 \%$ of 
hematological malignancies, with an estimated 34,920 cases in the United States in 2021, and 12,410 deaths [1-3]. Multiple new therapies emerged recently for the treatment of MM, yet unfortunately MM patients continue to progress toward a refractory disease and thus MM remains incurable with current treatment strategies and novel treatment strategies are required to improve patient outcomes.

Cytosolic $\mathrm{Ca}^{2+}$ homeostasis is essential for multiple physiological functions including metabolism, protein phosphorylation, cell proliferation, gene transcription, homing and contractility, and thus the coordinated regulation of $\mathrm{Ca}^{2+}$ channels, pumps, transporters, and exchangers is essential for survival [4,5]. Cytoplasmic intracellular $\mathrm{Ca}^{2+}$ concentration ranges between 10-100 nM, while extracellular $\mathrm{Ca}^{2+}$ concentration is $1.2 \mathrm{mM}[6]$. Multiple $\mathrm{Ca}^{2+}$ channels, pumps, transporters, and exchangers are located on the plasma membrane and on cytoplasmic organelles membranes and function to maintain the $\mathrm{Ca}^{2+}$ gradient across the plasma membrane and equilibrate $\mathrm{Ca}^{2+}$ intracellularly [5]. $\mathrm{Ca}^{2+}$ depletion of intracellular stores triggers the influx of extracellular $\mathrm{Ca}^{2+}$ through $\mathrm{Ca}^{2+}$-permeable channels in the plasma membrane, a mechanism termed Store-Operated $\mathrm{Ca}^{2+}$-entry (SOCE). This pathway is considered the major $\mathrm{Ca}^{2+}$ entry pathway in many nonexcitable cells.

The core of the SOCE pathway is the $\mathrm{Ca}^{2+}$ Release-Activated $\mathrm{Ca}^{2+}$ (CRAC) channels located in the plasma membrane. These CRAC channels can form homo- or heteromeric channels encoded

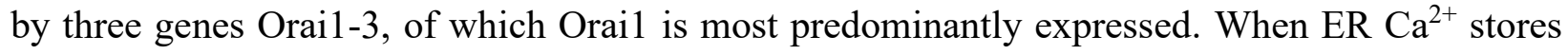
become depleted, ER-bound $\mathrm{Ca}^{2+}$-sensing partners Stromal interaction molecules (STIM1 and STIM2) multimerize and translocate to the ER-PM junction. STIM1 interacts with Orai subunits forming a $\mathrm{Ca}^{2+}$-conducting channel complex that functions to elevate cytoplasmic $\mathrm{Ca}^{2+}$ and replenish $\mathrm{ER} \mathrm{Ca}^{2+}$ stores $[7,8]$. In some cells, $\mathrm{Ca}^{2+}$ entry can be modulated by TRPC channels that also interact with STIM [9]. The SOCE pathway functions to increase cytoplasmic $\mathrm{Ca}^{2+}$ following 
signal transduction of several pathways: i) agonist-targeted G protein-coupled receptors (GPCR); ii) ligand-target receptor tyrosine-kinases (RTK), and iii) engagement of lymphocyte antigen receptors. Physiological activation of these receptors leads to the activation of PLC and subsequent hydrolysis of phosphatidylinositol 4,5-bisphosphate (PIP2), generating inositol 1,4,5trisphosphate $\left(\mathrm{IP}_{3}\right)$, which in turn directly activates the $\mathrm{IP}_{3}$ receptor (IP3R), mediating $\mathrm{Ca}^{2+}$ release from the ER lumen and active store depletion [10]. The sarcoplasmic/endoplasmic reticulum $\mathrm{Ca}^{2+}$ ATPase (SERCA) maintains low cytoplasmic $\mathrm{Ca}^{2+}$ levels by pumping $\mathrm{Ca}^{2+}$ into the SR and ER lumens. Pharmacological inhibition of the SERCA by thapsigargin (Tg) or cyclopiazonic acid (CPA) prevents ER refilling and enables leak pathways to passively deplete stored $\mathrm{Ca}^{2+}$ leading to the activation of the SOCE pathway [11].

STIM1/Orail co-localization generates inwardly rectifying and highly selective $\mathrm{Ca}^{2+}$ currents known as CRAC currents ( $\mathrm{I}_{\mathrm{CRAC}}$ ) [12]. $\mathrm{I}_{\mathrm{CRAC}}$ can be triggered by depleting $\mathrm{ER} \mathrm{Ca}^{2+}$ stores with SERCA pump inhibitors (Tg, and CPA), chelating cytoplasmic $\mathrm{Ca}^{2+}$, or by applying $\mathrm{IP}_{3}$ to the internal side of a cell during a patch-clamp recording [13-15]. On the other hand, STIM1/TRPC co-localization may generate a non-selective, cationic channel that allows entry of $\mathrm{Ca}^{2+}$ and $\mathrm{Na}^{+}$, and has been referred to as the ISOC current $[12,16]$. Activation of GPCR or RTKs can signal laterally in the membrane and augment signals in a context specific manner[17]. For example, integrin signaling has been shown to augment both growth factor receptor signaling and GPCR signaling. However, integrin signaling also changes multiple downstream pathways including MAPK, AKT, FAK and formation of focal adhesion leading to cytoskeletal rearrangements [17]. Thus ligand stimulated activation of $\mathrm{I}_{\mathrm{CRAC}}$ in the context of interactions with the tumor microenvironment is likely more complex when compared to isolation of the ICRAC signaling cascade; via specific pharmacological tools including cell permeable $\mathrm{IP}_{3}$ and blocking of the SERCA pump [18-20]. TRPC1 can form heteromeric channel assembles with TRPC4 and TRPC5 
subunits, contributing to $\mathrm{Ca}^{2+}$ entry and the activation of these channels remains poorly understood [21-23].

We previously reviewed the role of TRPC1 as a function of tumor progression and the hallmarks of cancer [24]. Multiple studies have reported the role of TRPC1 in cancer proliferation, migration, and invasion in pancreatic, lung, breast, colorectal, and multiple myeloma cancers [25-28]. However, the mechanism by which TRPC channels and the SOCE pathway contribute to these pathophysiological outcomes is not fully understood. Furthermore, there is a pharmacological opportunity to consider this pathway as a strategy for novel cancer treatment. [21]. HYD-1 is a D-amino acid linear peptide that was originally discovered to inhibit tumor cell adhesion to immobilized extracellular matrix proteins [29]. We later reported that HYD-1 and the more potent cyclic peptide MTI-101 induced necrotic cell death through depolarization of the mitochondrial membrane potential, reactive oxygen species (ROS) production, and ATP depletion[30,31]. To further understand the mechanism and determinants of resistance we developed a HYD-1-acquired drug resistant $\mathrm{MM}$ cell line. A comparative gene expression profiling between the parental drug sensitive and resistant variant revealed changes in genes encoding for multiple components of $\mathrm{Ca}^{2+}$ entry pathways including TRPC1, TRPM7, ATP2A3, PLCB, and ITPR3 [32]. The cell line was selected for resistance to the linear peptide HYD-1, but the resistant variant was cross-resistant to MTI-101 induced cell death. Finally, we showed that HYD-1 and MTI-101 induced increased $\mathrm{Ca}^{2+}$ influx, and that relapsed multiple myeloma patients' specimens were more sensitive to treatment with MTI-101 when compared to specimens obtained from newly diagnosed patients [32]. The non-specific SOCE inhibitor 2-APB attenuated MTI-101-induced cell death in MM cell lines and in patients' specimens. Translationally, MTI-101 synergized with MM standard of care treatment bortezomib in C57BL/KaLwRijHsd mice, where the combination treatment significantly 
increased survival [32]. In this study, we sought to further characterize the role of STIM1-TRPC heteromers in contributing to MTI-101 induced cell death.

\subsection{Materials and Methods}

\subsubsection{Cells and Reagents}

U266 (ATCC Cat\# TIB-196) and MM.1s (ATCC Cat\# CRL-2974) multiple myeloma (MM) cells, and HS-5 (ATCC Cat\# CRL-11882) bone marrow stroma cells were purchased from American Type Culture Collection (Manassas, VA), they were maintained in RPMI-1640 medium with Lglutamine (Gibco; Life Technologies) with 10\% Fetal Bovine Serum (FBS) and 1\% penicillin/streptomycin. The cell lines were validated by short tandem repeat (STR) and they were also tested for mycoplasma every six months. MTI-101 was synthesized by Bachem (San Diego, CA). Thapsigargin (Tg) (Millipore Sigma) was used to inhibit the SERCA pumps, calpeptin (Selleckchem) was used to inhibit calpain I/II, SKF96365 (Selleckchem), or ML204 (Selleckchem) were used to inhibit TRPC channels, and GSK7975A (Millipore Sigma) was used to inhibit CRAC channels.

\subsection{2. $\mathrm{Ca}^{2+}$ Imaging and Cell Death Assay}

Intracellular $\mathrm{Ca}^{2+}$ levels were measured in U266, MM.1s, and HS-5 cell lines using the Fluo-4AM calcium indicator dye. Briefly, cells were seeded at $7.5 \times 10^{5}$ cells per $\mathrm{ml}$ in their respective media with $2.5 \mu \mathrm{M} \mathrm{Ca}^{2+}$ sensitive dye Fluo-4-AM (Life Technologies) for 45 minutes in $37{ }^{\circ} \mathrm{C}$ in $5 \%$ tissue culture incubator, cells were washed and resuspended in media to allow to deesterification for 30 minutes. Cells were then resuspended in either Live Cell Imaging Solution (molecular probes; Life Technologies), $50 \mathrm{mM} \mathrm{KCl}$ physiological saline solution (PSS) or $5 \mu \mathrm{M}$ $\mathrm{CaCl}_{2}$ PSS, N-methyl-d-glucamine (NMDG)-Ringer, or $\mathrm{Na}^{+}$Ringer solutions. All solutions 
contained $1 \mu \mathrm{g} / \mathrm{ml}$ DAPI (Thermo Scientific) as an indicator of cell death. $50 \mathrm{mM}$ PSS contained (in $\mathrm{mM}$ ): $\mathrm{NaCl} 93, \mathrm{KCl} 50, \mathrm{CaCl}_{2} 2.5, \mathrm{MgCl}_{2} 1.2$, glucose 7.7, HEPES 10, and $\mathrm{PH}$ at 7.2 by $\mathrm{NaOH}$, while $5 \mu \mathrm{M} \mathrm{CaCl}_{2}$ PSS contained (in $\mathrm{mM}$ ): $\mathrm{NaCl} 140, \mathrm{KCl} 3$, and $\mathrm{CaCl}_{2}$ at $5 \mu \mathrm{M}$, NMDGRinger contained (in mM): NMDG 140, $\mathrm{KCl} 3, \mathrm{CaCl} 2$ 2,5, $\mathrm{MgCl}_{2}$ 1.2, glucose 7.7, HEPES 10, and $\mathrm{PH}$ at 7.2 by $\mathrm{NaOH}, \mathrm{Na}^{+}$Ringer contained (in $\mathrm{mM}$ ): $\mathrm{NaCl} 140, \mathrm{KCl} 3, \mathrm{CaCl} 2$ 2,5, $\mathrm{MgCl}_{2}$ 1.2, glucose 7.7, HEPES 10, and $\mathrm{PH}$ at 7.2 by $\mathrm{NaOH}$. Cells were plated in black-side, clear bottom 384-well plates (Nunc), pre-coated with Cell-Tak (Corning) at $3 \mu \mathrm{g} / \mathrm{cm}^{2}$ in $\mathrm{NaHCO}_{3}$ per manufacturer's instructions. $\mathrm{Ca}^{2+}$ fluorescence by Fluo-4-AM was captured using excitation and emission of 488, and 510, respectively. Cell death was measured by DAPI using excitation and emission of 377, 447 respectively. Images were captured using the BIOTEK Cytation 5 imager. $\mathrm{Ca}^{2+}$ imaging was performed every 30 seconds for 60 minutes. Captured images were analyzed using Nikon NIS Elements AR software. Images of individual cells $(n=50)$ were traced over time and analyzed for their Fluo-4-AM and DAPI fluorescence. Data presented in graphs show single cell Fluo-4-AM signal as a representative for 50 cells, while the mean of 50 cells was used to determine the peak area under the curve (AUC), and the maximum peak intensity. To correlate the level of intracellular $\mathrm{Ca}^{2+}$ with induction of death, experiments were done as mentioned above, but with imaging every 5 minutes under the same conditions. Data analysis were done using the BioTek GEN 5.0.3 software, where the threshold of DAPI fluorescence was set to capture only dead cells, and all data in the field of the image were analyzed and normalized to the total cell count in the same field of view.

\subsubsection{DiBAC4(3) Membrane Potential Measurement}

Cells were plated in a 384-well plate pre-treated with Cell-Tak (Corning) at 25,000 cells/well. Cells were then loaded with 250nM DiBAC4(3) (Bis-(1,3-Dibutylbarbituric Acid) Trimethine 
Oxonol) (Thermo Fisher) for 20 minutes in $37^{\circ} \mathrm{C}$ in $5 \%$ tissue culture incubator. DiBAC4(3) was added to cells in Live Cell Imaging Solution and $50 \mathrm{mM} \mathrm{KCl}$ physiological saline solution (PSS) (as mentioned above). The indicator was removed, and cells were loaded with their respective buffer. Membrane potential fluorescence indicated by DiBAC4(3) was captured using excitation and emission of 488, and 510, respectively, using the BIOTEK Cytation 5 imager. Fluorescence was captured every 30 seconds and analyzed as mentioned previously.

\subsubsection{Quantitative Real-Time PCR (qRT-PCR)}

qRT-PCR was performed as previously described [32]. Briefly, $5 \mu \mathrm{g}$ of total RNA was reverse transcribed using SuperScript III First-Strand Synthesis (Thermofisher) following Total RNA extraction by Trizol (Invitrogen). Real-time PCR was performed on the ABI Prism 7500 Fast instrument (Applied Biosystems) using Sybr Green I Mastermix (Thermofisher). Samples were tested in triplicates, three independent times and GAPDH was used as endogenous control product. Primer sequences were as follows: GAPDH forward 5'-GCATCTTCTTTTGCGTCGCC-3' and

reverse 5'- GCGCCCAATACGACCAAATC-3', TRPC1 forward 5'GAGCAGAGGATGACGTGAGG-3' and reverse 5'- CCCAGGAAGAGGACGAGAGA-3', TRPC4 forward 5'-AACAATAGGGAGGCGAGCTG-3' and reverse 5' CGGTCAGGOCCTTCTTCAGTT-3', and TRPC5 forward 5'-GCCACACCTTGIAGGACCTC3' and reverse 5'- CTGCCCACGTACACTAAGCA-3'.

\subsubsection{Small Interfering RNA Transfection}

The transfection of U266 and MM.1s cell lines were done using the Lonza 4D-Nucleofector system (Lonza, Switzerland). Briefly, 2x10 6 cells were resuspended in the Lonza SF-kit (Lonza, V4XC) with $10 \mu 1$ of $20 \mu \mathrm{M}$ stock of the respective small interfering RNA (siRNA). siRNA concentration was determined as previously reported [31]. Cells along with siTRPC4 (Dharmacon, ON- 
TARGETplus SMARTpool), siTRPC5 (Santa Cruz Biotechnology, sc-42670), siTRPC1 (Santa Cruz Biotechnology, sc-42664) and siControl (Dharmacon ON-TARGETplus Non-targeting Pool) were added along with buffer to the cuvette and electroporated at the recommended settings by LONZA. Cells were incubated in the buffer for 10 minutes at $37^{\circ} \mathrm{C}$, cells were then transferred to a T25 flask in $5 \mathrm{ml}$ of media and incubated for 96 hours.

\subsubsection{Fura-2AM Based $\mathrm{Ca}^{2+}$ Imaging}

Cells were loaded with 4.0 $\mu \mathrm{M}$ Fura-2-AM, then plated in a 96-well plate at a density of 60000 cells/well and fluorescence measurements were made on a Hamamatsu FDSS7000EX kinetic plate reader. Fura-2 was excited at 340 and $380 \mathrm{~nm}$, and the ratio of the respective emission fluorescence at $510 \mathrm{~nm}$ was determined. Sampling interval was $3 \mathrm{~s}$. The change in fluorescence ratios from baseline were reported. Bath solutions contained (in mm): $\mathrm{NaCl} 140, \mathrm{KCl} 5.4, \mathrm{CaCl}_{2} 2, \mathrm{MgCl}_{2} 0.8$, glucose 10, and HEPES $20(\mathrm{pH} 7.2$ with $\mathrm{NaOH})$. Stock solutions of thapsigargin (Tg) were prepared in DMSO at a concentration of $1 \mathrm{mM}$.

\subsubsection{Membrane Proteins Biotinylation}

The isolation of membrane proteins in U266 cells was done using the Pierce ${ }^{\mathrm{TM}}$ Cell Surface Biotinylation and Isolation Kit (Thermo Fisher, A44390). In brief, $1 \times 10^{6}$ cells $/ \mathrm{ml}$ were treated with MTI-101 $(20 \mu \mathrm{M})$ for 10 minutes in Live Cell Imaging Solution followed by resuspension in the Biotin containing solution. Cells were then lysed with the kit's lysis buffer. A BCA assay was done to ensure equal loading of protein (1 $\mathrm{mg})$ to the NeutrAvidin Agarose beads. The elute from the beads and control whole cell lysates we subjected to Western blot analysis. 


\subsubsection{Co-immunoprecipitation}

Co-immunoprecipitation protocol was adapted from Hofmann et al [33]. Briefly, 10x10 cells were treated with $20 \mu \mathrm{M}$ of MTI-101 for 10 minutes in Live Cell Imaging Solution (Molecular Probes by Life Technologies), centrifuged at $4{ }^{\circ} \mathrm{C}$ and lysed with $1 \%$ Triton X-100 (Thermo Scientific; 85111 ) in PBS, with protease and phosphatase inhibitors cocktail (Millipore Sigma). BCA assay was used to quantify protein concentration. $1 \mathrm{mg}$ of protein for each treatment and control groups were incubated with the primary antibody (TRPC1; Santa Cruz Biotechnology, and host species $\mathrm{IgG}$ ) overnight rotating in $4^{\circ} \mathrm{C}$. Later, protein $\mathrm{A} / \mathrm{G}$ plus agarose (Santa Cruz Biotechnology; sc2003) was added to the sample and allowed to incubate rotating in $4{ }^{\circ} \mathrm{C}$ for one hour. Samples were washed $3 \mathrm{x}$ in lysis buffer and samples were subjected to Western blot analysis.

\subsubsection{TRPC1 Cleavage Analysis}

U266, MM.1s, or HS-5 cells were seeded at a density of $7 \times 10^{5}$ cell $/ \mathrm{ml}$ in $10 \mathrm{ml}$ Live Cell Imaging solution at $37{ }^{\circ} \mathrm{C}$ in $5 \%$ tissue culture incubator. $15 \mu \mathrm{M}$ MTI-101, $2 \mu \mathrm{M}$ thapsigargin, and $80 \mu \mathrm{M}$ calpeptin were used to treat appropriate samples and cells were collected at 5, 30, 60, and 90 minutes post treatment. Following drug treatment cells were lysed using 1X RIPA buffer (Thermo Fisher) with protease and phosphatase inhibitors cocktail (Protease Inhibitor Cocktail Set III, Millipore Sigma; 539135, and Phosphatase Inhibitor Cocktail Set II, Millipore Sigma; 524625) for 30 minutes on ice. Lysates were spun down and supernatant was taken off, the pellet was then resuspended in 1X RIPA buffer plus $2 \%$ SDS and lysed for 30 minutes on ice. Pellets was then sonicated using a probe homogenizer. Protein concentration from both compartments were measured using Pierce BCA Protein analysis kit, and $30 \mu \mathrm{g}$ were analyzed using Western blot.

Cleavage of TRPC1 using recombinant calpain-1 was adopted from Kaczmarek et al. In short, U266 and HS-5 cells were collected at $7 \times 10^{5}$ cells $/ \mathrm{ml}$, resuspended and sonicated in Live Cell 
Imaging Solution (Molecular Probes; Life Technologies). Lysates were incubated in the presence of $2.5 \mathrm{mM} \mathrm{CaCl}_{2}, 50 \mathrm{ug} / \mathrm{ml}$ recombinant calpain-1 (LSBio) and in the presence or absence of 80 $\mu \mathrm{M}$ calpeptin. Extracts were incubated at room temperature for 1 hour to allow for enzymatic cleavage. After the incubation, cell lysates were subjected to Western blot analysis for the detection of full length and cleaved TRPC1.

\subsubsection{Survival Analysis with Multiple Myeloma Patients}

Overall survival analysis was done using expression data (in transcripts per million) and overall survival records (in days) from newly diagnosed MM patients enrolled in the CoMMpass trial (release IA14), downloaded from the Multiple Myeloma Research Foundation researcher gateway (https://research.themmrf.org/). Additional overall survival analysis was conducted using microarray expression data and overall survival records (in days) for patients with relapsed myeloma obtained the APEX/SUMMIT trail (GEO accession \#: GSE9782) [34]. The survival curves were generated with the survival R package, and $\mathrm{P}$ value was calculated by log-rank test.

\subsubsection{Statistical Analysis}

Cell death percentage is reported as a representative of experiment performed in quadruplicate, one-way ANOVA was used to determine significance $(\mathrm{p}<0.05)$, and Tukey's multiple comparisons test was used to determine significance between groups. $\mathrm{Ca}^{2+}$ and $\mathrm{Na}^{+}$influx measurements were done by measuring the fluorescence intensity of 50 cells and subtracting the baseline fluorescence intensity. We reported the mean of 50 cells with error bars representing the standard error of the mean (SEM), and a single cell that fell in the median. Response magnitudes were quantified by measuring the Maximum Peak and integrating the area under the curve (Peak AUC), respectively, for the first 30 minutes. Peak AUC was measured using GraphPad Prism (GraphPad Prism, RRID:SCR_002798) by following the trapezoid rule using the equation $\Delta \mathrm{X}^{*}([(\mathrm{Y} 1+\mathrm{Y} 2) / 2]-$ 
Baseline] to calculate the area. Significance was determined by one-way ANOVA $(p<0.05)$, and Tukey's multiple comparisons test was used to determine in-between groups significance. All experiments were done three independent times, and shown is a representative experiment. mRNA expression analysis was done by Quantitative real-time PCR 3 independent times from 3 different days in triplicates. We reported the mean of the three experiments by calculating delta CT (Cycle Threshold) and subtracting the CT of the mRNA of interest from GAPDH. For siRNA knockdown experiments, we reported the fold change in expression by measuring the ratio of siRNA of interest to the siControl. We reported the mean of three independent experiments as well.

\subsection{Results}

\subsubsection{MTI-101 Induces Sustained $\mathrm{Ca}^{2+}$ Flux Leading to Cell Death}

We previously reported MTI-101 induced cell death in U266 and H929 MM cells through increased calcium flux leading to necrotic cell death [32]. To determine the involvement of SOCE pathway in MTI-101 induced cell death, we treated MM cells U266, MM.1s and the fibroblast stroma cell line HS-5 with MTI-101 and thapsigargin, and measured $\mathrm{Ca}^{2+}$ influx and cell death. MTI-101 treatment induced a delayed, and irreversible $\mathrm{Ca}^{2+}$ influx with peak accumulation occurring between 10 and 30 minutes. Thapsigargin induced a rapid, and robust $\mathrm{Ca}^{2+}$ influx in both U266 (Fig. 1 A, C, G, H, and M) and MM.1s cell lines (Fig. 1 B, D, I, and J) that peaked within the first five minutes of application. In the presented data in Fig. $1 \mathrm{C}$ and D, we selected a cell representing the median $\mathrm{Ca}^{2+}$ peak of the 50 analyzed cells. Because time to peak varies in-between cells, this reshapes the curves when averaging the population (Fig. 1 A and B). MTI-101-induced cell death closely paralleled the time corresponding to the peak $\mathrm{Ca}^{2+}$ level (Fig. $1 \mathrm{E}$ and F). HS-5 cells were treated with the same dose of MTI-101 $(20 \mu \mathrm{M})$ and thapsigargin $(1 \mu \mathrm{M})$ for the same treatment period (Supplementary Fig. S1 A-C). Interestingly, MTI-101 did not induce $\mathrm{Ca}^{2+}$ influx 
in HS-5 cells throughout the treatment period, while thapsigargin induced a rapid and robust $\mathrm{Ca}^{2+}$ influx, similar to MM cell lines. The lack of induction of $\mathrm{Ca}^{2+}$ influx correlated with the finding that MTI-101 did not induce cell death in HS-5 cells (Supplementary Fig. 1 D). Collectively, these data suggest that MTI-101 induced cell death in MM cells is correlated with a sustained, delayed, and irreversible $\mathrm{Ca}^{2+}$ influx, unlike thapsigargin which induces a rapid and reversible $\mathrm{Ca}^{2+}$ influx, that is not sufficient to induce immediate cell death.

\subsubsection{Extracellular $\mathrm{Na}^{+} / \mathrm{K}^{+} / \mathrm{Ca}^{2+}$ contribution to MTI-101 activity}

We next sought to determine the role of specific ions in mediating MTI-101-induced $\mathrm{Ca}^{2+}$ cytotoxicity. The Orail channel demonstrates high specificity for $\mathrm{Ca}^{2+}[35,36]$, whereas TRPC channel complexes are less specific for $\mathrm{Ca}^{2+}$ and additionally permeate both $\mathrm{Na}^{+}$and $\mathrm{K}^{+}$as well [21]. To learn more about the role of $\mathrm{Na}^{+}$in MTI-101-mediated cytotoxicity, we first asked the question whether MTI-101 treatment induced $\mathrm{Na}^{+}$influx. We addressed this question using the $\mathrm{Na}^{+}$sensitive fluorescent dye ION NaTRIUM Green-2 AM, to measure the level of $\mathrm{Na}^{+}$influx following MTI-101 treatment in both $\mathrm{Na}^{+}$-Ringer and NMDG-Ringer solutions (devoid of $\mathrm{Na}^{+}$but contains the non-permeable monovalent cation N-methyl-d-glucamine or NMDG). MTI-101 treatment induced a peak in $\mathrm{Na}^{+}$accumulation within ten minutes, similar to the pattern of MTI101-induced $\mathrm{Ca}^{2+}$ entry. The $\mathrm{Na}^{+}$-sensitive fluorescence signal was significantly diminished but not completely abolished in cells bathed in $\mathrm{Na}^{+}$-free NMDG solution, suggesting a low degree of background fluorescence (Fig. 2 A). As shown in Fig. 2 B, replacing $\mathrm{Na}^{+}$with NMDG was not sufficient to attenuate MTI-101-induced cell death. MTI-101 did however, increase U266 cell permeability to $\mathrm{Na}^{+}$. Together, these data indicate that MTI-101 treatment induced activation of a $\mathrm{Na}^{+}$-permeable cationic channel, even though sodium influx per se does not play an apparent role in MTI-101-induced cell death. 
To address the role of $\mathrm{Ca}^{2+}$ entry in MTI-101 induced cytotoxicity, we reduced extracellular $\mathrm{CaCl}_{2}$ from $2.5 \mathrm{mM}$ to $5 \mu \mathrm{M} \mathrm{CaCl}_{2}$ and measured MTI-101 mediated $\mathrm{Ca}^{2+}$ accumulation and cell death. Decreasing external $\mathrm{Ca}^{2+}$ significantly reduced MTI-101 mediated $\mathrm{Ca}^{2+}$ influx (Fig. 2 C). Furthermore, decreasing extracellular $\mathrm{Ca}^{2+}$ significantly attenuated MTI-101 induced cell death by 34\% in U266 cells (Fig. 2 D). Unlike $\mathrm{Na}^{+}$, extracellular $\mathrm{Ca}^{2+}$ contributes to MTI-101 mediated cell death.

Calcium signaling in immune cells is modulated by $\mathrm{K}^{+}$conductance that regulate the driving force for $\mathrm{Ca}^{2+}$ entry [37,38]. Plasma membrane potential is largely set by the $\mathrm{K}^{+}$equilibrium across the membrane, and this in turn establishes the inward driving force for $\mathrm{Ca}^{2+}$. We sought to determine whether lowering the driving force for $\mathrm{Ca}^{2+}$ entry by depolarizing cells would modulate the potency of MTI-101. STIM1/Orail are continuously active in patch clamp experiments following store depletion by $\mathrm{IP}_{3}$ or ionomycin [15]. Further, when extracellular $\mathrm{Ca}^{2+}$ is depleted, and intact cells are treated with thapsigargin or cyclopiazonic acid, a large $\mathrm{Ca}^{2+}$ influx occurs when $\mathrm{Ca}^{2+}$ is re-added to the extracellular solution. This $\mathrm{Ca}^{2+}$ influx is attributed to the SOCE pathway and $\mathrm{Ca}^{2+}$ entry is driven by the negative membrane potential. However, in Jurkat T cells, when extracellular $\mathrm{K}^{+}$levels are increased to $140 \mathrm{mM}$, the membrane potential collapses to $0 \mathrm{mV}$ and $\mathrm{Ca}^{2+}$ entry is diminished due to the reduction in driving force. To test the effect of high extracellular $\mathrm{K}^{+}$ concentration on MTI-101-induced $\mathrm{Ca}^{2+}$ entry, we compared MTI-101-mediated $\mathrm{Ca}^{2+}$ entry among cells bathed in either physiological saline solution $(3 \mathrm{mM} \mathrm{KCl})$ or high $\mathrm{K}^{+}(50 \mathrm{mM} \mathrm{KCl})$ saline solution. Elevated external $\mathrm{K}^{+}$reduced $\mathrm{Ca}^{2+}$ accumulation by 55.6\% (Fig. 2 E). Furthermore, high extracellular $\mathrm{K}^{+}$concentration completely abolished MTI-101-induced cell death (Fig. 2 F). Moreover, we measured the membrane potential for the respective treatment groups in Fig. $2 \mathrm{G}$ using the membrane-potential sensitive dye DIBAC 4 (3) in U266 cells (Fig. 2 G). As expected, 50 $\mathrm{mM} \mathrm{KCl} \mathrm{PSS} \mathrm{resulted} \mathrm{in} \mathrm{membrane} \mathrm{depolarization.} \mathrm{MTI-101} \mathrm{treatment} \mathrm{also} \mathrm{increased} \mathrm{dye}$ 
fluorescence indicative of strong depolarization, likely caused by membrane depolarization due to $\mathrm{Na}^{+}$influx through non-selective cation channels. Combining high $\mathrm{K}^{+}$depolarization with MTI101 failed to further depolarize the membrane potential of cells already depolarized by $50 \mathrm{mM}$ $\mathrm{KCl}$. Collectively, these data indicate that $\mathrm{Ca}^{2+}$ influx is the predominant driver for MTI-101mediated cell death, and reducing $\mathrm{Ca}^{2+}$ influx either by reducing extracellular $\mathrm{Ca}^{2+}$, or reducing the driving force for $\mathrm{Ca}^{2+}$ diminishes MTI-101-mediated cell death.

\subsubsection{Pharmacological inhibition of TRPC channels block MTI-101 induced $\mathrm{Ca}^{2+} / \mathrm{Na}^{+}$ influx and cell death in MM cell lines and inhibition of CRAC channels inhibits MTI-101 induced $\mathrm{Ca}^{2+}$ influx and cell death}

Even though $\mathrm{Na}^{+}$influx was not responsible for cell death, experimental data indicated that MTI101 treatment resulted in influx of both $\mathrm{Na}^{+}$and $\mathrm{Ca}^{2+}$, prompting us to determine the role of TRPC channels in mediating the influx of these ions. We initially sought to use pharmacological tools to delineate the role of TRPC channels in mediating MTI-101 induced cell death. SKF96365 is a somewhat non-specific inhibitor of receptor-mediated $\mathrm{Ca}^{2+}$ entry pathways (RMCE) and SOCE $[39,40]$. We pre-treated U266 cells with SKF96365 $(25 \mu \mathrm{M})$ for 1 hour and measured $\mathrm{Ca}^{2+}$ influx in the presence of MTI-101 and Tg, respectively (Fig. 3 A and B). Cells pre-treated with SKF96365 showed a significant reduction in $\mathrm{Ca}^{2+}$ entry when stimulated with either MTI-101 (Fig. 3 A) or Tg (Fig. 3 B). SKF96365 reduced peak $\mathrm{Ca}^{2+}$ accumulation evoked by MTI-101 by $80 \%$, and decreased the peak Tg-induced $\mathrm{Ca}^{2+}$ response by $51 \%$ (Fig. 3 C). Because SFK96365 treatment blocked the Tg-induced $\mathrm{Ca}^{2+}$ response these data suggest that SKF9635 likely also blocks CRAC channels and therefore precludes a clear discrimination between CRAC and TRPC-mediated $\mathrm{Ca}^{2+}$ influx in MM cells. 
To further test the idea that the MTI-101-mediated ion influx might be carried at least in part by TRPC channels that can conduct both $\mathrm{Na}^{+}$and $\mathrm{Ca}^{2+}$, we asked whether SKF96365 could inhibit MTI-101- mediated $\mathrm{Na}^{+}$influx. SKF96365-pretreatment significantly reduced $\mathrm{Na}^{+}$accumulation in U266 cells by $29 \%$ measured by average maximum $\mathrm{Na}^{+}$peak of 50 cells (Fig. $3 \mathrm{D}$ ) and decreased MTI-101-induced cell death in both U266 and MM.1 cells by 58\% and 38\%, respectively (Fig. 3 E and F). These data suggest that MTI-101 activates a non-specific cation channel that contributes to MM cell death and can be modulated by pre-treatment with SKF96365.To address the role of CRAC channels on MTI-101-induced cell death and $\mathrm{Ca}^{2+}$ influx, we pre-treated U266 cells with CRAC specific inhibitor GSK7975A (Fig. 3 G). GSK7975A (10 $\mu$ M) attenuated MTI-101-induced cell death by $32 \%$. GSK7975A attenuated thapsigargin-induced $\mathrm{Ca}^{2+}$ influx, indicating the specificity of the drug towards CRAC activity, and significantly reduced MTI-101 induced $\mathrm{Ca}^{2+}$ influx (Fig. 3 H). , Taken together, the CRAC channels inhibitor GSK7975A attenuates MTI-101 induced $\mathrm{Ca}^{2+}$ influx and cell death.

\subsubsection{TRPC4/5 channel contributes to MTI-101 induced $\mathrm{Ca}^{2+} / \mathrm{Na}^{+}$influx and cell death}

We previously created a MM cell line resistant to HYD-1 (linear MTI-101) H929-60, and reported a down regulation of multiple genes contributing to $\mathrm{Ca}^{2+}$ entry pathways including TRPC1, ATP2A3, PLC- $\beta$, ITPR3 and TRPM7 [32]. Further, we reduced the expression of TRPC1 via shRNA and noted a reduction in MTI-101 induced cell death. Moreover, the broad-spectrum $\mathrm{IP}_{3}$ and TRPC channel inhibitor 2-APB significantly inhibited MTI-101 induced cell death in relapsed MM patients' specimens, U266 and H929 cell lines [32]. The TRPC family is comprised of seven members, and functional TRPC1-containing channels are formed by heterodimeric and heterotetrameric arrangements of subunits (e.g. TRPC1/4, TRPC1/5, TRPC1/4/5) [22,24,41]. To learn more about the possible components of TRPC channels expressed in MM cells, we measured 
the expression levels of TRPC1, TRPC4 and TRPC5 in MM cell lines by quantitative real-time PCR in U266 and MM.1s cell lines. Interestingly, TRPC1 and TRPC5 were both abundantly expressed in U266, MM.1s and HS-5 while TRPC4 was only expressed in U266 and HS-5 (Fig. 4 A). To determine the role of TRPC4 in MTI-101 induced cell death, we pretreated U266 and MM.1s cells with ML204 (20 $\mu \mathrm{M})$, a selective inhibitor of TRPC4 and TRPC5 channels, with no reported selectivity towards other TRP family members [42]. Pre-treated U266 cells showed a 49\% significant attenuation to MTI-101-induced cell death, with only 22\% attenuation in MM.1s cells (Fig. $4 \mathrm{~B}$ and C). These data suggest that pharmacological inhibition of TRPC4 and TRPC5 moderately reduced MTI-101 cytotoxicity. The efficacy of ML204 may have been confounded by the heterogeneity of TRPC channel complexes.

To further address the role of TRPC4, small interfering-RNA (siRNA) was used to reduce the expression of TRPC4 (Fig. 4 D). Reducing the expression of TRPC4 significantly inhibited MTI101 induced cell death by 50\%, supporting the role of TRPC4 in MTI-101-mediated cell death (Fig. 4 E). Interestingly, $\mathrm{Ca}^{2+}$ influx was significantly reduced by 57\% in MTI-101 treated TRPC4 knockdown cells, but was not attenuated in the Tg-treated cells (Fig. 4 F), indicating that both SOCE and RMCE pathways may contribute to $\mathrm{Ca}^{2+}$ influx independently.

To test whether TRPC5 expression is a determinant in MTI-101 induced $\mathrm{Ca}^{2+}$ influx and cell death, we used siRNA to knockdown TRPC5 expression in U266 and MM.1s cell lines (Fig. 5 A). Reducing TRPC5 expression attenuated MTI-101 induced cell death by $60 \%$ and 36\% in U266 and MM.1s respectively (Fig. 5 B and C). Furthermore, cells with reduced expression of TRPC5 showed a significant reduction in MTI-101 induced $\mathrm{Ca}^{2+}$ influx by $37 \%$ and $33 \%$ in both cell lines, respectively, similar to what was observed by reducing TRPC4 expression (Fig. 5 D and E). Finally, TRPC5 knockdown had no discernable effect on peak Tg-induced $\mathrm{Ca}^{2+}$ influx levels (Fig. $5 \mathrm{D}$ and $\mathrm{E})$. Taken together, these data indicate that TRPC4 and TRPC5 significantly contribute to 
the MTI-101 induced $\mathrm{Ca}^{2+}$ influx and cell death, and delineates a role of TRPC channels in MTI101-mediated $\mathrm{Ca}^{2+}$ influx in parallel to the canonical SOCE pathway.

\subsubsection{MTI-101 activity is dependent on STIM1/TRPC1 trafficking and heteromeric assembly in the plasma membrane}

TRPC1 appears to contribute to the sustained $\mathrm{Ca}^{2+}$ influx following MTI-101-induced signaling in parallel with the canonical SOCE pathway, as has been previously reported [43]. To determine whether STIM1 was necessary for MTI-101-mediated $\mathrm{Ca}^{2+}$ entry, we examined the effect of knocking down STIM1 expression by siRNA on $\mathrm{Ca}^{2+}$ signaling (Fig. 6 A and B). Reducing STIM1 expression decreased the Tg-evoked rise in store operated $\mathrm{Ca}^{2+}$ entry by $40 \%$, and reduced MTI101-mediated $\mathrm{Ca}^{2+}$ entry by $64 \%$. ISOC currents mediated by STIM1/TRPC1 complex occurs following the trafficking of TRPC1 to the plasma membrane following the initial activation of STIM1/Orail [44]. To confirm that MTI-101 induces trafficking of TRPC1 to the plasma membrane, we treated U266 and MM.1s cells with MTI-101 (20 $\mu \mathrm{M}$ and $25 \mu \mathrm{M}$, respectively) for 10 minutes followed by a membrane biotinylation of surface proteins (Fig. $6 \mathrm{C}$ and D). Cells treated with MTI-101 showed an increased level of TRPC1 in comparison to control. We utilized p27 as a cytoplasmic/nuclear control of protein to ensure increased levels of TRPC1 were not due to MTI-101 induced increases of the permeability of the chemical probe and increases of the detection of cytoplasmic protein. To confirm that TRPC1 trafficking is facilitated by binding to STIM1, we demonstrate the binding of TRPC1 to STIM1 at the 10 minutes time points in U266 and MM1.s cells in Fig. $6 \mathrm{E}$ and F. These findings support the hypothesis that MTI-101 activity is dependent on STIM1 expression, TRPC1 trafficking and incorporation into the plasma membrane and a STIM1/TRPC1 complex formation. 


\subsubsection{MTI-101 induces TRPC1 Truncation by Calpain Activation}

Kaczmarek and colleagues reported that the $\mathrm{Ca}^{2+}$ activated proteases calpain I/II cleaves and further activate TRPC5 in neuronal cells in the presence of semaphorin 3A [45]. Further, they reported that the calpain inhibitor calpeptin blocks the cleavage and attenuates downstream $\mathrm{Ca}^{2+}$ currents. In addition, the $\mathrm{Ca}^{2+}$ influx through TRPC1 activity is reported to activate calpains [46]. The additional impact provided by MTI-101 activity is the absence of a turn off switch to the $\mathrm{Ca}^{2+}$ currents, resulting in sustained $\mathrm{Ca}^{2+}$ entry and leading to cell death. To determine the potential role of calpain I/II in MTI-101 effects, we treated cells with MTI-101 $(15 \mu \mathrm{M})$ and Tg $(1 \mu \mathrm{M})$ and analyzed the RIPA insoluble cellular compartment via Western blot analysis (Fig. 7 A). Interestingly, we noticed a cleaved TRPC1 fraction at $60 \mathrm{kD}$ molecular weight only with MTI-101 treatment. Further, we noticed decreased levels of TRPC1 cleaved fractions when we pre-treated cells with calpeptin $(80 \mu \mathrm{M})$ in U266 and MM.1s cells (Fig. 7 B and C, and Supplementary Fig. S2 A and B). Moreover, calpeptin pre-treatment significantly reduced $\mathrm{Ca}^{2+}$ influx and MTI-101induced cell death (Fig. 7 D and E). To assess whether TRPC1 cleavage is calpain I - dependent, we treated sonicated U266 and HS-5 stroma lysates with recombinant calpain I (Fig. 7 F, and Supplementary Fig. 2 C). Recombinant calpain I cleaved TRPC1 at approximately the same molecular weight as the downstream effect of MTI-101 treatment. Furthermore, pre-treatment with the calpain inhibitor calpeptin blocked the cleavage of TRPC1 (Supplementary Fig. 2 D). We found that TRPC1 in HS-5 stroma cells are prone to cleavage by active calpain I, while MTI-101 did not show any associated TRPC1 cleaved fraction (Supplementary Fig. S2 E). Previously we reported that decreasing TRPC1 protected from MTI-101 induced cell death[32]. To test the effect of TRPC1 on MTI-101-induced $\mathrm{Ca}^{2+}$ influx, we used siRNA to knockdown TRPC1 expression in U266 and MM.1s cell lines (Fig 7. F and Supplementary Fig. S2 F).Reducing TRPC1 expression attenuated MTI-101 induced cell death by $48 \%$ and $20 \%$ in U266 and MM.1s respectively, 
furthermore, calpain pre-treatment in cells with reduced TRPC1 expression attenuated MTI-101 effect by $72 \%$ and $76 \%$ in both cell line respectively (Fig. 7 G and Supplementary Fig. S2 G). Reducing TRPC1 showed a significant reduction in MTI-101 induced $\mathrm{Ca}^{2+}$ influx in both cell lines, and calpain pre-treatment contributed to increased reduction in $\mathrm{Ca}^{2+}$ levels (Fig. $7 \mathrm{H}$ and Supplementary Fig. S2 H). In aggregate, these data suggest that calpain I activation following MTI-101 treatment contributes to the sustained $\mathrm{Ca}^{2+}$ influx, and potentially is a feed forward loop for activation of TRPC containing channels following treatment with MTI-101 in MM cells.

\subsubsection{Members of the SOCE pathway correlates with poor patient outcomes}

Aside from the SOCE role in replenishing ER/SR $\mathrm{Ca}^{2+}$ stores, the extracellular $\mathrm{Ca}^{2+}$ influx through TRPC regulates multiple $\mathrm{Ca}^{2+}$-dependent gene expressions patterns (ex. NFAT pathway) [47]. Increased TRPC1 expression has been reported to contribute to pancreatic cancer cell motility, breast cancer, non-small cell lung cancer, colon cancer, and glioblastoma multiforme proliferation and migration [48-52]. Further, we previously discussed the role of $\mathrm{Ca}^{2+}$ homeostasis in cancer progression. Interestingly, this class of compounds is more active in CD138 cells isolated from MM patients that have relapsed compared to newly diagnosed patients [30,32]. These data suggest that determinants of MTI-101 sensitivity including the SOCE pathway maybe upregulated in aggressive MM disease. Thus, we sought to determine whether expression of the components of the SOCE pathway correlate with aggressive disease. To address this question, we used two publically available gene expression datasets with paired patient survival data. The COMPASS data set is multi-site trial initiated by MMRF [53]. Expression profiling was based on newly diagnosed specimens using RNA-SEQ as the platform (Fig. 8 A). The APEX/SUMMIT data was a multi-site international trial for patients enrolled in Phase II and Phase III clinical trials of Bortezomib [34].Thus these patients were relapsing on current therapy prior to proteasome related 
regimens. The expression profiling platform was GeneArray 3000 Affymetrix for this study. As shown in Fig. $8 \mathrm{~A}$ and $\mathrm{B}$, multiple components of the SOCE pathway were poor or unfavorable prognostic markers in both studies. Interestingly, TRPC components were not as strong predictors compared to STIM1. However, these data do not rule out that a readout of activity such as plasma membrane localization of TRPC1 may be required for prediction of disease outcome. Future studies will address the role of membrane localized TRPC1 as a prognostic indicator for MM progression. In Fig. $8 \mathrm{C}$ we show a working model for the mechanism of action of MTI-101 based on the current data presented in this manuscript and previously reported data [30-32].

\subsection{Discussion and Conclusions}

$\mathrm{Ca}^{2+}$ entry through SOCE regulates multiple genetic pathways, where $\mathrm{Ca}^{2+}$ signals through CRAC currents activate the NFAT and NFkB pathways; $\mathrm{Ca}^{2+}$ currents through TRPC1 and the ISOC complex predominantly activate the NFkB pathway [47,54,55]. Although TRPC1 expression contributes to various tumor outcomes, its over expression is predominantly and most consistently correlated with poor cancer outcomes in lung, pancreatic, breast, glioblastoma multiforme, and colon cancers $[24,48-52]$. In this study we show that RNA expression of components of the SOCE pathway correlates with poor survival in newly diagnosed MM patients when examining the expression levels in 1150 patients using the CoMMpass dataset and 669 relapsed patients in the APEX/SUMMIT trial. Based on these data it is intriguing to speculate that increased capacity to respond to the RMCE/SOCE pathway is required for aggressive disease and potentially contributes to the emergence of drug refractory disease. Interestingly, at the RNA level STIM1/ORAI was a stronger prognostic indicator compared to components of TRPC. However, considering our data indicating that TRPC1 needs to be trafficked to the cell membrane, it is feasible that protein localization rather than absolute expression levels might be a determinant of aggressive disease. 
This signature may lead to strategies to pharmacologically block this pathway or conversely, represents an Achilles heel of aggressive disease having increased susceptibility to cell death via $\mathrm{Ca}^{2+}$ overload. With that in mind, targeting $\mathrm{Ca}^{2+}$ homeostasis, and more specifically the SOCE pathway presents a novel pathway for the treatment of MM.

Our findings indicate that the MTI-101 mechanism of action is different from the standard blocker of the SERCA pump thapsigargin. While thapsigargin inhibits SERCA function causing rapid depletion of the ER $\mathrm{Ca}^{2+}$ stores, MTI-101 treatment induces a more delayed and sustained $\mathrm{Ca}^{2+}$ entry. This difference could be attributed to the $\mathrm{I}_{\text {CRAC }}$ currents through STIM1 coupling with Orai1 activity, while MTI-101 is mostly dependents on ISOC currents through STIM1/TRPC1/4/5 activity, but not completely independent of STIM1/Orail activity. Baudel and colleagues previously reviewed the role of SOCE in vascular smooth muscles (VSMCs) contractility, where cells isolated from mice with Orai1-/- were capable of activating the SOCE pathway via STIM1 and TRPC1 only [56,57]. Furthermore, Romani et al reported that in arterial myocytes Orai1 expression levels were inherently low in the contractile phenotype, yet maintained SOCE activity, while the proliferative phenotype showed increased expression of Orai1, STIM1, and TRPC1 [58]. In contrast, it has been reported that in salivary glands, Isoc currents mediated through STIM1 and, TRPC1 interaction is dependent on prior activation of STIM1/Orai1, and the knockdown of Orai1 abolishes TRPC1 activation [59].

Owing to this diversity in TRPC1 mode of activation, it is conceivable that MTI-101 activity could be dependent on coupling STIM1 and TRPCs in MM cells. Consistent with this notion, we observed that MTI-101-induced cell death is partially dependent on the expression of TRPC $1 / 4 / 5$, suggesting that they participate in the complex formation with STIM1. We further report that in an inactive state, and in absence of MTI-101, we failed to detect TRPC1 at the plasma membrane, and the activation of the SOCE pathway by MTI-101 allowed TRPC1 trafficking and insertion 
into the plasma membrane. TRPC1 recycling to and from the plasma membrane following SOCE activation has been reported previously by De Souza and colleagues [60]. They reported that the TRPC1 fast recycling is dependent on trafficking to the plasma membrane by Rab4 and the internalization into Rab5-containing endosomes is an ARF6-dependent pathway. Future studies will determine the mechanism underpinning MTI-101-induced trafficking of TRPC1 to the plasma membrane. We propose that MTI-101 is a unique tool for delineation of TRPC1 membrane trafficking.

The $\mathrm{Ca}^{2+}$-activated protease calpain 1 is associated with poor survival in $\mathrm{MM}$ patients in the COMPASS dataset. Kaczmarek et al reported that the pharmacological inhibition of calpain I/II inhibited TRPC5 [45]; further, Verheijden and colleagues reported that TRPC6 contributes to calpain I activation, and pharmacologically inhibiting calpain I or genetically knocking it down abrogated TRPC6 effects on podocyte injury in the kidneys [61]. Other reports indicated that $\mathrm{Ca}^{2+}$ entry through active TRPC1 activates calpain I in neurons and regulates axon outgrowth [46]. Our findings indicated that MTI-101 treatment induces cleavage of TRPC1 and that TRPC1 is a substrate for recombinant calpain I. In addition, pharmacological inhibition of calpains blocked MTI-101-induced calcium influx and cell death. Based on these data it is attractive to reason that the calpain-dependent feed-forward loop is due to cleavage of TRPC1 either via induction of a higher conductance or open probability of the channel. Further studies are required to determine the functional consequence of TRPC1 cleavage on MTI-101-induced calcium and sodium entry. Cleavage of TRPC1 was targeted in cells sensitive to MTI-101, while cleavage was not observed in the stroma cell line HS-5. However, $\mathrm{Ca}^{2+}$-activated recombinant calpain I was able to cleave TRPC1 from HS-5 derived lysates. These finding correlate with failure of MTI-101 to evoke a calcium response in HS-5 stroma cells. Again, more studies are required to fully understand the mechanism underpinning the MTI-101-induced trafficking of TRPC1 to the plasma membrane, 
and its continuous activation leading to the sustained $\mathrm{Ca}^{2+}$ influx and cell death. In summary, MTI101 is a novel drug that leverages one of the cancer cells' main survival machinery, the augmented $\mathrm{Ca}^{2+}$ circuitry. Future studies will define the dependency of TRPC1 for survival in the bonemarrow microenvironment and whether this signaling pathway is required for growth, cell adhesion-mediated drug resistance (CAM-DR) or soluble mediate drug resistance (SM-DR). Our data support a unique mechanism of $\mathrm{Ca}^{2+}$-induced necrotic cell death, and the targeting of storeoperated $\mathrm{Ca}^{2+}$ entry pathways for the treatment of multiple myeloma.

Supplementary Materials: The following are available online at www.mdpi.com/xxx/s1, Figure S1: Stroma cells are not sensitive to MTI-101-induced $\mathrm{Ca}^{2+}$ flux and cell death, Figure S2: MTI101 induces TRPC1 Truncation by Calpain Activation

Author Contributions: All authors have read and agreed to the published version of the manuscript. Conceptualization, O.M.E., B.E.J., W.C., R.P., and L.A.H.; Methodology, O.M.E., B.E.J., W.C., G.H., R.P., L.A.H.; Software, O.M.E., G.H.; Validation, O.M.E., and L.A.H.; Formal Analysis, O.M.E., B.E.J., G.H., and L.A.H.; Investigation, O.M.E., B.E.J., R.P., and L.A.H.; Resources, L.A.H.; Data Curation, O.M.E.; Writing - Original Draft, O.M.E.; Writing - Review \& Editing, O.M.E., B.E.J., W.C., G.H., R.P., and L.A.H.; Visualization, O.M.E., G.H., and L.A.H.; Supervision, L.A.H.; Funding Acquisition, L.A.H.

Funding: Research reported in this publication was supported by the National Institute of General Medical Sciences of the National Institutes of Health under Award Number 5U54GM104942-05, R44-CA221554 Hazlehurst PI NCI, NCI 1R01CA195727-01_LAH, WV-INBRE grant: P20GM103434, and P30 GM121322. The content is solely the responsibility of the authors and does not necessarily represent the official views of the National Institutes of Health. 
Acknowledgments: We would like to acknowledge Amanda G. Ammer, Ph.D. at the WVU Imaging Facilities for help with the data analysis of single cell imaging experiments.

Conflicts of Interest: Dr. Hazlehurst is a co-founder of Modulation Therapeutics Inc. which has a license to MTI-101 for treatment of cancer.

\subsection{References}

1. Siegel, R.L.; Miller, K.D.; Fuchs, H.E.; Jemal, A. Cancer Statistics, 2021. CA Cancer J Clin 2021, 71, 7-33, doi:10.3322/caac.21654.

2. Kyle, R.A.; Therneau, T.M.; Rajkumar, S.V.; Larson, D.R.; Plevak, M.F.; Melton, L.J., 3rd. Incidence of multiple myeloma in Olmsted County, Minnesota: Trend over 6 decades. Cancer 2004, 101, 2667-2674, doi:10.1002/cncr.20652.

3. Phekoo, K.J.; Schey, S.A.; Richards, M.A.; Bevan, D.H.; Bell, S.; Gillett, D.; Moller, H.; Consultant Haematologists, S.T.H.S.C. A population study to define the incidence and survival of multiple myeloma in a National Health Service Region in UK. Br J Haematol 2004, 127, 299-304, doi:10.1111/j.1365-2141.2004.05207.x.

4. Giorgi, C.; Danese, A.; Missiroli, S.; Patergnani, S.; Pinton, P. Calcium Dynamics as a Machine for Decoding Signals. Trends Cell Biol 2018, 28, 258-273, doi:10.1016/j.tcb.2018.01.002.

5. Bootman, M.D.; Bultynck, G. Fundamentals of Cellular Calcium Signaling: A Primer. Cold Spring Harb Perspect Biol 2020, 12, doi:10.1101/cshperspect.a038802.

6. Raffaello, A.; Mammucari, C.; Gherardi, G.; Rizzuto, R. Calcium at the Center of Cell Signaling: Interplay between Endoplasmic Reticulum, Mitochondria, and Lysosomes. Trends Biochem Sci 2016, 41, 1035-1049, doi:10.1016/j.tibs.2016.09.001. 
7. Clapham, D.E. Calcium signaling. Cell 2007, 131, 1047-1058, doi:10.1016/j.cell.2007.11.028.

8. Zhang, S.L.; Yu, Y.; Roos, J.; Kozak, J.A.; Deerinck, T.J.; Ellisman, M.H.; Stauderman, K.A.; Cahalan, M.D. STIM1 is a $\mathrm{Ca}^{2+}$ sensor that activates CRAC channels and migrates from the $\mathrm{Ca}^{2+}$ store to the plasma membrane. Nature 2005, 437, 902-905, doi:10.1038/nature04147.

9. Prevarskaya, N.; Skryma, R.; Shuba, Y. Ion channels and the hallmarks of cancer. Trends Mol Med 2010, 16, 107-121, doi:10.1016/j.molmed.2010.01.005.

10. Roos, J.; DiGregorio, P.J.; Yeromin, A.V.; Ohlsen, K.; Lioudyno, M.; Zhang, S.; Safrina, O.; Kozak, J.A.; Wagner, S.L.; Cahalan, M.D., et al. STIM1, an essential and conserved component of store-operated $\mathrm{Ca}^{2+}$ channel function. J Cell Biol 2005, 169, 435-445, doi:10.1083/jcb.200502019.

11. Vandecaetsbeek, I.; Vangheluwe, P.; Raeymaekers, L.; Wuytack, F.; Vanoevelen, J. The $\mathrm{Ca}^{2+}$ pumps of the endoplasmic reticulum and Golgi apparatus. Cold Spring Harb Perspect Biol 2011, 3, doi:10.1101/cshperspect.a004184.

12. Hogan, P.G.; Rao, A. Store-operated calcium entry: Mechanisms and modulation. Biochem Biophys Res Commun 2015, 460, 40-49, doi:10.1016/j.bbrc.2015.02.110.

13. Hoth, M.; Penner, R. Depletion of intracellular calcium stores activates a calcium current in mast cells. Nature 1992, 355, 353-356, doi:10.1038/355353a0.

14. Zweifach, A.; Lewis, R.S. Mitogen-regulated $\mathrm{Ca}^{2+}$ current of $\mathrm{T}$ lymphocytes is activated by depletion of intracellular $\mathrm{Ca}^{2+}$ stores. Proc Natl Acad Sci U S A 1993, 90, 6295-6299, doi:10.1073/pnas.90.13.6295. 
15. Hofer, A.M.; Fasolato, C.; Pozzan, T. Capacitative $\mathrm{Ca}^{2+}$ entry is closely linked to the filling state of internal $\mathrm{Ca}^{2+}$ stores: a study using simultaneous measurements of ICRAC and intraluminal $\left[\mathrm{Ca}^{2+}\right]$. J Cell Biol 1998, 140, 325-334, doi:10.1083/jcb.140.2.325.

16. Lopez, J.J.; Jardin, I.; Albarran, L.; Sanchez-Collado, J.; Cantonero, C.; Salido, G.M.; Smani, T.; Rosado, J.A. Molecular Basis and Regulation of Store-Operated Calcium Entry. Adv Exp Med Biol 2020, 1131, 445-469, doi:10.1007/978-3-030-12457-1_17.

17. Schwartz, M.A.; Ginsberg, M.H. Networks and crosstalk: integrin signalling spreads. Nat Cell Biol 2002, 4, E65-68, doi:10.1038/ncb0402-e65.

18. Leyme, A.; Marivin, A.; Perez-Gutierrez, L.; Nguyen, L.T.; Garcia-Marcos, M. Integrins activate trimeric G proteins via the nonreceptor protein GIV/Girdin. J Cell Biol 2015, 210, 1165 1184, doi:10.1083/jcb.201506041.

19. Shen, B.; Delaney, M.K.; Du, X. Inside-out, outside-in, and inside-outside-in: G protein signaling in integrin-mediated cell adhesion, spreading, and retraction. Curr Opin Cell Biol 2012, 24, 600-606, doi:10.1016/j.ceb.2012.08.011.

20. Miyamoto, S.; Teramoto, H.; Gutkind, J.S.; Yamada, K.M. Integrins can collaborate with growth factors for phosphorylation of receptor tyrosine kinases and MAP kinase activation: roles of integrin aggregation and occupancy of receptors. J Cell Biol 1996, 135, 1633-1642, doi:10.1083/jcb.135.6.1633.

21. Bon, R.S.; Beech, D.J. In pursuit of small molecule chemistry for calcium-permeable nonselective TRPC channels -- mirage or pot of gold? Br J Pharmacol 2013, 170, 459-474, doi:10.1111/bph.12274. 
22. Broker-Lai, J.; Kollewe, A.; Schindeldecker, B.; Pohle, J.; Nguyen Chi, V.; Mathar, I.; Guzman, R.; Schwarz, Y.; Lai, A.; Weissgerber, P., et al. Heteromeric channels formed by TRPC1, TRPC4 and TRPC5 define hippocampal synaptic transmission and working memory. EMBO $J$ 2017, 36, 2770-2789, doi:10.15252/embj.201696369.

23. Obukhov, A.G.; Nowycky, M.C. TRPC5 channels undergo changes in gating properties during the activation-deactivation cycle. $J$ Cell Physiol 2008, 216, 162-171, doi:10.1002/jcp. 21388 .

24. Elzamzamy, O.M.; Penner, R.; Hazlehurst, L.A. The Role of TRPC1 in Modulating Cancer Progression. Cells 2020, 9, doi:10.3390/cells9020388.

25. Chen, Y.F.; Lin, P.C.; Yeh, Y.M.; Chen, L.H.; Shen, M.R. Store-Operated $\mathrm{Ca}\left({ }^{2+}\right)$ Entry in Tumor Progression: From Molecular Mechanisms to Clinical Implications. Cancers (Basel) 2019, 11, doi:10.3390/cancers1 1070899 .

26. Fiorio Pla, A.; Kondratska, K.; Prevarskaya, N. STIM and ORAI proteins: crucial roles in hallmarks of cancer. Am J Physiol Cell Physiol 2016, 310, C509-519, doi:10.1152/ajpcell.00364.2015.

27. Chen, Y.F.; Hsu, K.F.; Shen, M.R. The store-operated $\mathrm{Ca}\left({ }^{2+}\right)$ entry-mediated signaling is important for cancer spread. Biochim Biophys Acta 2016, 1863, 1427-1435, doi:10.1016/j.bbamcr.2015.11.030.

28. Chen, Y.F.; Chen, Y.T.; Chiu, W.T.; Shen, M.R. Remodeling of calcium signaling in tumor progression. J Biomed Sci 2013, 20, 23, doi:10.1186/1423-0127-20-23. 
29. DeRoock, I.B.; Pennington, M.E.; Sroka, T.C.; Lam, K.S.; Bowden, G.T.; Bair, E.L.; Cress, A.E. Synthetic peptides inhibit adhesion of human tumor cells to extracellular matrix proteins. Cancer Res 2001, 61, 3308-3313.

30. Gebhard, A.W.; Jain, P.; Nair, R.R.; Emmons, M.F.; Argilagos, R.F.; Koomen, J.M.; McLaughlin, M.L.; Hazlehurst, L.A. MTI-101 (cyclized HYD1) binds a CD44 containing complex and induces necrotic cell death in multiple myeloma. Mol Cancer Ther 2013, 12, 2446-2458, doi:10.1158/1535-7163.MCT-13-0310.

31. Nair, R.R.; Emmons, M.F.; Cress, A.E.; Argilagos, R.F.; Lam, K.; Kerr, W.T.; Wang, H.G.; Dalton, W.S.; Hazlehurst, L.A. HYD1-induced increase in reactive oxygen species leads to autophagy and necrotic cell death in multiple myeloma cells. Mol Cancer Ther 2009, 8, 24412451, doi:10.1158/1535-7163.MCT-09-0113.

32. Emmons, M.F.; Anreddy, N.; Cuevas, J.; Steinberger, K.; Yang, S.; McLaughlin, M.; Silva, A.; Hazlehurst, L.A. MTI-101 treatment inducing activation of Stim1 and TRPC1 expression is a determinant of response in multiple myeloma. Sci Rep 2017, 7, 2685, doi:10.1038/s41598-01702713-0.

33. Hofmann, T.; Schaefer, M.; Schultz, G.; Gudermann, T. Subunit composition of mammalian transient receptor potential channels in living cells. Proc Natl Acad Sci U S A 2002, 99, 7461-7466, doi:10.1073/pnas.102596199.

34. Mulligan, G.; Mitsiades, C.; Bryant, B.; Zhan, F.; Chng, W.J.; Roels, S.; Koenig, E.; Fergus, A.; Huang, Y.; Richardson, P., et al. Gene expression profiling and correlation with outcome in clinical trials of the proteasome inhibitor bortezomib. Blood 2007, 109, 3177-3188, doi:10.1182/blood-2006-09-044974. 
35. Yuan, J.P.; Zeng, W.; Dorwart, M.R.; Choi, Y.J.; Worley, P.F.; Muallem, S. SOAR and the polybasic STIM1 domains gate and regulate Orai channels. Nat Cell Biol 2009, 11, 337-343, doi:10.1038/ncb1842.

36. Stathopulos, P.B.; Schindl, R.; Fahrner, M.; Zheng, L.; Gasmi-Seabrook, G.M.; Muik, M.; Romanin, C.; Ikura, M. STIM1/Orail coiled-coil interplay in the regulation of store-operated calcium entry. Nat Commun 2013, 4, 2963, doi:10.1038/ncomms3963.

37. Launay, P.; Cheng, H.; Srivatsan, S.; Penner, R.; Fleig, A.; Kinet, J.P. TRPM4 regulates calcium oscillations after $\mathrm{T}$ cell activation. Science 2004, 306, 1374-1377, doi:10.1126/science.1098845.

38. Ren, Y.R.; Pan, F.; Parvez, S.; Fleig, A.; Chong, C.R.; Xu, J.; Dang, Y.; Zhang, J.; Jiang, H.; Penner, R., et al. Clofazimine inhibits human Kv1.3 potassium channel by perturbing calcium oscillation in T lymphocytes. PLoS One 2008, 3, e4009, doi:10.1371/journal.pone.0004009.

39. Merritt, J.E.; Armstrong, W.P.; Benham, C.D.; Hallam, T.J.; Jacob, R.; Jaxa-Chamiec, A.; Leigh, B.K.; McCarthy, S.A.; Moores, K.E.; Rink, T.J. SK\&F 96365, a novel inhibitor of receptormediated calcium entry. Biochem J 1990, 271, 515-522, doi:10.1042/bj2710515.

40. Singh, A.; Hildebrand, M.E.; Garcia, E.; Snutch, T.P. The transient receptor potential channel antagonist SKF96365 is a potent blocker of low-voltage-activated T-type calcium channels. Br J Pharmacol 2010, 160, 1464-1475, doi:10.1111/j.1476-5381.2010.00786.x.

41. Zhang, Z.; Reboreda, A.; Alonso, A.; Barker, P.A.; Seguela, P. TRPC channels underlie cholinergic plateau potentials and persistent activity in entorhinal cortex. Hippocampus 2011, 21, 386-397, doi:10.1002/hipo.20755. 
42. Miller, M.; Shi, J.; Zhu, Y.; Kustov, M.; Tian, J.B.; Stevens, A.; Wu, M.; Xu, J.; Long, S.; Yang, P., et al. Identification of ML204, a novel potent antagonist that selectively modulates native TRPC4/C5 ion channels. J Biol Chem 2011, 286, 33436-33446, doi:10.1074/jbc.M111.274167.

43. Cheng, K.T.; Ong, H.L.; Liu, X.; Ambudkar, I.S. Contribution and regulation of TRPC channels in store-operated $\mathrm{Ca}^{2+}$ entry. Curr Top Membr 2013, 71, 149-179, doi:10.1016/B978-012-407870-3.00007-X.

44. Cheng, K.T.; Liu, X.; Ong, H.L.; Swaim, W.; Ambudkar, I.S. Local Ca(2)+ entry via Orail regulates plasma membrane recruitment of TRPC1 and controls cytosolic $\mathrm{Ca}(2)+$ signals required for specific cell functions. PLoS Biol 2011, 9, e1001025, doi:10.1371/journal.pbio.1001025.

45. Kaczmarek, J.S.; Riccio, A.; Clapham, D.E. Calpain cleaves and activates the TRPC5 channel to participate in semaphorin 3A-induced neuronal growth cone collapse. Proc Natl Acad Sci U S A 2012, 109, 7888-7892, doi:10.1073/pnas.1205869109.

46. Kerstein, P.C.; Jacques-Fricke, B.T.; Rengifo, J.; Mogen, B.J.; Williams, J.C.; Gottlieb, P.A.; Sachs, F.; Gomez, T.M. Mechanosensitive TRPC1 channels promote calpain proteolysis of talin to regulate spinal axon outgrowth. $J$ Neurosci 2013, 33, 273-285, doi:10.1523/JNEUROSCI.2142-12.2013.

47. Putney, J.W. Calcium signaling: deciphering the calcium-NFAT pathway. Curr Biol 2012, 22, R87-89, doi:10.1016/j.cub.2011.12.030.

48. Dong, H.; Shim, K.N.; Li, J.M.; Estrema, C.; Ornelas, T.A.; Nguyen, F.; Liu, S.; Ramamoorthy, S.L.; Ho, S.; Carethers, J.M., et al. Molecular mechanisms underlying $\mathrm{Ca}^{2+}-$ mediated motility of human pancreatic duct cells. Am J Physiol Cell Physiol 2010, 299, C14931503, doi:10.1152/ajpcell.00242.2010. 
49. Bomben, V.C.; Turner, K.L.; Barclay, T.T.; Sontheimer, H. Transient receptor potential canonical channels are essential for chemotactic migration of human malignant gliomas. $J$ Cell Physiol 2011, 226, 1879-1888, doi:10.1002/jcp.22518.

50. Davis, F.M.; Peters, A.A.; Grice, D.M.; Cabot, P.J.; Parat, M.O.; Roberts-Thomson, S.J.; Monteith, G.R. Non-stimulated, agonist-stimulated and store-operated $\mathrm{Ca}^{2+}$ influx in MDA-MB468 breast cancer cells and the effect of EGF-induced EMT on calcium entry. PLoS One 2012, 7, e36923, doi:10.1371/journal.pone.0036923.

51. Jiang, H.N.; Zeng, B.; Zhang, Y.; Daskoulidou, N.; Fan, H.; Qu, J.M.; Xu, S.Z. Involvement of TRPC channels in lung cancer cell differentiation and the correlation analysis in human non-small cell lung cancer. PLoS One 2013, 8, e67637, doi:10.1371/journal.pone.0067637.

52. Faouzi, M.; Hague, F.; Geerts, D.; Ay, A.S.; Potier-Cartereau, M.; Ahidouch, A.; OuadidAhidouch, H. Functional cooperation between KCa3.1 and TRPC1 channels in human breast cancer: Role in cell proliferation and patient prognosis. Oncotarget 2016, 7, 36419-36435, doi:10.18632/oncotarget.9261.

53. Settino, M.; Arbitrio, M.; Scionti, F.; Caracciolo, D.; Di Martino, M.T.; Tagliaferri, P.; Tassone, P.; Cannataro, M. MMRF-CoMMpass Data Integration and Analysis for Identifying Prognostic Markers. In Computational Science - ICCS 2020, 2020; 10.1007/978-3-030-504205_42pp. 564-571.

54. Berridge, M.J.; Lipp, P.; Bootman, M.D. The versatility and universality of calcium signalling. Nat Rev Mol Cell Biol 2000, 1, 11-21, doi:10.1038/35036035. 
55. Yu, Z.M.; Li, X.Y.; Li, J.P.; Dang, S.P.; Wang, B.; Wu, Y.; Chen, Y.X.; Wang, R.X.; Qian,

L.L.; Zheng, J., et al. Increased transient receptor potential canonical type 1 improves diabetic nephropathy via inhibiting NF-kappa B pathway. Biomed Res-India 2016, 27, 1348-1353.

56. Shi, J.; Miralles, F.; Kinet, J.P.; Birnbaumer, L.; Large, W.A.; Albert, A.P. Evidence that Orail does not contribute to store-operated TRPC1 channels in vascular smooth muscle cells. Channels (Austin) 2017, 11, 329-339, doi:10.1080/19336950.2017.1303025.

57. Baudel, M.; Shi, J.; Large, W.A.; Albert, A.P. Insights into Activation Mechanisms of Store-Operated TRPC1 Channels in Vascular Smooth Muscle. Cells 2020, 9, doi:10.3390/cells9010179.

58. Berra-Romani, R.; Mazzocco-Spezzia, A.; Pulina, M.V.; Golovina, V.A. Ca ${ }^{2+}$ handling is altered when arterial myocytes progress from a contractile to a proliferative phenotype in culture. Am J Physiol Cell Physiol 2008, 295, C779-790, doi:10.1152/ajpcell.00173.2008.

59. Ambudkar, I.S.; de Souza, L.B.; Ong, H.L. TRPC1, Orai1, and STIM1 in SOCE: Friends in tight spaces. Cell Calcium 2017, 63, 33-39, doi:10.1016/j.ceca.2016.12.009.

60. de Souza, L.B.; Ong, H.L.; Liu, X.; Ambudkar, I.S. Fast endocytic recycling determines TRPC1-STIM1 clustering in ER-PM junctions and plasma membrane function of the channel. Biochim Biophys Acta 2015, 1853, 2709-2721, doi:10.1016/j.bbamcr.2015.07.019.

61. Verheijden, K.A.T.; Sonneveld, R.; Bakker-van Bebber, M.; Wetzels, J.F.M.; van der Vlag, J.; Nijenhuis, T. The Calcium-Dependent Protease Calpain-1 Links TRPC6 Activity to Podocyte Injury. J Am Soc Nephrol 2018, 29, 2099-2109, doi:10.1681/ASN.2016111248. 


\subsection{Figure Legends}

Figure 1: MTI-101 treatment Induces Sustained $\mathrm{Ca}^{2+}$ Flux and cell death in two independent MM cell lines: A and B) The effect of MTI-101 was compared to thapsigargin (Tg) by measuring $\mathrm{Ca}^{2+}$ influx using Fluo-4-AM fluorescence intensity in U266 (A) and MM.1s (B) cell lines. The line graph shows the mean and standard error of the mean (SEM) of 50 cells fluorescence after subtracting the baseline over one hour. Cells were treated with MTI-101 (20 $\mu \mathrm{M}$ for U266, and 30 $\mu \mathrm{M}$ for MM.1s), $\operatorname{Tg}(1 \mu \mathrm{M})$, and vehicle control and imaged every 30 seconds. Shown is a representative experiment ( $\mathrm{n}=50$ individual cells). $\mathrm{C}$ and $\mathrm{D}$ ) Shown is a single cell tracing for $\mathrm{Ca}^{2+}$ influx following treatment from figures A and B. The individual cells were chosen based on the median peak for $\mathrm{Ca}^{2+}$ influx for the re-spective treatment group. E and F) Overlay of Fluo-4-AM and DAPI fluorescence in a single cell following MTI-101 treatment over one hour. G and H) Mean maximum peak of $\mathrm{Ca}^{2+}$ influx in 50 cells in U266 and MM.1s cell lines. I and J) The total levels of $\mathrm{Ca}^{2+}$ influx mediated by MTI-101, Tg, and vehicle control was measured by calculating the peak area under the curve (Peak AUC) of the 50 cells. K and L) The effect of MTI-101 (20 $\mu \mathrm{M})$ and $\operatorname{Tg}(1 \mu \mathrm{M})$ on cell death was measured in U266 and MM.1s cell lines by imaging the respective treatment group every 5 minutes for one hour. Cell death was determined by a threshold of DAPI fluorescence indicative of a dead cell. M) Fluo-4-AM and DAPI pre-loaded U266 cells were used as indicators for $\mathrm{Ca}^{2+}$ uptake and cell death, respectively. Cells were imaged every 30 seconds at 10X using the BIOTEK Cytation 5 imager. All experiments were repeated three independent times, and shown is a repre-sentative experiment. Error bars represent SEM $(p<0.05$ One-way ANOVA, inter-group comparison was done by Tukey's multiple comparisons test).

Figure 2: Extracellular $\mathrm{Na}^{+} / \mathrm{Ca}^{2+} / \mathrm{K}^{+}$contribution to MTI-101 activity: A) Shown is a single cell tracing for $\mathrm{Na}^{+}$influx following treatment with MTI-101 $(20 \mu \mathrm{M})$ in $\mathrm{U} 266$ cells . $\mathrm{Na}^{+}$influx 
was measured using the $\mathrm{Na}^{+}$indicator ION NaTRIUM Green-2 AM, and was imaged every 30 seconds. The individual cells were chosen based on the median peak for $\mathrm{Na}^{+}$influx for the respective treatment group. Mean maximum peak of $\mathrm{Na}^{+}$influx in 50 cells in U266. B) The effect of MTI-101 $(20 \mu \mathrm{M})$ on U266 cell death was measured by imaging the respective treatment groups in NaCl-ringer or NMDG-ringer solutions every five minutes for one hour. C and E) Single cell tracing $\mathrm{Ca}^{2+}$ levels for $\mathrm{U} 266$ cells in $5 \mu \mathrm{M} \mathrm{CaCl}_{2}, 50 \mathrm{mM} \mathrm{KCl}$ and physiological saline solutions with MTI-101 $(20 \mu \mathrm{M})$. Cells were imaged every 30 second. Mean maximum peak of $\mathrm{Ca}^{2+}$ fluorescence in 50 cells. D and F) The effect of MTI-101 $(20 \mu \mathrm{M})$ on U266 cell death in $5 \mu \mathrm{M}$ $\mathrm{CaCl}_{2}, 50 \mathrm{mM} \mathrm{KCl}$ and physiological saline solutions. Cells were imaged every five minutes. G) Fluorescence of DIBAC 4 (3) pre-loaded U266 cells treated with MTI-101 $(20 \mu \mathrm{M})$ in either $50 \mathrm{mM}$ $\mathrm{KCl}$, or physiological saline solutions $(3 \mathrm{mM} \mathrm{KCl})$. Presented fluorescence data were measured by subtracting the mean control fluorescence of cells in $3 \mathrm{mM} \mathrm{KCL} \mathrm{PSS} \mathrm{buffer} \mathrm{from} \mathrm{all} \mathrm{other}$ treatment groups. Cells were imaged every 30 seconds for 1 hour. Error bars represent SEM ( $<<0.05$ One-way ANOVA, inter-group comparison was done by Tukey's multiple comparisons test). All experiments were repeated three independent times, and shown is a representative experiment.

Figure 3: Pharmacological inhibition TRPC channels blocks MTI-101 induced $\mathrm{Ca}^{2+} / \mathrm{Na}^{+}$ influx and cell death in MM cell lines and inhibition of CRAC channels inhibits MTI-101 induced $\mathrm{Ca}^{2+}$ influx and cell death: $\mathrm{A}$ and B) The effect of blocking non-specific cation channels was tested using the inhibitor SKF96365 $(25 \mu \mathrm{M})$ in combination with MTI-101 $(20 \mu \mathrm{M})$ and Tg $(1 \mu \mathrm{M})$ on $\mathrm{U} 266$ cell line. $\mathrm{Ca}^{2+}$ influx fluorescence signal was measured every 30 seconds in a single cell. The individual cells were chosen based on the median peak for $\mathrm{Ca}^{2+}$ influx for the respective treatment group. C) Mean maximum peak of $\mathrm{Ca}^{2+}$ influx in 50 cells in U266 cell line. D) Single cell tracing of $\mathrm{Na}^{+}$influx in cells pre-treated with SKF96365 $(25 \mu \mathrm{M})$ followed by MTI- 
$101(20 \mu \mathrm{M})$ treatment. Cells were imaged every 30 seconds. The individual cells were chosen based on the median peak for $\mathrm{Na}^{+}$influx for the respective treatment group. $\mathbf{E}$ and $\mathbf{F}$ ) The effect of SKF96365 $(25 \mu \mathrm{M})$ and MTI-101 $(20 \mu \mathrm{M})$ on cell death was measured in U266 and MM.1s cell lines. Cell death was measured every five minutes. G) The effect of blocking CRAC channels was determined using the inhibitor GSK7975A $(10 \mu \mathrm{M})$ in combination with MTI-101 $(20 \mu \mathrm{M})$ on U266 cell death. Cell death was measured every five minutes. H) Single cell tracing $\mathrm{Ca}^{2+}$ levels for GSK7975A (10 $\mu \mathrm{M})$ pre-treated U266 cells followed by MTI-101 $(20 \mu \mathrm{M})$ or Tg $(1 \mu \mathrm{M})$. Cells were imaged every 30 second. Mean maximum peak of $\mathrm{Ca}^{2+}$ fluorescence in 50 cells. Error bars represent SEM ( $<<0.05$ One-way ANOVA, inter-group comparison was done by Tukey's multiple comparisons test).

\section{Figure 4: TRPC4 channel contributes to MTI-101 induced $\mathrm{Ca}^{2+} / \mathrm{Na}^{+}$influx and cell death:}

A) TRPC1, TRPC4, and TRPC5 mRNA relative expression levels in U266, MM.1s, and HS-5 cell lines. Abundance of expression is shown for the respective mRNA compared to GAPDH in each cell line. Experiments were done in triplicates three independent times. Shown is the mean of the three experiments. B and C) The effect of ML204 (20 $\mu \mathrm{M})$ pre-treatment on U266 and MM.1s cell death with MTI-101 (20 $\mu \mathrm{M}$ and $30 \mu \mathrm{M}$ respectively). Error bars represent SEM, experiments were done three independent times, shown is a representative single experiment $(\mathrm{p}<0.05$ One-way ANOVA). D) TRPC4 mRNA fold change expression in U266 with siTRPC4 relative to U266 with siControl is shown. SEM of three independent experiments is shown $(\mathrm{p}<0.05$ student $\mathrm{t}-\mathrm{Test}) . \mathbf{E})$ Effect of knocking down TRPC4 in U266 cell death by MTI-101 (20 $\mu \mathrm{M})$. Experiments were done three independent times, and shown is a single representative experiment $(\mathrm{p}<0.05$ One-way ANOVA). F) Single-cell tracing for $\mathrm{Ca}^{2+}$ influx in Fluo-4-AM preloaded U266 cells with siTRPC4 and siControl. Cells were treated with MTI-101 $(20 \mu \mathrm{M})$ and Tg $(1 \mu \mathrm{M})$. Cells were imaged every 30 seconds for one hour. 
Figure 5: TRPC5 channel contributes to MTI-101 induced $\mathrm{Ca}^{2+} / \mathrm{Na}^{+}$influx and cell death:

A) TRPC5 mRNA fold change expression in U266 and MM.1s with siTRPC5 relative to siControl cell lines. SEM of three independent experiments is shown $(\mathrm{p}<0.05$ student $\mathrm{t}$-Test $)$. B and C) Effect of knocking down TRPC5 in U266 and MM.1s on cell death mediated by MTI-101 (20 $\mu$ M and $30 \mu \mathrm{M}$ respectively). Experiments were done three independent times, and shown is a single representative experiment ( $p<0.05$ One-way ANOVA). D and E) Single cell tracing for $\mathrm{Ca}^{2+}$ influx in Fluo-4-AM loaded U266 and MM1.s cells with siTRPC5 and siControl. Cells were treated with MTI-101 $(20 \mu \mathrm{M})$ and Tg $(1 \mu \mathrm{M})$. Cells imaged every 30 seconds for one hour. Mean maximum peak of $\mathrm{Ca}^{2+}$ influx in 50 cells in U266 and MM.1s cell lines. Error bars represent SEM ( $p<0.05$ One-way ANOVA, inter-group comparison was done by Tukey's multiple comparisons test $\mathrm{p}<0.0001)$.

Figure 6: MTI-101 activity is dependent on STIM1/TRPC1 trafficking and heteromeric formation in the plasma membrane: $\mathbf{A}$ and $\mathbf{B}) \mathrm{Ca}^{2+}$ accumulation in populations of approximately 60,000 U266 cells loaded with Fura-2AM with STIM1 siRNA or siControl. Cells were treated with either MTI-101 $(40 \mu \mathrm{M})$ or $\operatorname{Tg}(2 \mu \mathrm{M})$. Cells were imaged every $3 \mathrm{~s}$ for 30 minutes. Error bars show SEM. C and D) Detection of TRPC1 in the biotinylated membrane proteins in U266 and MM.1s cell lines following treatment with MTI-101 (20 $\mu \mathrm{M}$ and $30 \mu \mathrm{M}$, respectively) for 10 minutes. P27 used as cytoplasmic control and Integrin $\beta 1$ is a plasma membrane control. E and F) Co-localization detection of SOCE pathway proteins was done by co-immunoprecipitation of STIM1 following MTI-101 treatment for 10 minutes in U266 and MM.1s cells (20 $\mu \mathrm{M}$ and $25 \mu \mathrm{M}$, respectively). Experiments were done three independent times. 
Figure 7: MTI-101 induces TRPC1 Truncation by Calpain Activation: A) U266 cells treated with MTI-101 $(15 \mu \mathrm{M})$ and $\mathrm{Tg}(1 \mu \mathrm{M})$ for 5 and 30 minutes. TRPC1 cleaved fraction was detected at $\approx 60 \mathrm{kDa}$ only with MTI-101 treatment in RIPA insoluble cell fraction. B and C) U266 cells pretreated with calpeptin $(80 \mu \mathrm{M})$ for one hour, followed by treatment with MTI-101 $(15 \mu \mathrm{M})$ for 0, 5, 30, 60, 90 minutes. TRPC1 cleaved fractions was detected in the calpeptin-free group. Quantification of the cleaved fraction TRPC1 normalized to $\beta$-actin. D) Single cell $\mathrm{Ca}^{2+}$ tracing for Fluo-4-AM pre-loaded U266 cells pretreated with calpeptin $(80 \mu \mathrm{M})$ for one hour. Cells were imaged every 30 seconds for one hour. Mean maximum peak of $\mathrm{Ca}^{2+}$ influx in 50 cells in U266 cells. Error bars represent SEM ( $<<0.05$ One-way ANOVA, inter-group comparison was done by Tukey's multiple comparisons test $\mathrm{p}<0.05)$. E) The effect of calpeptin $(80 \mu \mathrm{M})$ pretreatment on MTI-101 induced cell death in U266 cells. Experiments were done in quadruplicates and repeated three independent times. Error bars represent SEM $(\mathrm{p}<0.05$ One-way ANOVA, inter-group comparison was done by Tukey's multiple comparisons test $\mathrm{p}<0.05)$. F) $\mathrm{CaCl}_{2}$ activated calpain I induced TRPC1 cleaved fraction at $\approx 60 \mathrm{kDa}$ in U266 cells. G) Western blot analysis for TRPC1 expression levels in U266 cells. H) Effect of knocking down TRPC1 in U266 cells on cell death mediated by MTI-101 $(20 \mu \mathrm{M})$ at 1 hour ( $<<0.05$ One-way ANOVA). I) Single cell tracing for $\mathrm{Ca}^{2+}$ influx in Fluo-4-AM loaded U266 with siTRPC1 and siControl. Cells were treated with MTI$101(20 \mu \mathrm{M})$ with or without one-hour pre-treatment with calpeptin $(80 \mu \mathrm{M})$. Cells imaged every 30 seconds for one-hour. Mean maximum peak of $\mathrm{Ca}^{2+}$ influx in 50 cells in U266 cell line. Error bars represent SEM $(\mathrm{p}<0.05$ One-way ANOVA, inter-group comparison was done by Tukey's multiple comparisons test $\mathrm{p}<0.0001)$.

Figure 8: Members of the SOCE pathway correlates with poor patient outcomes: A) Overall survival analysis for selected components of the SOCE pathways for newly diagnosed MM patients from the CoMMpass study. B) Overall survival analysis for selected components of the 
SOCE pathway for relapsed MM patients in the APEX/SUMMIT trail. $p$-value was determined by log-rank test; (x) indicates expression data not available. Time is shown in days. C) A working model for MTI-101 mechanism of action.

\section{Supplementary Figures:}

Figure S1: Stroma cells are not sensitive to MTI-101-induced $\mathrm{Ca}^{2+}$ flux and cell death: A and B) The effect of MTI-101 was compared to thapsigargin (Tg) by measuring $\mathrm{Ca}^{2+}$ influx using Fluo4-AM fluorescence intensity in HS-5 cell line. The line graph shows a single cell tracing for $\mathrm{Ca}^{2+}$ influx following treatment with MTI-101 $(20 \mu \mathrm{M})$ and $\operatorname{Tg}(1 \mu \mathrm{M})$. The individual cells were chosen based on the median peak for $\mathrm{Ca}^{2+}$ influx for the respective treatment group. Cells were imaged every 30 seconds. B) Mean maximum peak of $\mathrm{Ca}^{2+}$ influx in 50 cells in HS-5 cell line. Error bars represent SEM ( $<0.05$ One-way ANOVA, inter-group comparison was done by Tukey's multiple comparisons test $\mathrm{p}<0.05)$. C) The total levels of $\mathrm{Ca}^{2+}$ influx mediated by MTI101, Tg, and vehicle control was measured by calculating the peak area under the curve (Peak AUC) of the 50 cells $(\mathrm{p}<0.05$ One-way ANOVA, inter-group comparison was done by Tukey's multiple comparisons test $\mathrm{p}<0.05)$. D) The effect of MTI-101 $(20 \mu \mathrm{M})$ and $\operatorname{Tg}(1 \mu \mathrm{M})$ on cell death was measured in HS- 5 cells by imaging the respective treatment group every 5 minutes for one hour. Cell death was determined by a threshold of DAPI fluorescence indicative of a dead cell. Error bars represent SEM ( $<<0.05$ one-way ANOVA).

Figure S2: MTI-101 induces TRPC1 Truncation by Calpain Activation: A and B) MM.1s cells pretreated with calpeptin $(80 \mu \mathrm{M})$ for one hour, followed by treatment with MTI-101 (25 $\mu \mathrm{M}$ ) for $0,5,30$ minutes. TRPC1 cleaved fractions was detected at $\approx 60 \mathrm{kDa}$ in the calpeptin-free group in the RIPA insoluble compartment. Quantification of the cleaved fraction TRPC1 normalized to $\beta$-actin. C) MTI-101 $(15 \mu \mathrm{M})$ does not induce TRPC1 cleavage in HS-5 cells in both RIPA Soluble and Insoluble compartments. D) $\mathrm{CaCl}_{2}$ activated calpain I induced TRPC1 
cleaved fraction at $\approx 60 \mathrm{kDa}$ in $\mathrm{U} 266$ cells following 1-hour incubation with the recombinant protein. Pre-treating cells with calpeptin $(80 \mu \mathrm{M})$ for 1 hour abrogated TRPC1 cleavage. $\mathbf{E}) \mathrm{CaCl}_{2}$ activated calpain I induced TRPC1 cleaved fraction at $\approx 60 \mathrm{kDa}$ in HS-5 cells. Pre-treating cells with calpeptin $(80 \mu \mathrm{M})$ for 1 hour abrogated TRPC1 cleavage, while no cleavage was seen with MTI-101 treatment. F) Western blot analysis for TRPC1 expression levels in MM.1s cells. G) Effect of knocking down TRPC1 in MM.1s cells on cell death mediated by MTI-101 (30 $\mu \mathrm{M})$ at 1 hour ( $\mathrm{p}<0.05$ One-way ANOVA). H) Single cell tracing for $\mathrm{Ca}^{2+}$ influx in Fluo-4-AM loaded MM.1s with siTRPC1 and siControl. Cells were treated with MTI-101 $(30 \mu \mathrm{M})$ with or without one-hour pre-treatement with calpeptin $(80 \mu \mathrm{M})$. Cells imaged every 30 seconds for one-hour. Mean maximum peak of $\mathrm{Ca}^{2+}$ influx in 50 cells in MM.1s cell line. Error bars represent SEM ( $<<0.05$ One-way ANOVA, inter-group comparison was done by Tukey's multiple comparisons test $\mathrm{p}<0.0001$ ). 


\subsection{Figures}

Figure 1

A

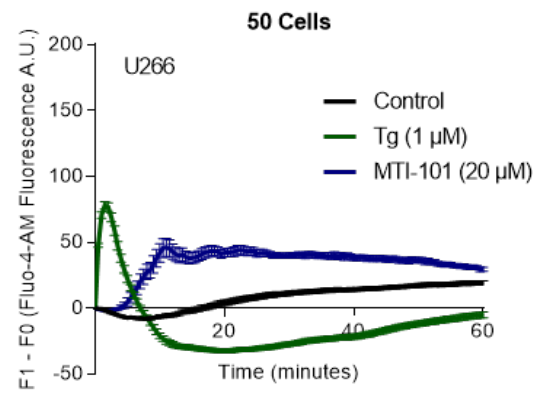

D

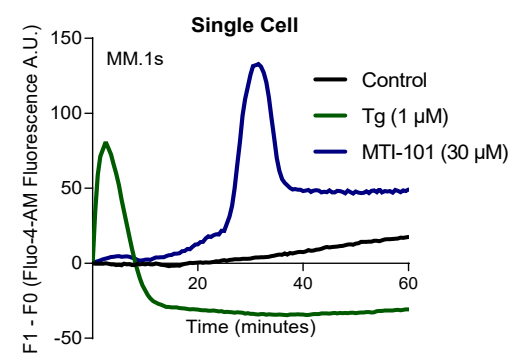

B

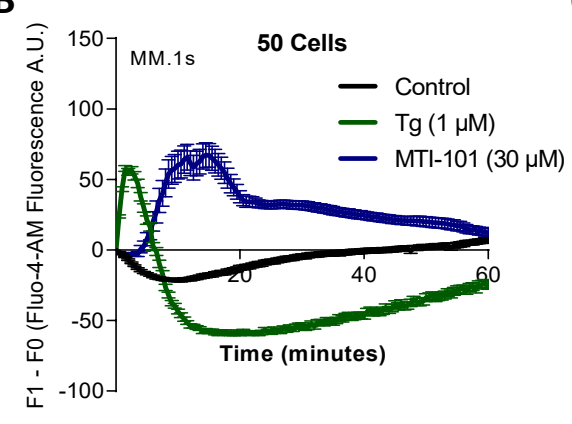

E

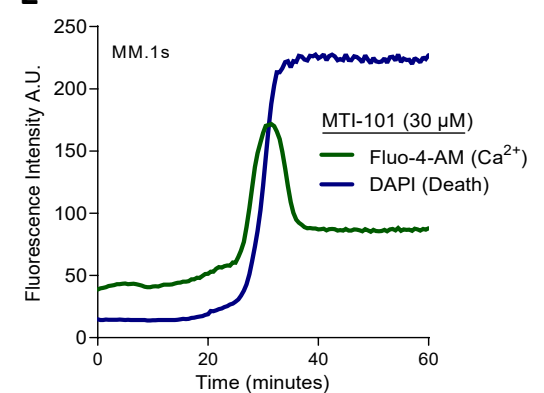

C
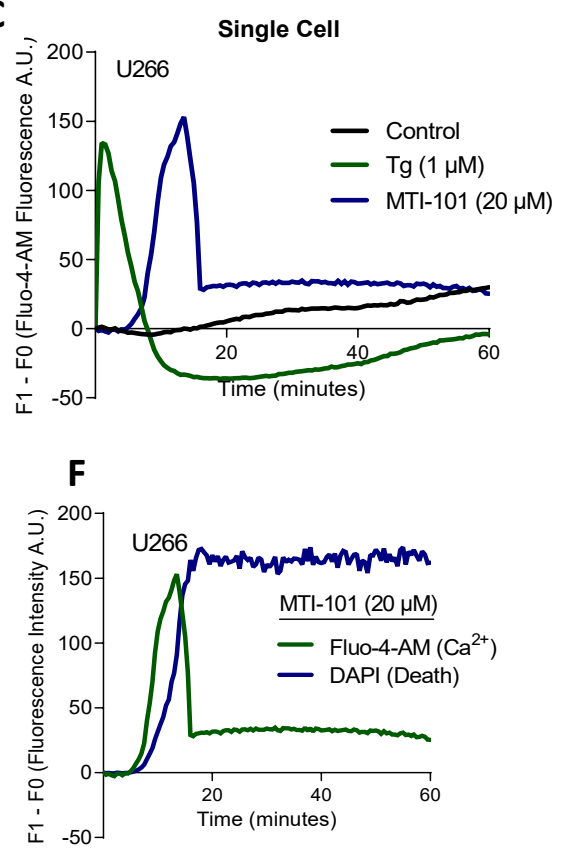

G Max Peak (50 Cells)

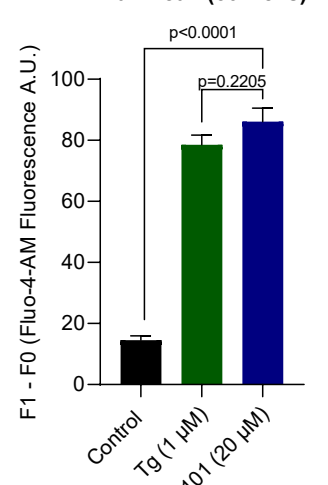

U266
H

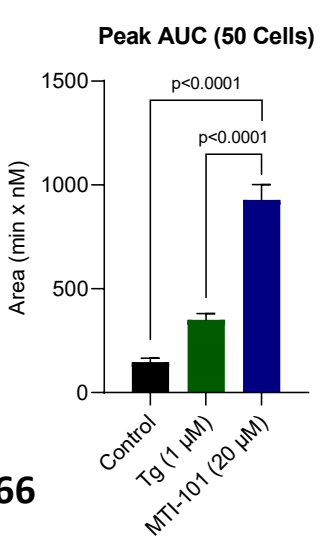

I

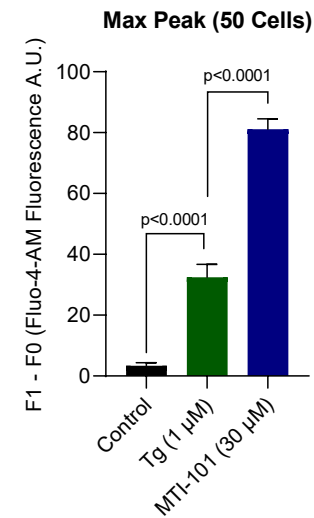

J

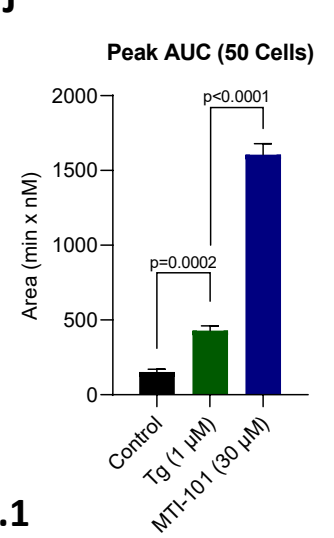

M

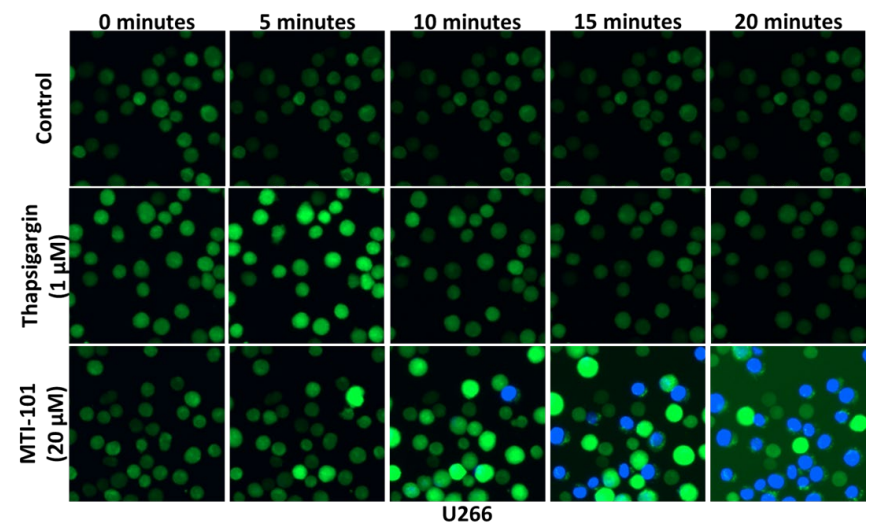




\section{Figure 2}

A

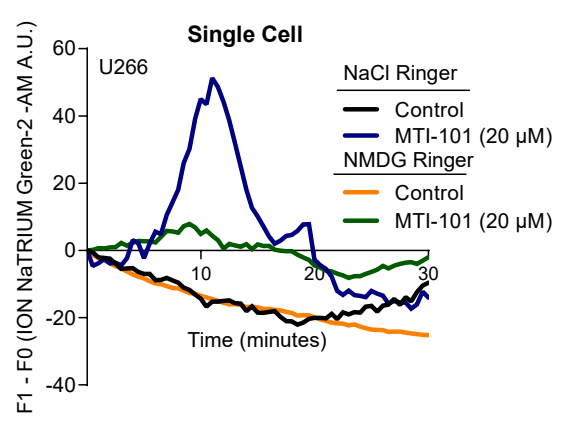

C
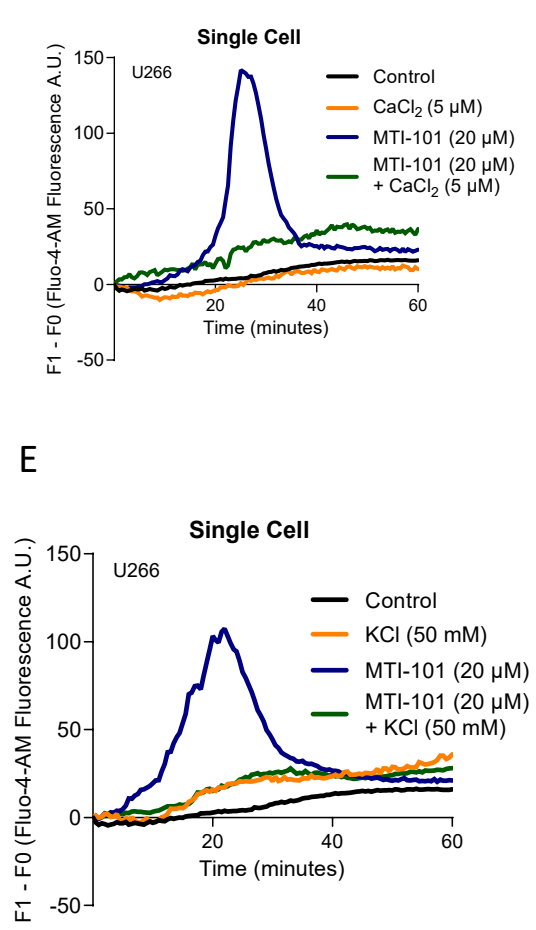

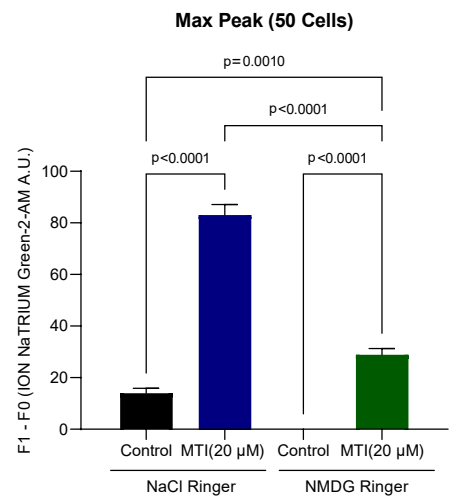

B

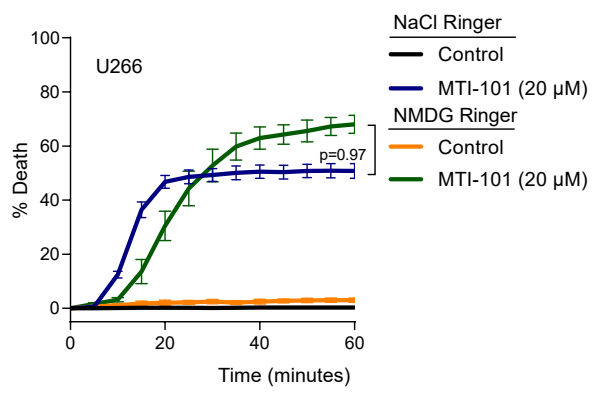

D
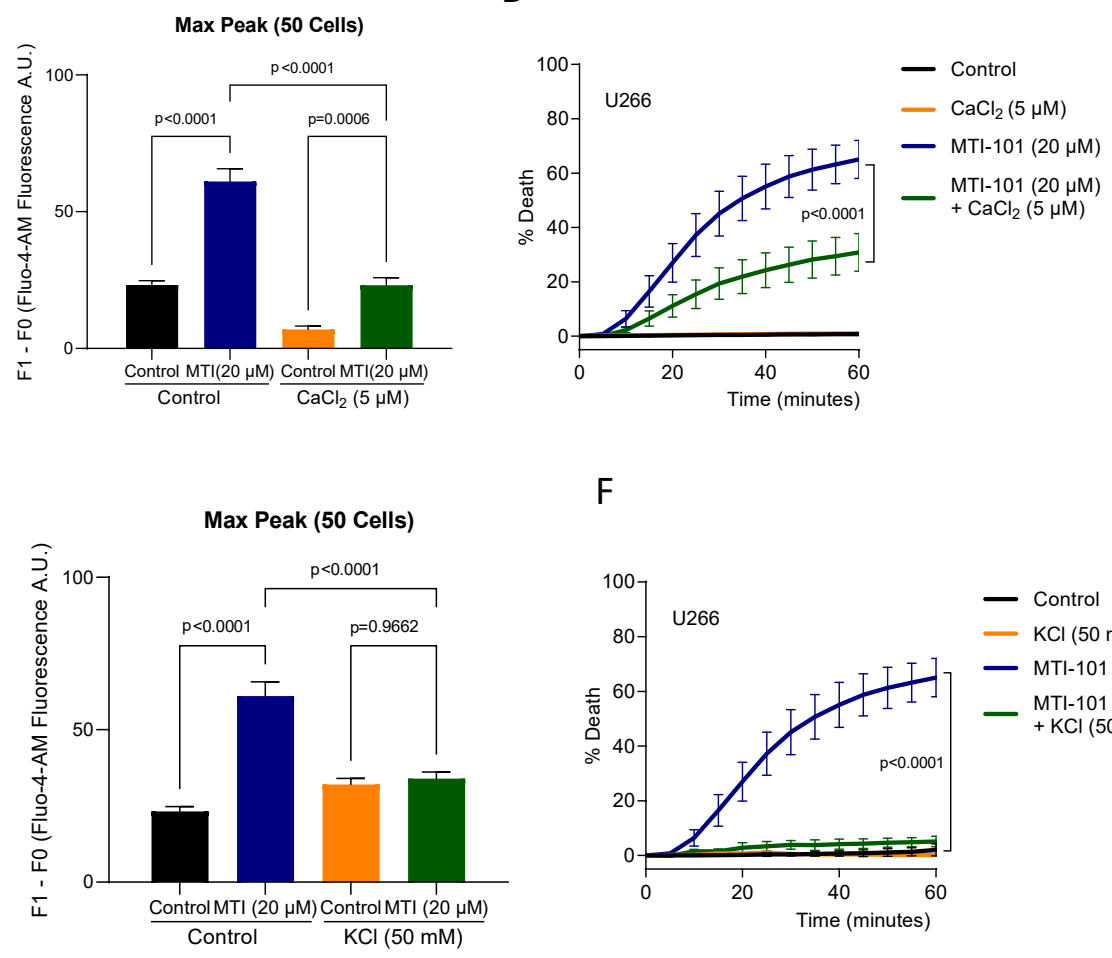

F

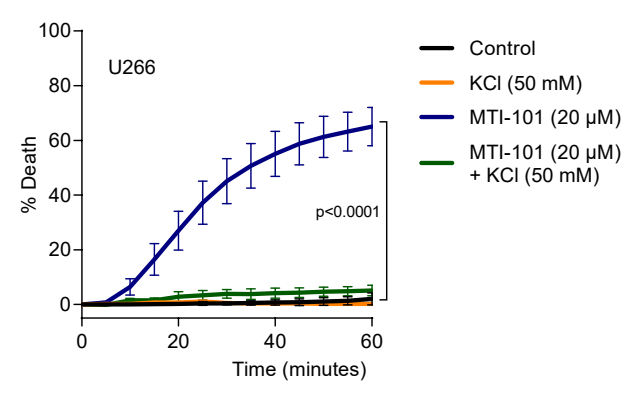

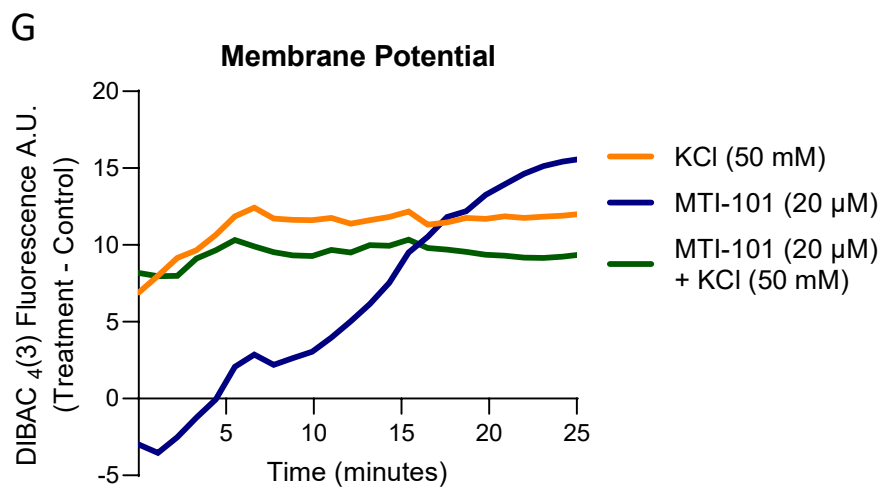




\section{Figure 3}

A

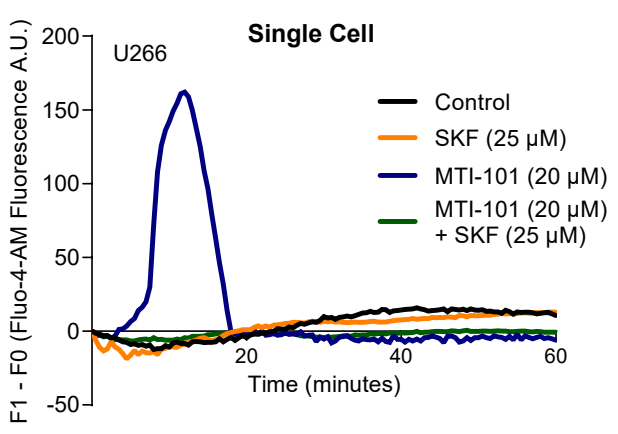

B

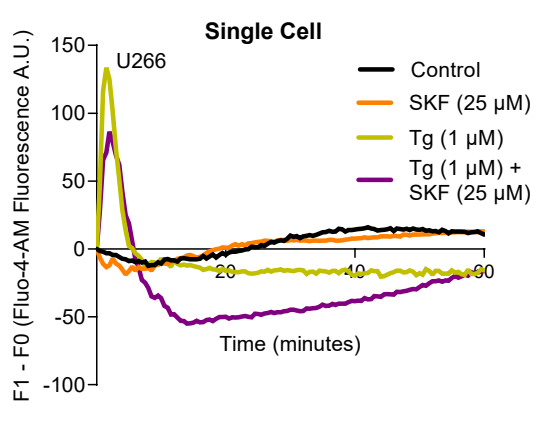

E
C
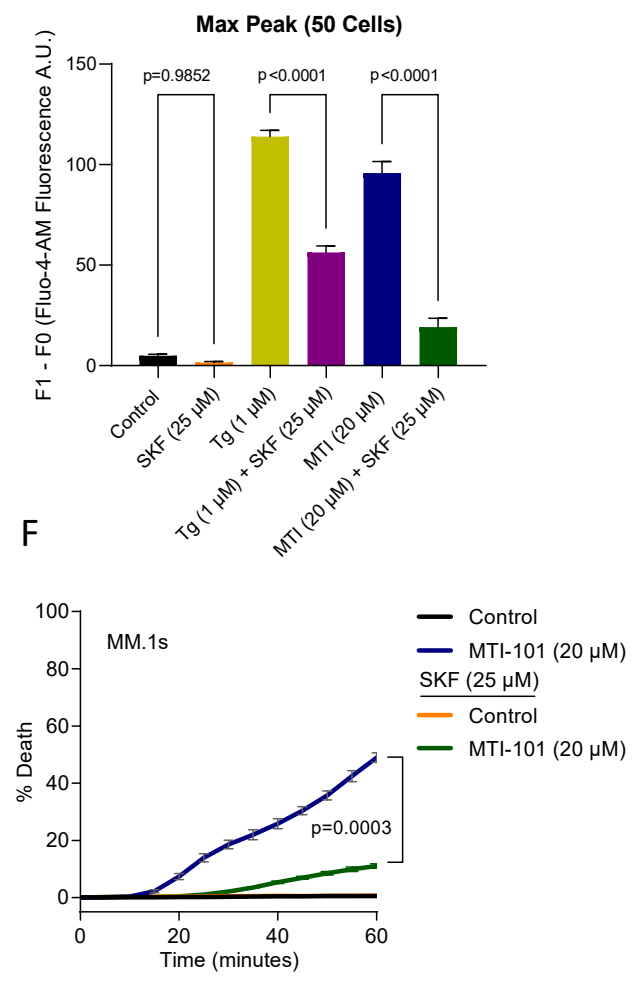
- MTI-101 $(20 \mu \mathrm{M})$

G
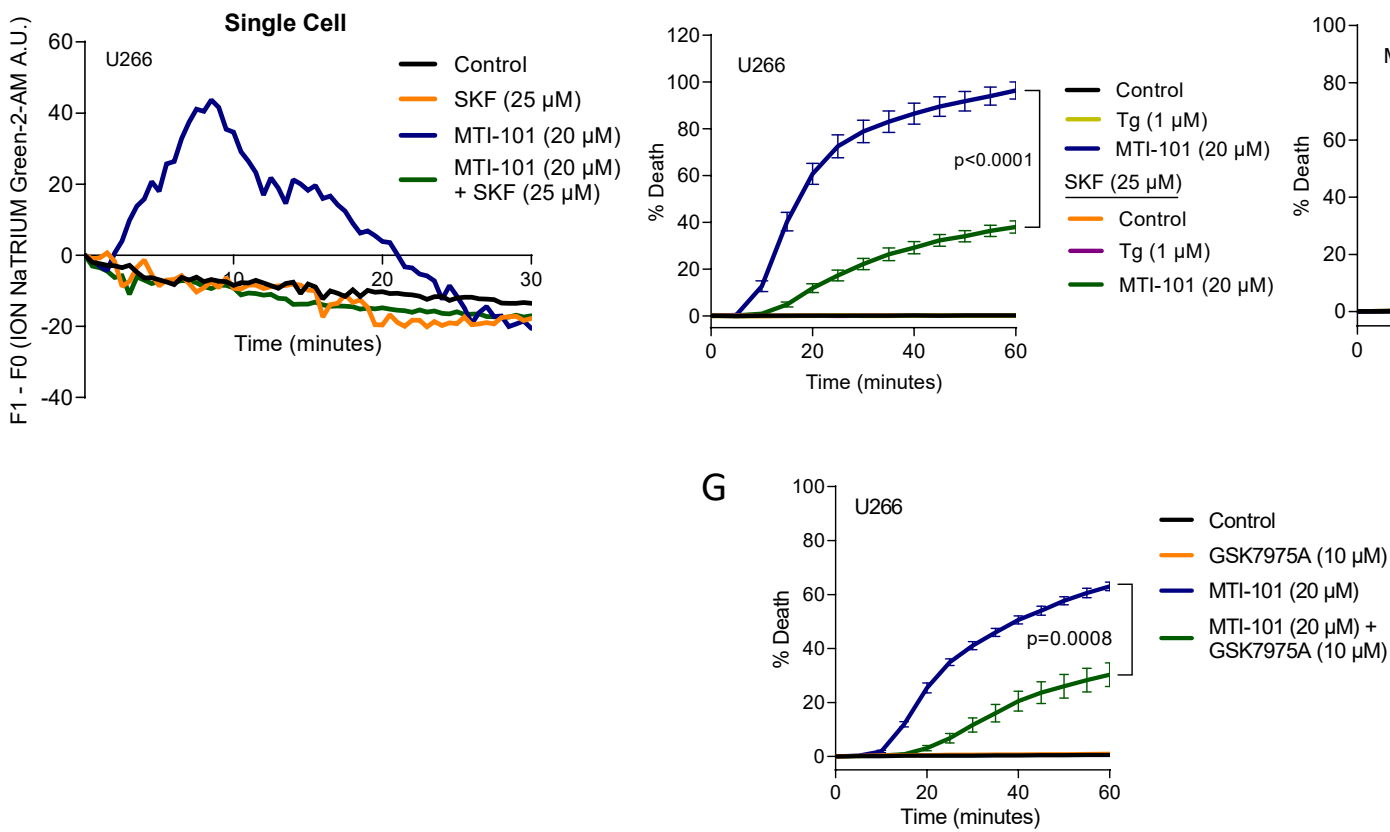

$\mathrm{H}$
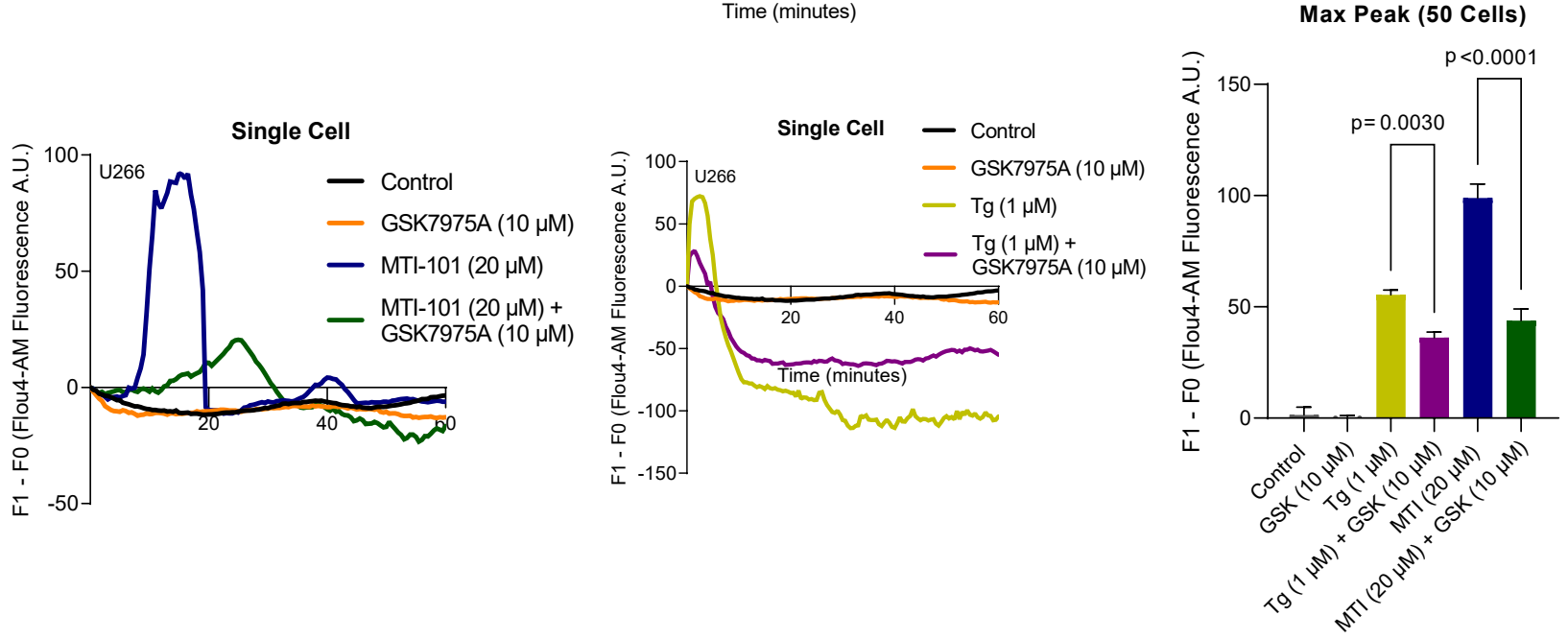
Figure 4

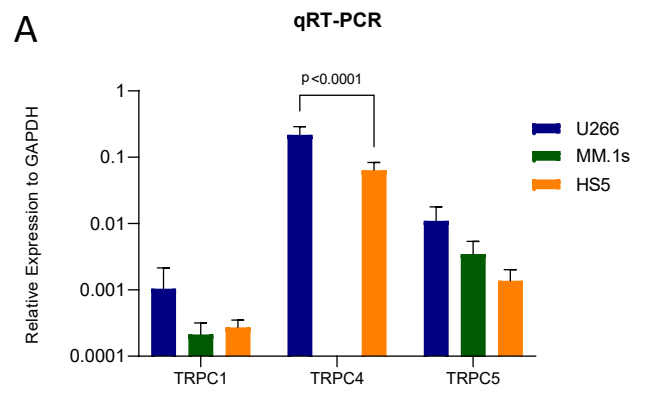

B
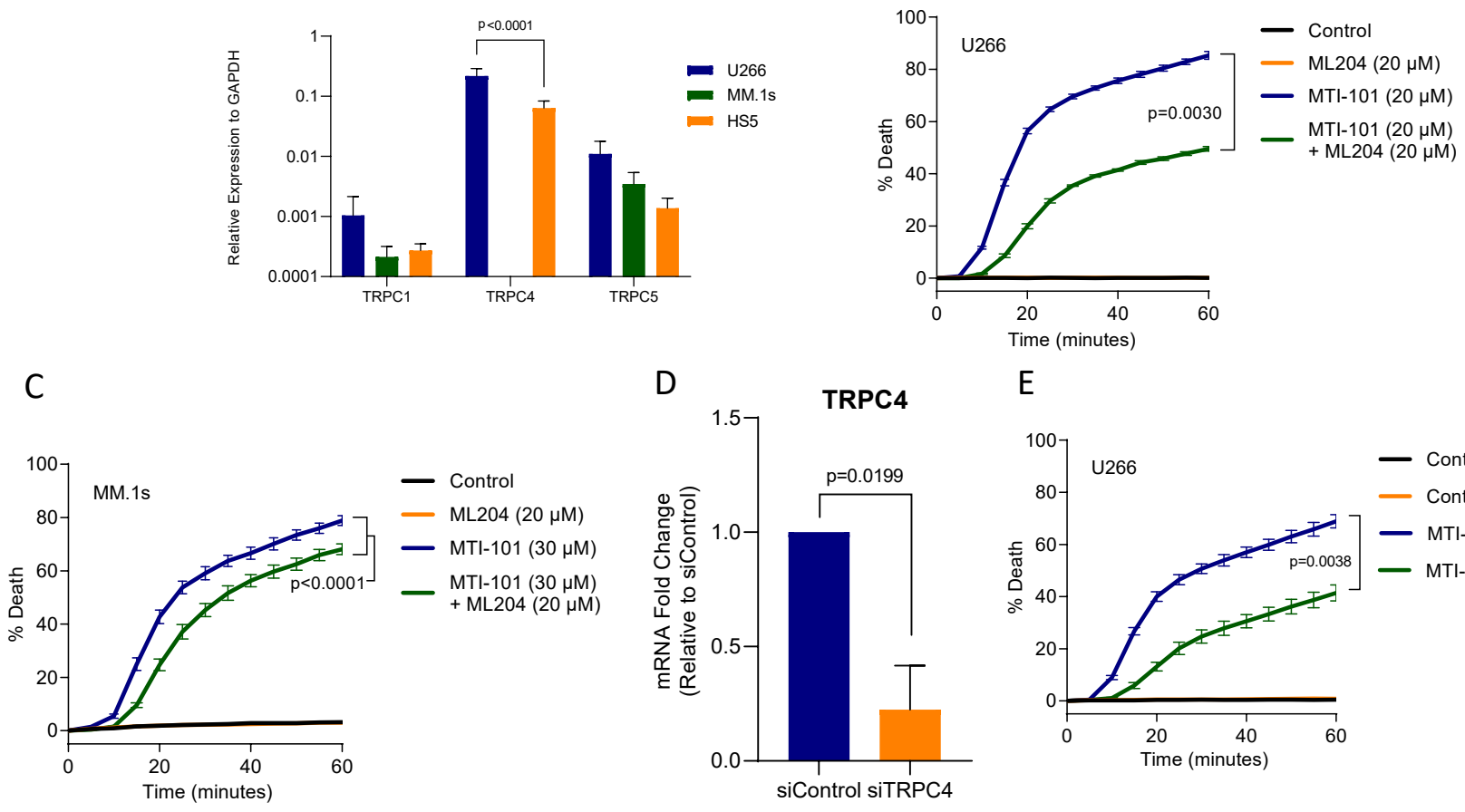

E

F
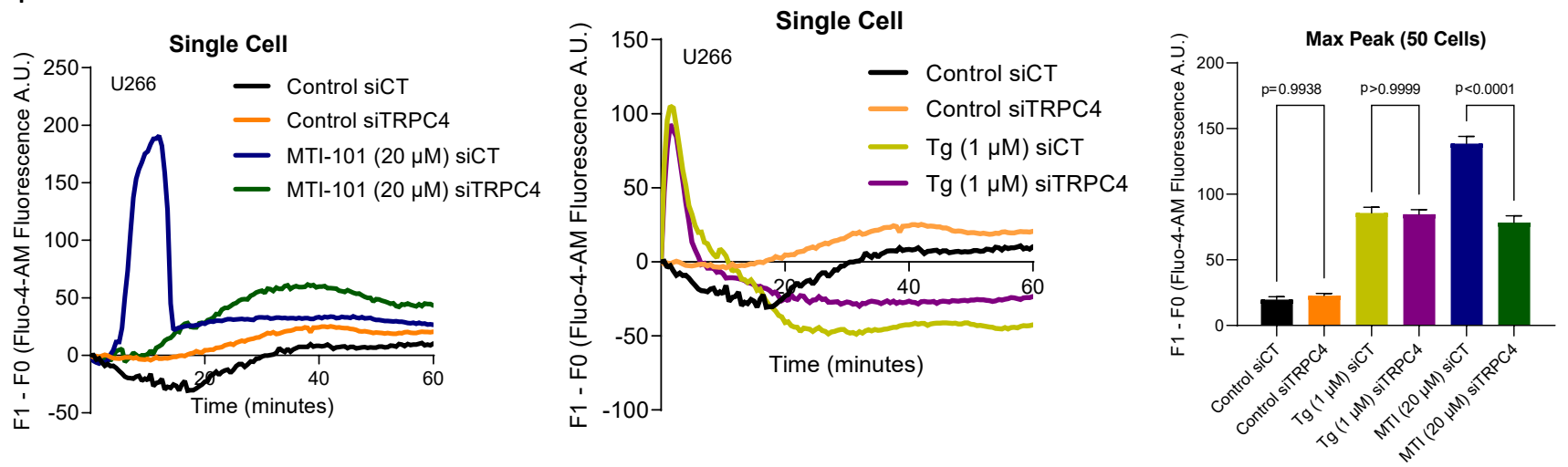


\section{Figure 5}

A B

C
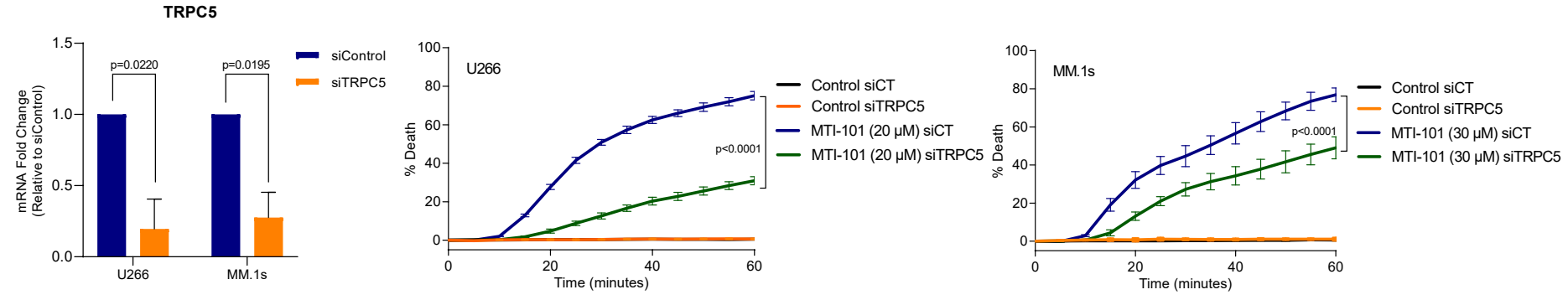

D
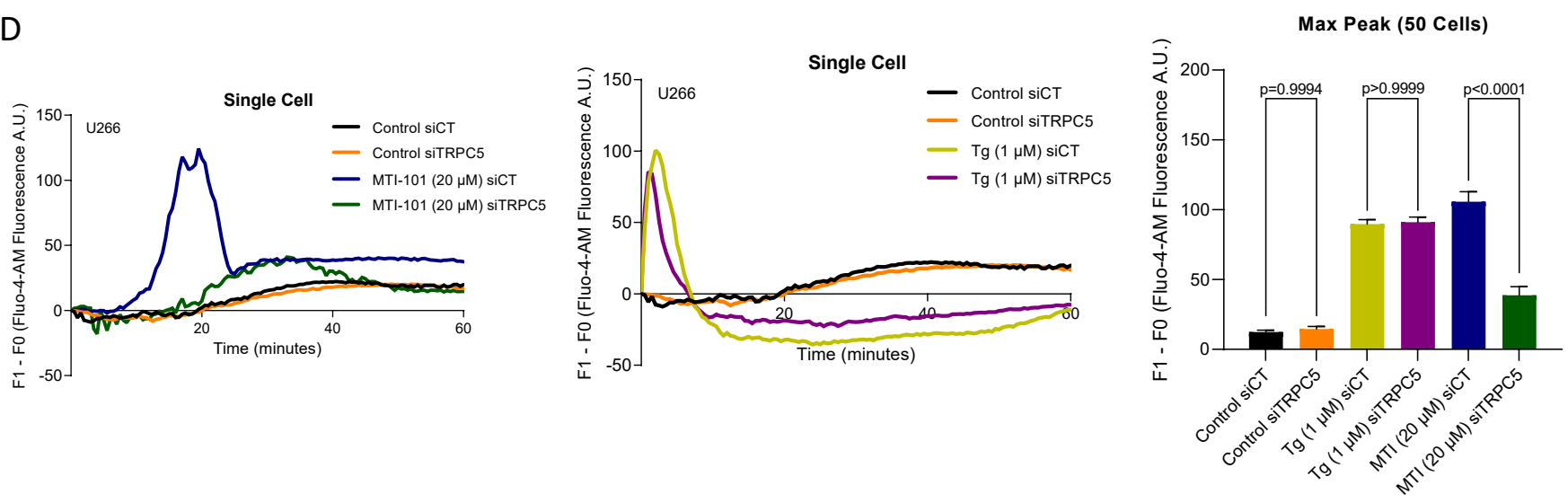

E
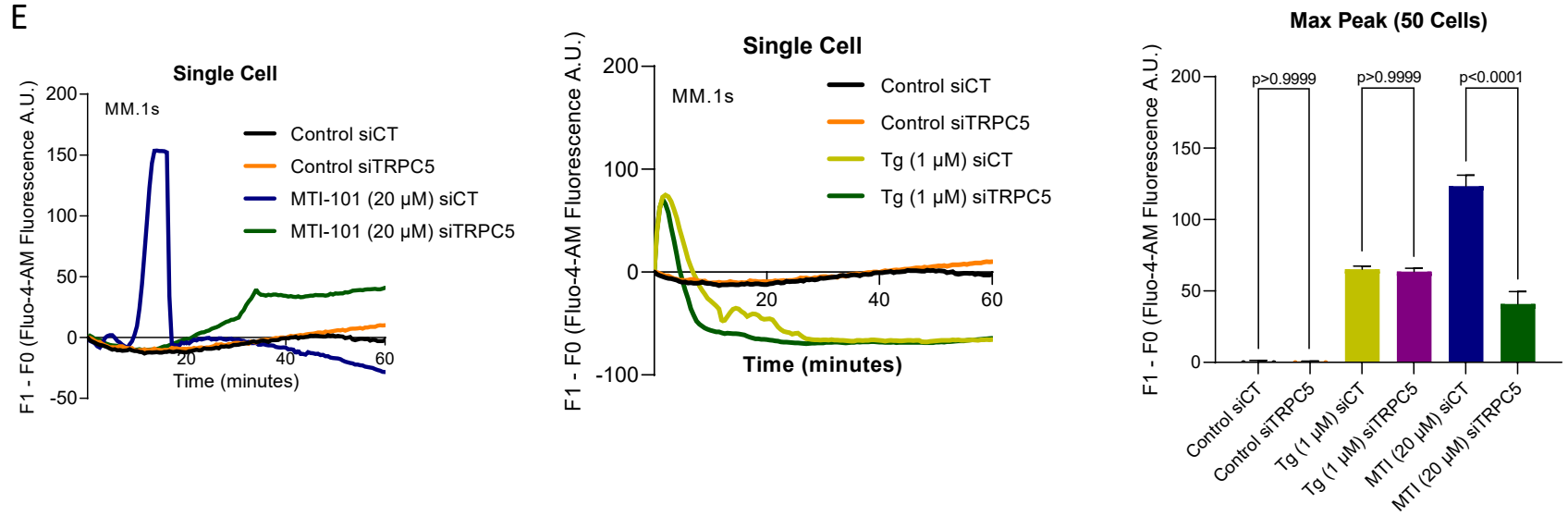
Figure 6

A
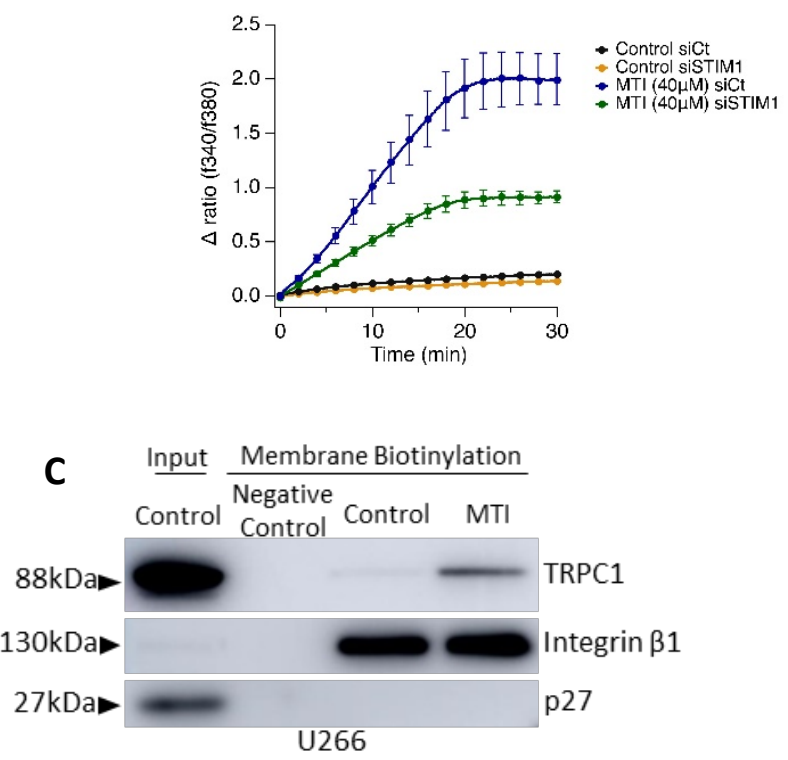

E

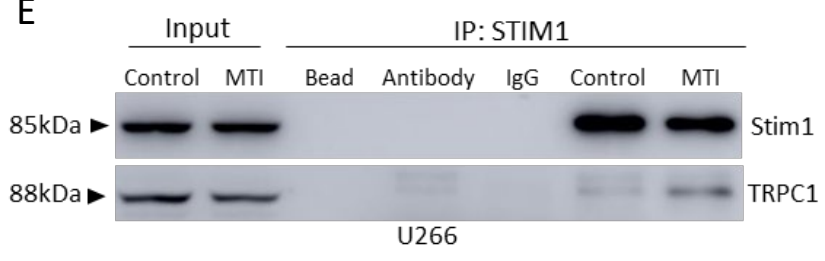

B
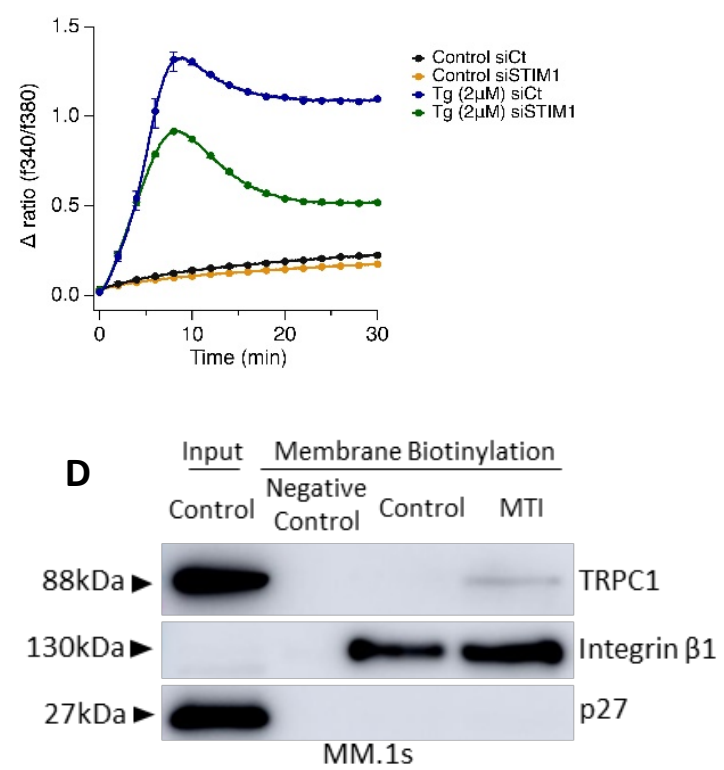

F

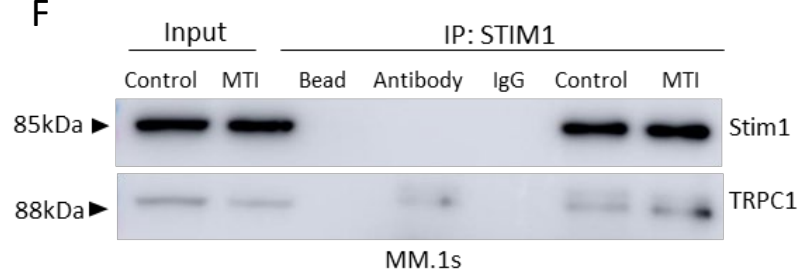


Figure 7
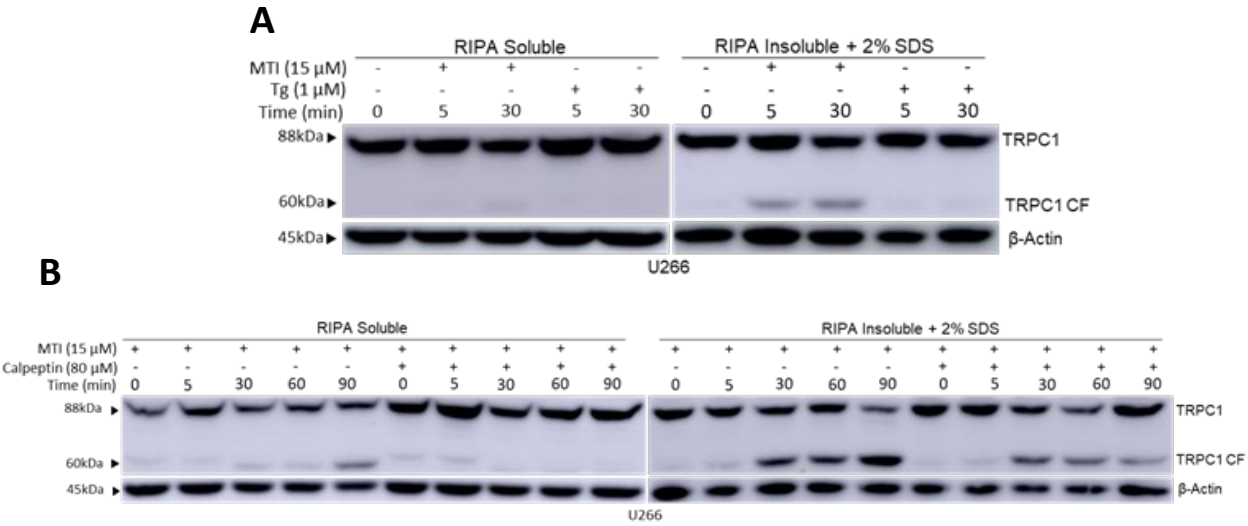

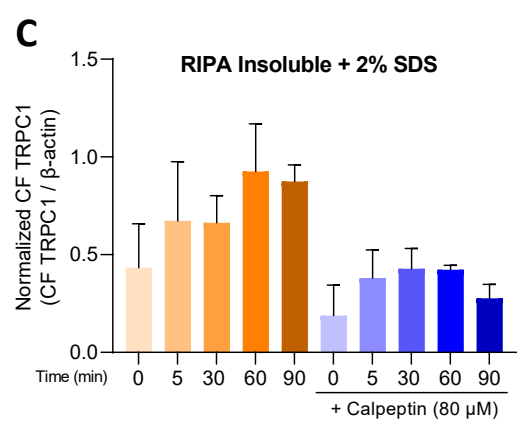

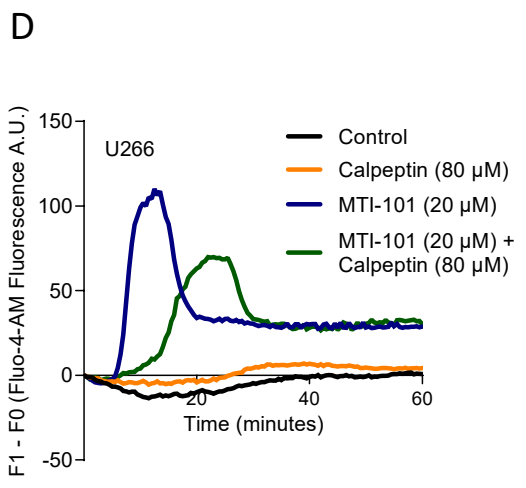

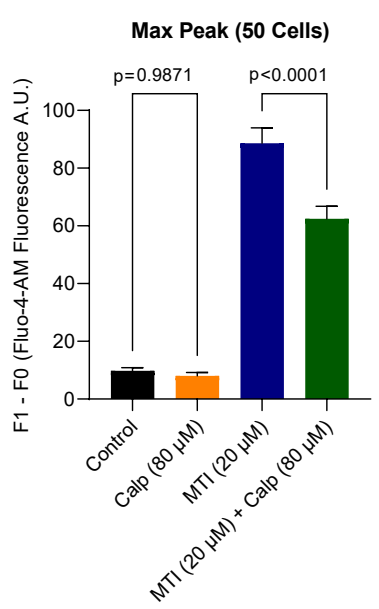

F

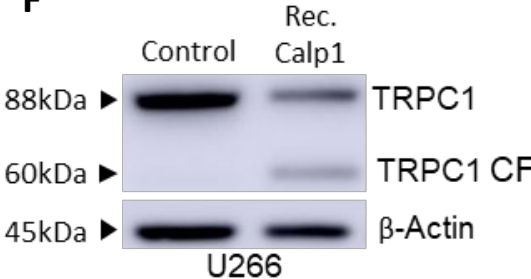

I

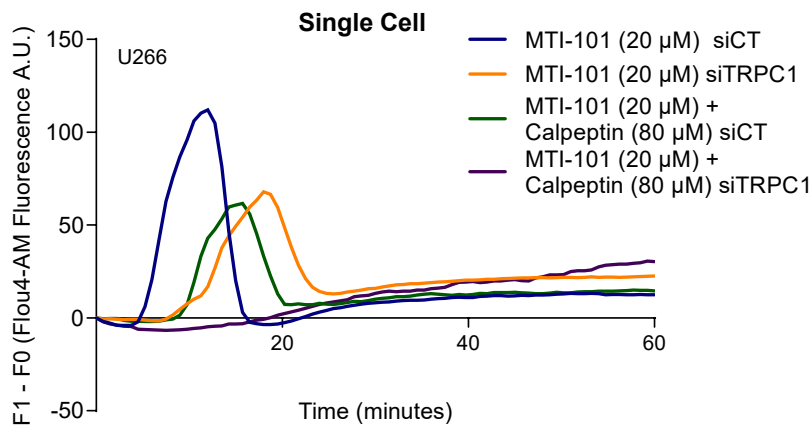

E

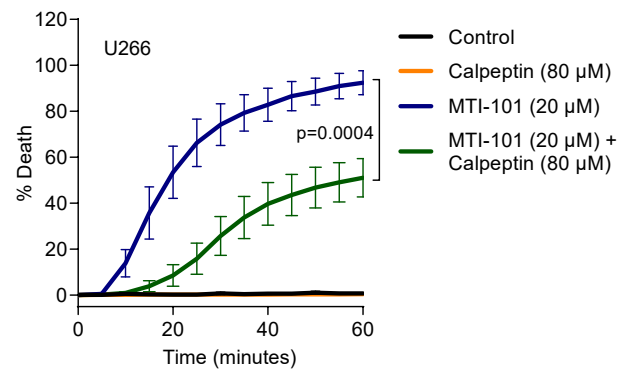

$\mathrm{H}$

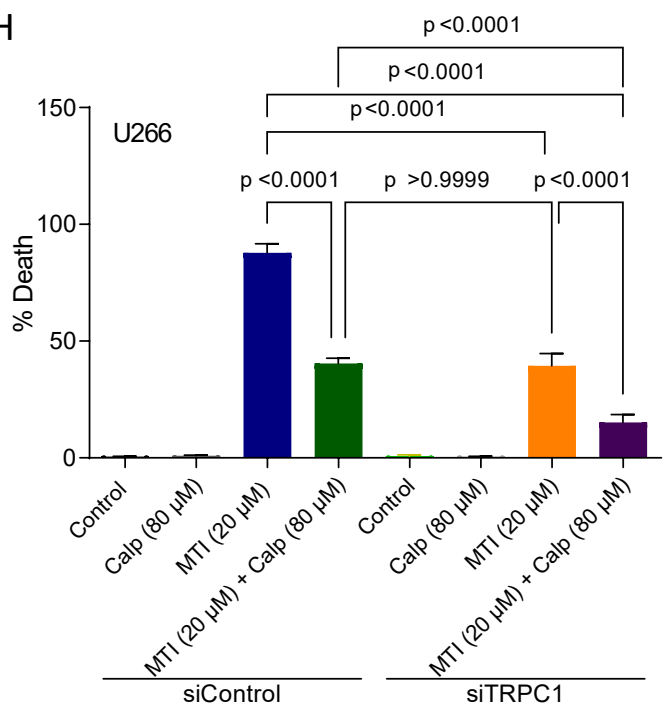


Figure 8

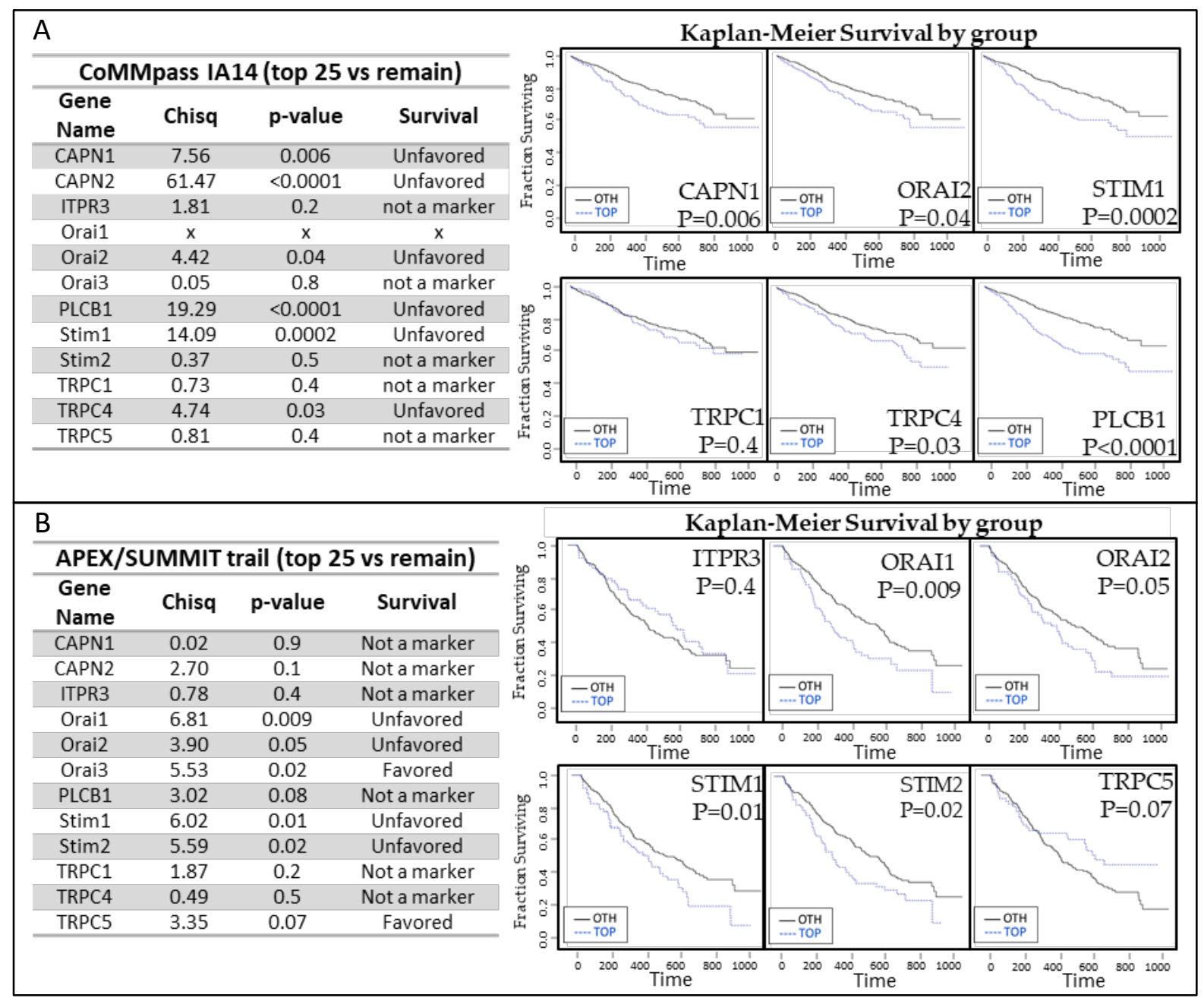
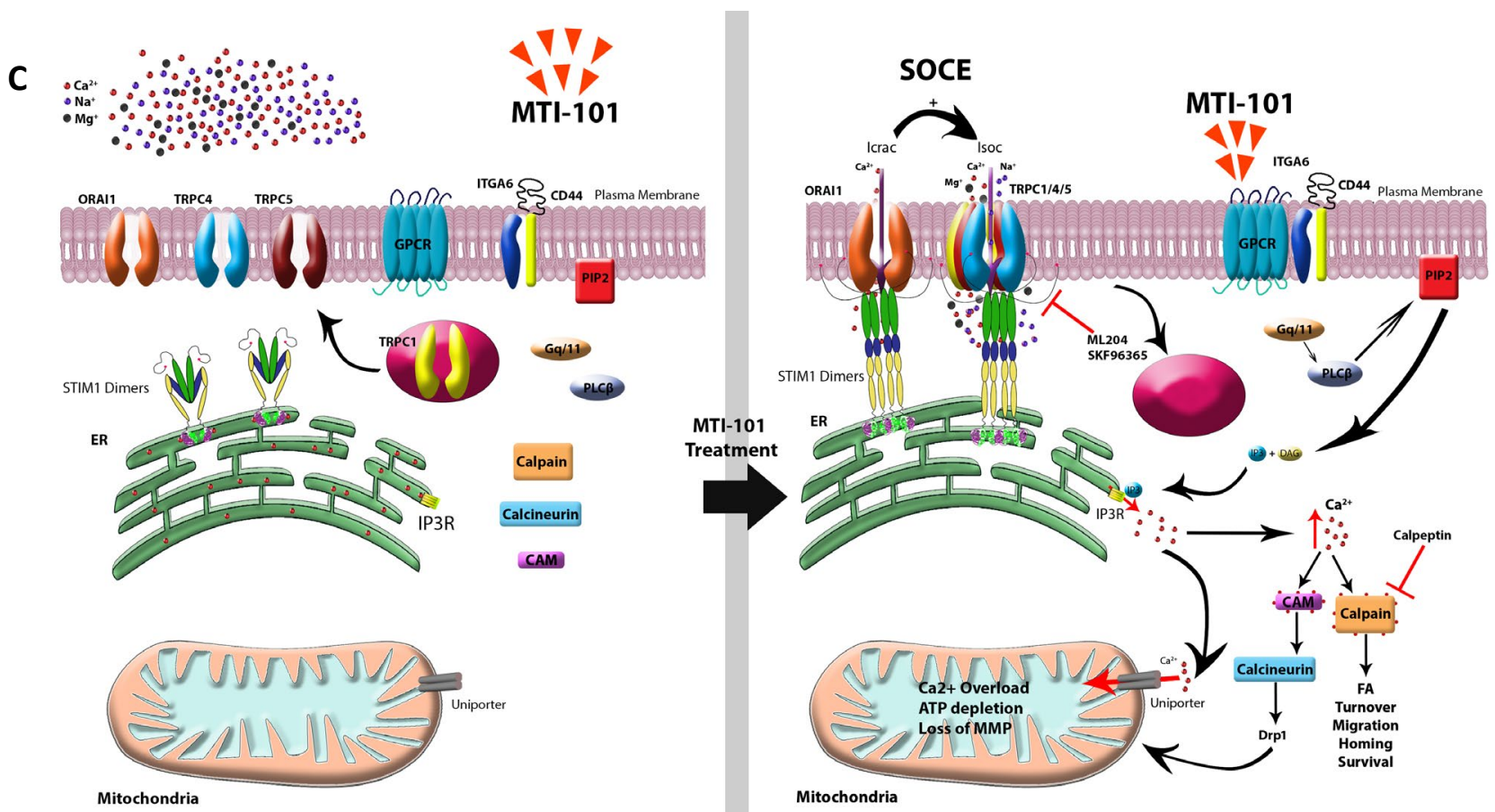


\subsection{Supplementary Figures:}

Figure S1:

A

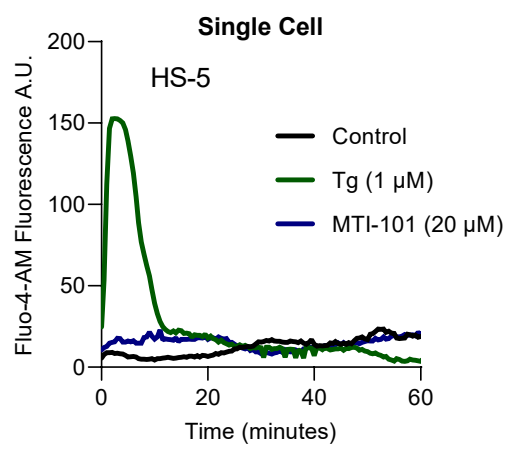

B

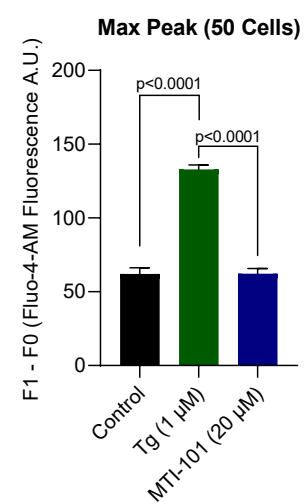

C

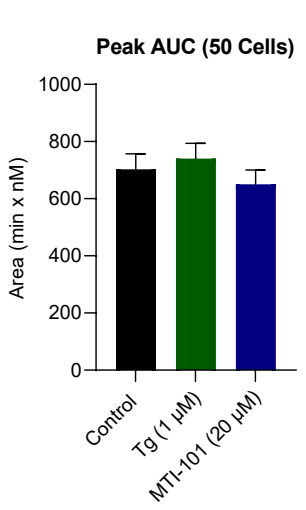

D

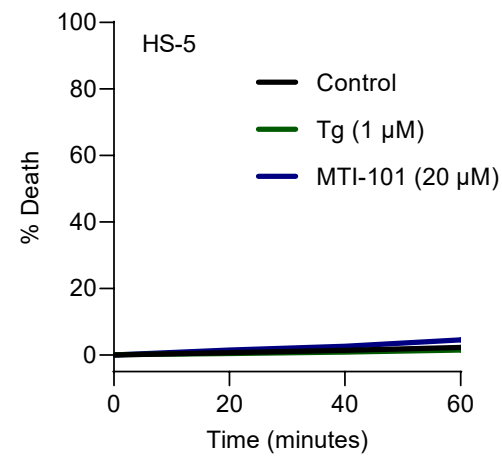


Figure S2:

A

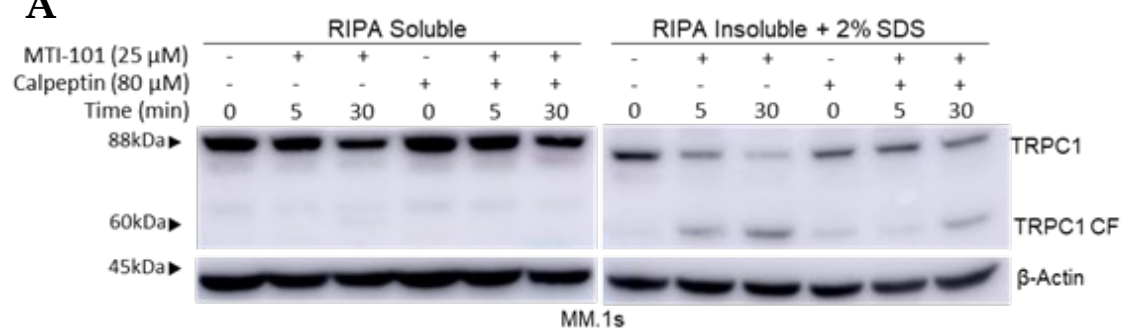

C

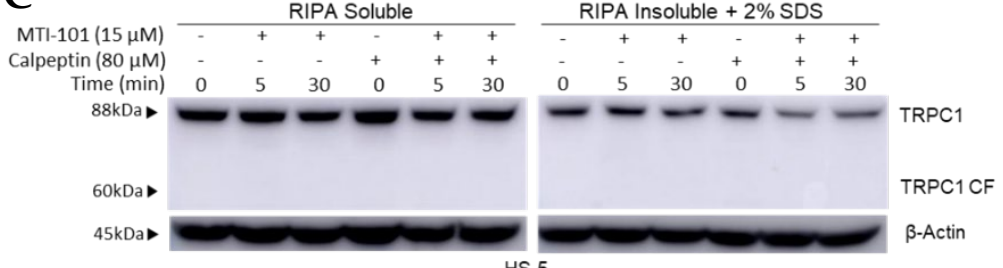

B

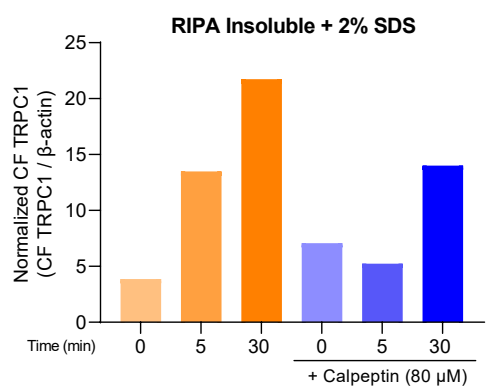

D

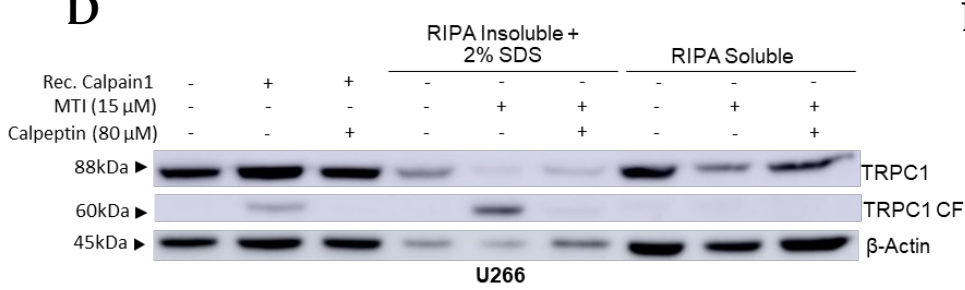

F

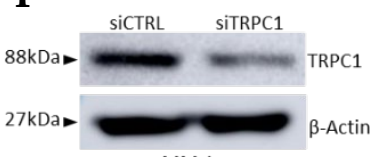

MM.1s
E

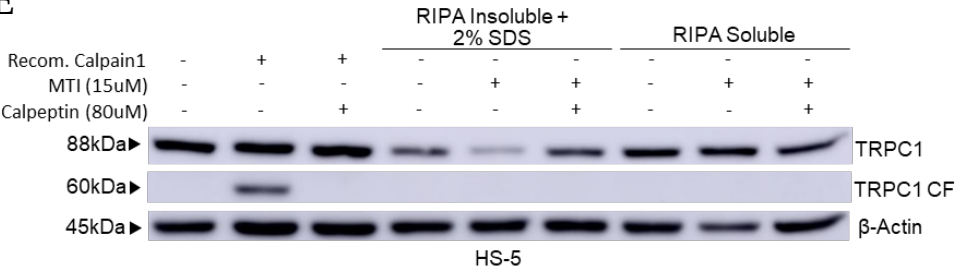

H

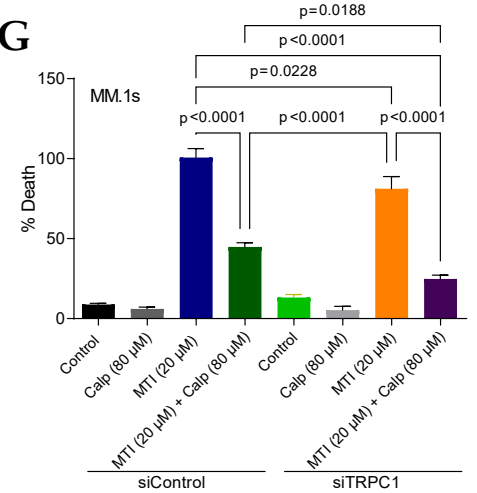

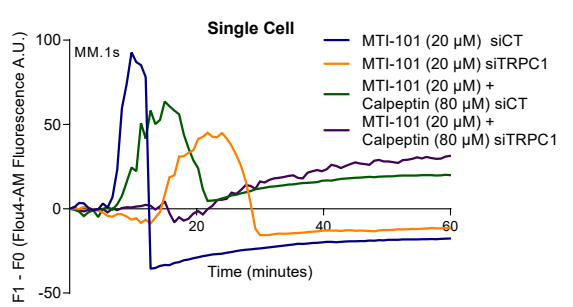

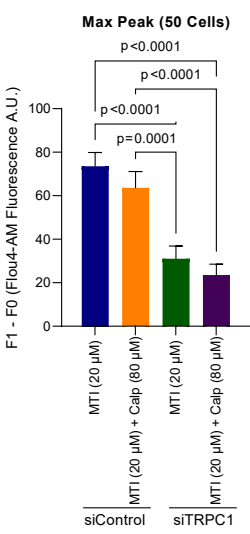




\section{Chapter 4 Conclusions and Future Directions}

Multiple Myeloma advanced from untreatable to treatable malignancy yet is still incurable. However, treatment options have been advancing over the decades. The first discovered treatment was the autologous stem cell transplant (ACST) discovered in the 1980s'[1]. ACST was followed by the discovery of novel agents including thalidomide and lenalidomide (IMID's). Later, treatment options further improved with the discovery of the proteasome inhibitors (PIs) lid by bortezomib. More recently, elotuzumab and daratumumab categorized as monocolonal antibodies, and Panobinostat the histone deacetylating agent has been approved by the US Food and Drug Administration [2]. More recently, the FDA has approved idecabtagene vicleucel (Abecma) as CAR-T therapy for multiple myeloma patients who failed or went through four different MM treatments [3]. Moreover, The NCCN guidelines for the treatment of MM has treatment recommendation for all stages of $\mathrm{MM}$, including transplant and non-transplant patients. However, With all these therapy, there is still an unmet need for a novel therapy targeting a novel pathway for MM, especially with minimal residual disease outgrowth and contribution to drug resistance.

As we mentioned earlier the NFAT pathway contributes to proliferation, migration, and survival. And to build on what Bucher and colleagues reported that NFAT activity is chronically elevated in diffuse large B-cell lymphoma (DLCBCL), where the inhibition of calcineurin with cyclosporin A or FK506 reduced cell death in DLCBCL, along with what was reported by Urso et al. where NFAT3c is determinant of proliferation of and migration of glioblastoma cell lines [4,5] .It would be intriguing to perform gene expression analysis on MM patients' specimens to determine the expression levels of genes regulated by the NFAT pathway, and to compare the levels in newly diagnosed to relapsed specimens. Based on our data, MTI-101-induced cell death is greatly dependent on the presence and activation of the SOCE pathway, as was previously reported that 
H929-60 MTI-101 resistant cell line showed downregulation of PLC $\beta$, ITPR3, ATP2A3, TRPC1, and TRPM7, all of which regulate the SOCE pathway. Furthermore, we reported that we are able to attenuate MTI-101 induced Ca2+ influx and cell death using pharmacological inhibitors targeting CRAC channels by GSK7975A, TRPC4 channel by ML204, and TRPC channels by SKF96365. Establishing the link between the NFAT pathway and above mentioned genes in MTI101 sensitive MM cell lines could prove beneficial in understanding the determinants of sensitivity to MTI-101 first in-vitro, and translationally but comparing the findings to the gene expression from patients' specimens. Being able to determine whether upregulated NFAT pathway along with other SOCE pathway genes contributing to MTI-101 would be instrumental in stratifying patients eligible to receive MTI-101. Furthermore, performing gene expression analysis on CD138+ cells from bone marrow patients' specimens, following determination of sensitivity to MTI-101 would aid in identifying eligible patients for MTI-101 treatment.

We previously reported that the fibroblast bone marrow stroma cell line HS-5 is insensitive to MTI-101, as was shown that MTI-101 does not induce Ca2+ influx or cell death. Furthermore, Nair and colleagues reported that peripheral blood mononuclear cells (PBMCs) from healthy individuals are not sensitive to MTI-101 parent drug HYD1 [6]. These findings although positive, raises the question, what are absolute determinant of response to MTI-101 in cancer cells, and what is the dose-limiting toxicity (DLT) to MTI-101. Future studies focusing on expression profiling for insensitive cell lines or PBMCs to MTI-101, or even cancer cells that don't respond to MTI-101 could prove beneficial in understating what mediates MTI-101 effect. Moreover, MTI101 did not induce Ca2+ influx in HS-5 cell line, and based on previous reports that MTI-101 binds a surface complex containing CD44, along with a reduction in cleaved $\alpha 4$ intergrin (VLA4) in H929-60-HYD1 resistant MM cell line, their still remains a gap in what is the upstream activator of the SOCE pathway, and what are the other binding partners in MTI-101 complex, and 
future experiments on the binding partner to MTI-101 could aid in the delineation between MTI101 -sensitive and insensitive cells [7,8].

Owing to this diversity in TRPC1 mode of activation, it is conceivable that MTI-101 activity could be dependent on coupling STIM1 and TRPCs in MM cells. Consistent with this notion, we observed that MTI-101-induced cell death is partially dependent on the expression of TRPC1/4/5, suggesting that they participate in the complex formation with STIM1. We further report that in an inactive state, and in absence of MTI-101, we failed to detect TRPC1 at the plasma membrane, and the activation of the SOCE pathway by MTI-101 allowed TRPC1 trafficking and insertion into the plasma membrane. TRPC1 recycling to and from the plasma membrane following SOCE activation has been reported previously by De Souza and colleagues [9]. They reported that the TRPC1 fast recycling is dependent on trafficking to the plasma membrane by Rab4 and the internalization into Rab5-containing endosomes is an ARF6-dependent pathway. Future studies determining the mechanism underpinning MTI-101-induced trafficking of TRPC1 to the plasma membrane, for example the overexpression of Rab5 induced retention of TRPC1 in the sub-plasma membrane TRPC1-containing vesicles [9].

The $\mathrm{Ca}^{2+}$-activated protease calpain 1 is associated with poor survival in MM patients in the COMPASS dataset. Kaczmarek et al reported that TRPC5 is a calpain substrate as they showed that the pharmacological inhibition of calpain I/II inhibited TRPC5, and is activated by calpain truncation [10]; further, Verheijden and colleagues reported that TRPC6 contributes to calpain I activation, and pharmacologically inhibiting calpain I or genetically knocking it down abrogated TRPC6 effects on podocyte injury in the kidneys [11]. Other reports indicated that $\mathrm{Ca}^{2+}$ entry through active TRPC1 activates calpain I in neurons and regulates axon outgrowth [12]. Our findings indicated that MTI-101 treatment induces cleavage of TRPC1 and that TRPC1 is a substrate for recombinant calpain I. In addition, pharmacological inhibition of calpains blocked 
MTI-101-induced calcium influx and cell death. Based on these data it is attractive to reason that the calpain-dependent feed-forward loop is due to cleavage of TRPC1 either via induction of a higher conductance or open probability of the channel. Future studies are required to determine the functional consequence of TRPC1 cleavage on MTI-101-induced calcium and sodium entry. Using a calpain consensus motif prediction software for TRPC1 (Group-based Prediction System - Calpain Cleavage Detector GPS-CCD), we were able to identify 19 possible positions where calpain is likely to induce cleavage [13]. Out of the 19 positions, position 249 (glutamic acid) is shown to be a possible truncation site. Cleavage at E249 corresponds to truncation of $\sim 28 \mathrm{kDa}$, and we identified a truncated fraction of TRPC 1 of approximately $28 \mathrm{kDa}$. To address the TRPC 1 calpain consensus site, transfecting MM cells with truncated mutant TRPC1, and test the cells sensitivity to MTI-101 would determine whether these truncated TRPC1 fractions are capable of forming channels, and whether they are able to a complex with STIM1.

Cleavage of TRPC1 was targeted in cells sensitive to MTI-101, while cleavage was not observed in the stroma cell line HS-5. However, $\mathrm{Ca}^{2+}$-activated recombinant calpain I was able to cleave TRPC1 from HS-5 derived lysates. These finding correlate with failure of MTI-101 to evoke a calcium response in HS-5 stroma cells. Again, more studies are required to fully understand the mechanism underpinning the MTI-101-induced trafficking of TRPC1 to the plasma membrane, and its continuous activation leading to the sustained $\mathrm{Ca}^{2+}$ influx and cell death. 


\section{References:}

1. Kazandjian, D.; Landgren, O. A look backward and forward in the regulatory and treatment history of multiple myeloma: Approval of novel-novel agents, new drug development, and longer patient survival. Semin Oncol 2016, 43, 682-689, doi:10.1053/j.seminoncol.2016.10.008.

2. Raju, G.K.; Gurumurthi, K.; Domike, R.; Kazandjian, D.; Landgren, O.; Blumenthal, G.M.; Farrell, A.; Pazdur, R.; Woodcock, J. A Benefit-Risk Analysis Approach to Capture Regulatory Decision-Making: Multiple Myeloma. Clin Pharmacol Ther 2018, 103, 67-76, doi:10.1002/cpt.871.

3. FDA Approves BCMA-Targeted CAR T-Cell Therapy for Multiple Myeloma was originally published by the National Cancer Institute. Availabe online: https://www.cancer.gov/news-events/cancer-currents-blog/2021/fda-ide-cel-car-tmultiple-myeloma (accessed on

4. Urso, K.; Fernandez, A.; Velasco, P.; Cotrina, J.; de Andres, B.; Sanchez-Gomez, P.; Hernandez-Lain, A.; Hortelano, S.; Redondo, J.M.; Cano, E. NFATc3 controls tumour growth by regulating proliferation and migration of human astroglioma cells. Sci Rep 2019, 9, 9361, doi:10.1038/s41598-019-45731-w.

5. Bucher, P.; Erdmann, T.; Grondona, P.; Xu, W.; Schmitt, A.; Schurch, C.; Zapukhlyak, M.; Schonfeld, C.; Serfling, E.; Kramer, D., et al. Targeting chronic NFAT activation with calcineurin inhibitors in diffuse large B-cell lymphoma. Blood 2020, 135, 121-132, doi:10.1182/blood.2019001866.

6. Nair, R.R.; Emmons, M.F.; Cress, A.E.; Argilagos, R.F.; Lam, K.; Kerr, W.T.; Wang, H.G.; Dalton, W.S.; Hazlehurst, L.A. HYD1-induced increase in reactive oxygen species 
leads to autophagy and necrotic cell death in multiple myeloma cells. Mol Cancer Ther 2009, 8, 2441-2451, doi:10.1158/1535-7163.MCT-09-0113.

7. Emmons, M.F.; Gebhard, A.W.; Nair, R.R.; Baz, R.; McLaughlin, M.L.; Cress, A.E.; Hazlehurst, L.A. Acquisition of resistance toward HYD1 correlates with a reduction in cleaved alpha4 integrin expression and a compromised CAM-DR phenotype. Mol Cancer Ther 2011, 10, 2257-2266, doi:10.1158/1535-7163.MCT-11-0149.

8. Gebhard, A.W.; Jain, P.; Nair, R.R.; Emmons, M.F.; Argilagos, R.F.; Koomen, J.M.; McLaughlin, M.L.; Hazlehurst, L.A. MTI-101 (cyclized HYD1) binds a CD44 containing complex and induces necrotic cell death in multiple myeloma. Mol Cancer Ther 2013, 12, 2446-2458, doi:10.1158/1535-7163.MCT-13-0310.

9. de Souza, L.B.; Ong, H.L.; Liu, X.; Ambudkar, I.S. Fast endocytic recycling determines TRPC1-STIM1 clustering in ER-PM junctions and plasma membrane function of the channel. Biochim Biophys Acta 2015, 1853, 2709-2721, doi:10.1016/j.bbamcr.2015.07.019.

10. Kaczmarek, J.S.; Riccio, A.; Clapham, D.E. Calpain cleaves and activates the TRPC5 channel to participate in semaphorin 3A-induced neuronal growth cone collapse. Proc Natl Acad Sci U S A 2012, 109, 7888-7892, doi:10.1073/pnas.1205869109.

11. Verheijden, K.A.T.; Sonneveld, R.; Bakker-van Bebber, M.; Wetzels, J.F.M.; van der Vlag, J.; Nijenhuis, T. The Calcium-Dependent Protease Calpain-1 Links TRPC6 Activity to Podocyte Injury. J Am Soc Nephrol 2018, 29, 2099-2109, doi:10.1681/ASN.2016111248.

12. Kerstein, P.C.; Jacques-Fricke, B.T.; Rengifo, J.; Mogen, B.J.; Williams, J.C.; Gottlieb, P.A.; Sachs, F.; Gomez, T.M. Mechanosensitive TRPC1 channels promote calpain 
proteolysis of talin to regulate spinal axon outgrowth. $J$ Neurosci 2013, 33, 273-285, doi:10.1523/JNEUROSCI.2142-12.2013.

13. Liu, Z.; Cao, J.; Gao, X.; Ma, Q.; Ren, J.; Xue, Y. GPS-CCD: a novel computational program for the prediction of calpain cleavage sites. PLoS One 2011, 6, e19001, doi:10.1371/journal.pone.0019001. 


\title{
4.1 Curriculum Vitae
}

\section{Appendix}

\section{Osama Mokhtar Elzamzamy, MBBCh}

Email: omelzamzamy@mix.wvu.edu

Phone (+1) 304-694-8899

\section{Education:}

2016 - Present Ph.D. Student at the Clinical and Translational Sciences Program, School of Medicine, West Virginia University, Morgantown, WV. (Expected graduation date: June15th , 2021)

2005 - 2011 Bachelor of Medicine \& Surgery “MBBCH” Degree, Medical School of Ain Shams University, Cairo, Egypt

\section{Work Experience:}

\author{
August Graduate Research Assistant in Clinical and Translational Sciences, School of Medicine, West
} 2016 -June Virginia University, Morgantown, WV

2021 - Dissertation research focuses on understanding the mechanism of action of a novel therapy (MTI101) for the treatment of multiple myeloma. The research further explores a group of calcium channels called Store Operated Calcium Entry (SOCE) channels that are activated by MTI-101 leading to multiple myeloma cell death. Moreover, I am looking into patients' SOCE gene expression levels and how they correlate with survival. Findings from my research would provide a relevant impact in the future studies on SOCE channels, and will open new avenues in targeting cancer cells

- $\quad$ Tissue culture, both adherent and non-adherent cell lines

- Design and execute cell survival assays

- $\quad$ Ability to process patients bone marrow and peripheral blood samples to isolate PBMCs and CD13 multiple myeloma cells

- $\quad$ Ability to design and conduct high throughput screening protocol for drug libraries

- Design and execute cell imaging protocols, including, TIRF and Confocal microscopy

- Western blotting, immunoprecipitation and co-immunoprecipitation assays

- Transformations, transfections, DNA purification, minipreps, midipreps, restriction digest, CRISPR/Cas9 technology for targeted genome editing, and infections by producing lentivirus, and retrovirus

- Immunofluorescence and immunohistochemistry assays

- $\quad$ Ability to design informative mechanistic pathways using Ingenuity Pathway Analysis (IPA) and Photoshop

- $\quad$ Real-time PCR

- Data collection and analysis

July 2015 - Medical Science Liaison at Novo Nordisk Inc. Cairo, Egypt

- $\quad$ Participate in the Pre-Launch activities for a new product by Novo Nordisk Inc.

June 2016

- Assist in preparation of presentations for Continuous Medical Education programs for Health Care Providers

- $\quad$ Identify and recruits qualified investigators to participate in company-sponsored activities

- Identify, contact, develop and maintain relations with health care providers, and key opinion leaders (KOLs) to establish and/or further the knowledge of Novo Nordisk products and their appropriate use; when necessary, develops resolving issues pertaining to that use

- Identify, respond to inquiries and develop relationships with health care professionals; identifying those individuals with novel research concepts, clinical experience and expertise, within identified therapeutic areas of interest to Novo Nordisk Inc.

- Attend both national and regional scientific/medical meetings to gain medical voice of the customer on recent data being presented on products and disease states of interest to Novo Nordisk Inc. 
- To respond orally or by providing appropriate written materials to unsolicited requests for on- or off-label information or safety concerns that may have been asked of Novo Nordisk sales staff or Medical and adhering to all policies and procedures regarding the provision of medical information

May 2014 - Clinical Research assistant at the anesthesiology department, West Virginia University Hospital. Morgantown, WV

June 2015 - Managing the recruitment, screening and enrollment of research patients

- Conducting research visits with study patients and study clinicians

- Data collection, entry, and analysis

- Manuscript and conference submission and preparation

- Preparation and submission of research protocols to the Institutional Review Board (IRB)

- Ensuring compliance with the Partners IRB and other federal and institutional guidelines Grant submissions

August Medical Information Associate, AstraZeneca. Cairo, Egypt (Part-time)

2013 - - Answering HCPs concerns regarding on and off label indications

March 2014 - Supporting HCPs with scientific data and evidences regarding company products Pharmaco-vigilance reporting to Astrazeneca after receiving reports from HCPs

April2013

$2013-$

January

Radiology resident, Ain Shams University Hospital. Cairo, Egypt

2014

March 2012

- February Medical Intern, Ain Shams University hospital. Cairo, Egypt

2013

\section{Research Experience:}

May 2017 -

Present

Jan 2017 -

May 2017

August 2016

- Feb 2017

May 2014 -

June 2015

\section{Graduate research assistant at Dr. Hazlehurst lab}

\section{Research Rotation - Graduate research assistant at West Virginia University Cancer Institute - Cancer Prevention and Control}

\section{Research Rotation - Graduate research assistant at Dr. Steven Frisch lab}

Dr. Frisch's lab has pioneered research in Epithelial Mesenchymal Transition (EMT). Dr. Frisch leads research on Grainyhead-Like 2 (GRHL2) and its role in EMT, cancer recurrence, and drug resistance. My contribution to this work was included in a publication recently published in Molecular Immunology.

\section{Post-baccalaureate Research at the Department of Anesthesiology at West Virginia University} Working under the supervision of Drs. Ahmed Attaallah, and Manuel Vallejo. Dr. Attaallah, and Dr. Vallejo are interested in improving the operating room efficiency through the monitoring time utilization. They were also interested in improving health outcomes during and after cesarean deliveries, and studying the risk factors for respiratory failure following anesthesia. During my one year, I helped develop and submit research protocols to the institutional review board (IRB), assessed in patient recruitment, follow-up afterwards, data collection, data analysis, manuscript writing, and grant submission. My contribution to these studies were included in multiple publications.

\section{Peer- reviewed Publications:}

April 2021 Osama M. Elzamzamy, Brandon E. Johnson, Wei-Chih Chen, Gangqing Hu, Reinhold Penner, Lori A. Hazlehurst. Transient Receptor Potential C 1/4/5 is a Determinant of MTI-101 Induced Calcium Influx and Cell Death in Multiple Myeloma. Cells June, 2021.

Feb 2020 Osama M Elzamzamy ,Reinhold Penner, Lori A Hazlehurst. The Role of TRPC1 in Modulating Cancer Progression. Cells 2020, 9(2), 388; https://doi.org/10.3390/cells9020388 [PMID: 32046188]

Mar 2019 Attaallah AF, Vallejo MC, Elzamzamy OM, Mueller MG, Eller WS. Perioperative risk factors for postoperative respiratory failure. J Perioper Pract. 2019 Mar;29(3):49-53 [PMID: 30035690]

Jan 2019 MacFawn I, Wilson H, Selth LA, Leighton I, Serebriiskii I, Bleackley RC, Elzamzamy O, Farris J, Pifer PM, Richer J, Frisch SM. Grainyhead-like-2 confers NK-sensitivity through interactions with epigenetic modifiers. Mol Immunol. 2019 Jan;105:137-149 [PMID: 30508726] 
Feb 2017 Vallejo MC, Attaallah AF, Shapiro RE, Elzamzamy OM, Mueller MG, Eller WS. Independent risk factors for surgical site infection after cesarean delivery in a rural tertiary care medical center. J Anesth. 2017 Feb;31(1):120126 [PMID: 27734126]

Feb 2017 M.C. Vallejo, A.F. Attaallah, O.M. Elzamzamy, D.T. Cifarelli, A.L. Phelps, G.R. Hobbs, R.E. Shapiro, P. Ranganathan. An open-label randomized controlled clinical trial for comparison of continuous phenylephrine versus norepinephrine infusion in prevention of spinal hypotension during cesarean delivery. Int J Obstet Anesth. 2017 Feb;29:18-25 [PMID: 27720613]

May 2016 Attaallah A, Elzamzamy O, Phelps A, Ranganathan P, Vallejo M. Increasing Operating Room Efficiency through Electronic Medical Record Analysis. J Perioper Pract. 2016 May;26(5):106-113 [PMID: 27400488]

Feb 2016 Dragan KE, Patten WD, Elzamzamy OM, Attaallah AF. Acute intraoperative neurogenic myocardial stunning during intracranial endoscopic fenestration and shunt revision in a pediatric patient. J Anesth. 2016 Feb; 30 (1), 152-155 [PMID: 26314948]

\title{
Presentations:
}

Oct 2019 Osama Elzamzamy, Karen Hayes, Werner Geldenhuys, Lori Hazlehurst. Role of MTI-101 in disrupting calcium homeostasis leading to cell death in multiple myeloma. Presented at 2019 AACR-NCI-EORTC International Conference, Molecular Targets and Cancer Therapeutics. Boston, MA

April 2019 Osama Elzamzamy, Karen Hayes, Weih-Chi Chen, Lori Hazlehurst. MTI-101 Treatment Induces Continuous Activation of SOCEs Leading Necrosis in Multiple Myeloma. Presented at 2019 West Virginia Clinical and Translational Sciences Institute Annual Meeting, White Sulphur Springs, WV

July 2018 Osama Elzamzamy, Mackenna Boone, Karen Hayes, Wei-Chih Chen, Christopher Frum, Werner Geldenhuys, Lori Hazlehurst. High Throughput Screen Identifies GSK-3 Inhibition Enhances MTI-101 Induced Necrosis in Multiple Myeloma. Presented at the 2018 Molecular Therapeutics of Cancer Research Meeting, Sundance, UT

May 2018 Osama Elzamzamy. High Throughput Screen Identifies GSK-3 Inhibition Enhances MTI-101 Induced Necrosis in Multiple Myeloma. Presented at 2018 West Virginia Clinical and Translational Sciences Institute Annual Meeting, Morgantown, WV. Selected best oral presentation

Oct 2017 Osama Elzamzamy, Christopher Frum, Weih-Chi Chen, Lori Hazlehurst. MTI-101 Induces Calcium Induced Necrosis in Multiple Myeloma Patient Sample and Spares Normal Bone Marrow Cell Line. Presented at South Regional WV-INBRE IDeA conference. Morgantown, WV

\section{Skill Sets:}

Communication _ - Strong communication/presentation skills: presented data clearly and confidently to both small and large groups in regional and national meetings, adapting style and content to the level of knowledge and understanding of others

Interpersonal _ - Coached and collaborated with other scientists, outlining objectives, methodology, and

Skills and conclusions, actively listening to people and stimulating interest and discussion

Teaching

- Exchanged constructive feedback and support and learned delegating responsibility

- $\quad$ Supervised and taught undergrad and PharmD. students, adapting to different scientific levels and backgrounds, and stimulating discussion

- Participated in evaluation juries for poster sessions in Van Lierre Research Day at WVU

- Wrote and submitted a F31 grant

\section{Membership and Honors:}

\author{
2019 - Present $\quad$ Member of the American Association for Cancer Research (AACR) \\ 2018 - Present Member of the American Association for the Advancement of Science (AAAS) \\ 2017 - 2018 Member of the PhD admissions committee for the Clinical and Translational Sciences PhD \\ program at WVU
}

\section{Professional Development:}


Nov 2017

May 2017
GATK (Gene-expression Analysis Tool Kit) Workshop by the Broad Institute, WV-INBRE at Marshall University, Huntington, WV

Bioinformatics Workshop at West Virginia University: Introduction to Unix Shell, R, R studio 


\subsection{Figures Copyright Permissions}

Chapter 1:

Figure 1: License to reuse:

Copyright (C) 2016 Simona Magi et al. This is an open access article distributed under the Creative Commons Attribution License, which permits unrestricted use, distribution, and reproduction in any medium, provided the original work is properly cited.

\section{Figure 5 License to reuse:}

This article is licensed under a Creative Commons Attribution 4.0 International License, which permits use, sharing, adaptation, distribution and reproduction in any medium or format, as long as you give appropriate credit to the original author(s) and the source, provide a link to the Creative Commons license, and indicate if changes were made. The images or other third party material in this article are included in the article's Creative Commons license, unless indicated otherwise in a credit line to the material. If material is not included in the article's Creative Commons license and your intended use is not permitted by statutory regulation or exceeds the permitted use, you will need to obtain permission directly from the copyright holder. To view a copy of this license, visit http://creativecommons.org/licenses/by/4.0/. 


\section{AMERICAN ASSOCIATION FOR CANCER RESEARCH LICENSE TERMS AND CONDITIONS}

Jun 02, 2021

This Agreement between West Virginia University -- Osama Elzamzamy ("You") and American Association for Cancer Research ("American Association for Cancer Research") consists of your license details and the terms and conditions provided by American Association for Cancer Research and Copyright Clearance Center.

License Number

License date

Licensed Content Publisher

Licensed Content Publication

Licensed Content Title
5081100260359

Jun 02, 2021

Molecular Cancer Therapeutics

MTI-101 (Cyclized HYD1) Binds a CD44 Containing Complex and Induces Necrotic Cell Death in Multiple Myeloma

Anthony W. Gebhard,Priyesh Jain,Rajesh R. Nair,Michael F.

Licensed Content Author Emmons,Raul F. Argilagos,John M. Koomen,Mark L.

McLaughlin,Lori A. Hazlehurst

Licensed Content Date Nov 1, 2013

Licensed Content Volume 12

Licensed Content Issue 11

Type of Use

Thesis/Dissertation

Requestor type

academic/educational 
Format

electronic

Portion

figures/tables/illustrations

Number of

figures/tables/illustrations 1

Will you be translating? no

Circulation

1

Territory of distribution North America

Title

Targeting Calcium Homeostasis for the Treatment of Multiple Myeloma

Institution name

West Virginia University

Expected presentation

date

Jun 2021

Portions

Figure $1 . \mathrm{B}$ on page 5

West Virginia University

64 Medical Center Dr

Hazlehurst Lab HSC BMRC Rm 2815

Requestor Location

MORGANTOWN, WV 26506

United States

Attn: West Virginia University

Total

0.00 USD

Terms and Conditions

\section{American Association for Cancer Research (AACR) Terms and Conditions}

\section{INTRODUCTION}

The Publisher for this copyright material is the American Association for Cancer Research (AACR). By clicking "accept" in connection with completing this licensing transaction, you 
agree to the following terms and conditions applying to this transaction. You also agree to the Billing and Payment terms and conditions established by Copyright Clearance Center (CCC) at the time you opened your Rightslink account.

\section{LIMITED LICENSE}

The AACR grants exclusively to you, the User, for onetime, non-exclusive use of this material for the purpose stated in your request and used only with a maximum distribution equal to the number you identified in the permission process. Any form of republication must be completed within one year although copies made before then may be distributed thereafter and any electronic posting is limited to a period of one year. Reproduction of this material is confined to the purpose and/or media for which permission is granted. Altering or modifying this material is not permitted. However, figures and illustrations may be minimally altered or modified to serve the new work.

\section{GEOGRAPHIC SCOPE}

Licenses may be exercised as noted in the permission process

\section{RESERVATION OF RIGHTS}

The AACR reserves all rights not specifically granted in the combination of 1) the license details provided by you and accepted in the course of this licensing transaction, 2) these terms and conditions, and 3) CCC's Billing and Payment terms and conditions.

\section{DISCLAIMER}

You may obtain permission via Rightslink to use material owned by AACR. When you are requesting permission to reuse a portion for an AACR publication, it is your responsibility to examine each portion of content as published to determine whether a credit to, or copyright notice of a third party owner is published next to the item. You must obtain permission from the third party to use any material which has been reprinted with permission from the said third party. If you have not obtained permission from the third party, AACR disclaims any responsibility for the use you make of items owned by them.

\section{LICENSE CONTINGENT ON PAYMENT}

While you may exercise the rights licensed immediately upon issuance of the license at the end of the licensing process for the transaction, provided that you have disclosed complete and accurate details of your proposed use, no license is finally effective unless and until full payment is received from you, either by the publisher or by the CCC, as provided in CCC's Billing and Payment terms and conditions. If full payment is not received on a timely basis, then any license preliminarily granted shall be deemed automatically revoked and shall be void as if never granted. Further, in the event that you breach any of these terms and conditions, or any of the CCC's Billing and Payment terms and conditions, the license is automatically revoked and shall be void as if never granted. Use of materials as described in a revoked license, as well as any use of the materials beyond the scope of an unrevoked license, may constitute copyright infringement and the publisher reserves the right to take any and all action to protect its copyright in the materials.

\section{COPYRIGHT NOTICE}

You must include the following credit line in connection with your reproduction of the licensed material: "Reprinted (or adapted) from Publication Title, Copyright Year, Volume/Issue, Page Range, Author, Title of Article, with permission from AACR".

\section{TRANSLATION}

This permission is granted for non-exclusive world English rights only.

\section{WARRANTIES}

Publisher makes no representations or warranties with respect to the licensed material. 


\section{INDEMNIFICATION}

You hereby indemnify and agree to hold harmless the publisher and CCC, and their respective officers, directors, employees and agents, from and against any and all claims arising out of your use of the licensed material other than as specifically authorized pursuant to this license.

\section{REVOCATION}

The AACR reserves the right to revoke a license for any reason, including but not limited to advertising and promotional uses of AACR content, third party usage and incorrect figure source attribution.

\section{NO TRANSFER OF LICENSE}

This license is personal to you and may not be sublicensed, assigned, or transferred by you to any other person without publisher's written permission.

\section{NO AMENDMENT EXCEPT IN WRITING}

This license may not be amended except in a writing signed by both parties (or, in the case of publisher, by CCC on publisher's behalf).

\section{OBJECTION TO CONTRARY TERMS}

Publishers hereby objects to any terms contained in any purchase order, acknowledgement, check endorsement or other writing prepared by you, which terms are inconsistent with these terms and conditions or CCC's Billing and Payment terms and conditions. These terms and conditions together with CCC's Billing and Payment terms and conditions (which are incorporated herein) comprise the entire agreement between you and publisher (and CCC) concerning this licensing transaction. In the event of any conflict between your obligations established by these terms and conditions, and those established by CCC's Billing and Payment terms and conditions, these terms and conditions shall control.

\section{THESIS/DISSERTATION TERMS}

If your request is to reuse an article authored by you and published by the AACR in your dissertation/thesis, your thesis may be submitted to your institution in either in print or electronic form. Should your thesis be published commercially, please reapply.

\section{ELECTRONIC RESERVE}

If this license is made in connection with a course, and the Licensed Material or any portion thereof is to be posted to a website, the website is to be password protected and made available only to the students registered for the relevant course. The permission is granted for the duration of the course. All content posted to the website must maintain the copyright information notice.

\section{JURISDICTION}

This license transaction shall be governed by and construed in accordance with the laws of Pennsylvania. You hereby agree to submit to the jurisdiction of the federal and state courts located in Pennsylvania for purposes of resolving any disputes that may arise in connection with this licensing transaction.

Other Terms and Conditions:

$\mathrm{v} 1.0$

Questions? customercare@copyright.com or +1-855-239-3415 (toll free in the US) or +1-978-646-2777. 


\section{SPRINGER NATURE LICENSE}

TERMS AND CONDITIONS

Jun 03, 2021

This Agreement between West Virginia University -- Osama Elzamzamy ("You") and Springer Nature ("Springer Nature") consists of your license details and the terms and conditions provided by Springer Nature and Copyright Clearance Center.

License Number

License date

Licensed Content Publisher

Licensed Content Publication

Licensed Content Title

Licensed Content Author

Licensed Content Date

Type of Use

Requestor type

Format

Portion

Number of

figures/tables/illustrations
5081670110034

Jun 03, 2021

Springer Nature

Nature Reviews Molecular Cell Biology

Molecular mechanisms of necroptosis: an ordered cellular explosion

Peter Vandenabeele et al

Sep 8, 2010

Thesis/Dissertation

academic/university or research institute

print and electronic

figures/tables/illustrations 
Will you be translating?

no

Circulation/distribution

$1000-1999$

Author of this Springer Nature content

no

Title

Targeting Calcium Homeostasis for the Treatment of Multiple Myeloma

Institution name

West Virginia University

Expected presentation date Jun 2021

Portions

Figure 1

West Virginia University

64 Medical Center Dr

Hazlehurst Lab HSC BMRC Rm 2815

Requestor Location

MORGANTOWN, WV 26506

United States

Attn: West Virginia University

Total

0.00 USD

Terms and Conditions

\section{Springer Nature Customer Service Centre GmbH Terms and Conditions}

This agreement sets out the terms and conditions of the licence (the Licence) between you and Springer Nature Customer Service Centre GmbH (the Licensor). By clicking 'accept' and completing the transaction for the material (Licensed Material), you also confirm your acceptance of these terms and conditions.

\section{Grant of License}

1. 1. The Licensor grants you a personal, non-exclusive, non-transferable, world-wide licence to reproduce the Licensed Material for the purpose specified in your order only. Licences are granted for the specific use requested in the order and for no other 
use, subject to the conditions below.

1. 2. The Licensor warrants that it has, to the best of its knowledge, the rights to license reuse of the Licensed Material. However, you should ensure that the material you are requesting is original to the Licensor and does not carry the copyright of another entity (as credited in the published version).

1. 3. If the credit line on any part of the material you have requested indicates that it was reprinted or adapted with permission from another source, then you should also seek permission from that source to reuse the material.

\section{Scope of Licence}

2. 1. You may only use the Licensed Content in the manner and to the extent permitted by these Ts\&Cs and any applicable laws.

2. 2. A separate licence may be required for any additional use of the Licensed Material, e.g. where a licence has been purchased for print only use, separate permission must be obtained for electronic re-use. Similarly, a licence is only valid in the language selected and does not apply for editions in other languages unless additional translation rights have been granted separately in the licence. Any content owned by third parties are expressly excluded from the licence.

2. 3. Similarly, rights for additional components such as custom editions and derivatives require additional permission and may be subject to an additional fee. Please apply to

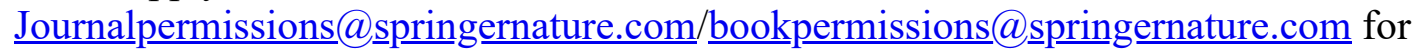
these rights.

2. 4. Where permission has been granted free of charge for material in print, permission may also be granted for any electronic version of that work, provided that the material is incidental to your work as a whole and that the electronic version is essentially equivalent to, or substitutes for, the print version.

2. 5. An alternative scope of licence may apply to signatories of the $\underline{\text { STM Permissions }}$ Guidelines, as amended from time to time.

\section{Duration of Licence}

3. 1. A licence for is valid from the date of purchase ('Licence Date') at the end of the relevant period in the below table:

\begin{tabular}{|l|l|}
\hline Scope of Licence & Duration of Licence \\
\hline Post on a website & 12 months \\
\hline \hline Presentations & 12 months \\
\hline Books and journals & Lifetime of the edition in the language purchased \\
\hline
\end{tabular}

\section{Acknowledgement}


4. 1. The Licensor's permission must be acknowledged next to the Licenced Material in print. In electronic form, this acknowledgement must be visible at the same time as the figures/tables/illustrations or abstract, and must be hyperlinked to the journal/book's homepage. Our required acknowledgement format is in the Appendix below.

\section{Restrictions on use}

5. 1. Use of the Licensed Material may be permitted for incidental promotional use and minor editing privileges e.g. minor adaptations of single figures, changes of format, colour and/or style where the adaptation is credited as set out in Appendix 1 below. Any other changes including but not limited to, cropping, adapting, omitting material that affect the meaning, intention or moral rights of the author are strictly prohibited.

5. 2. You must not use any Licensed Material as part of any design or trademark.

5. 3. Licensed Material may be used in Open Access Publications (OAP) before publication by Springer Nature, but any Licensed Material must be removed from OAP sites prior to final publication.

\section{Ownership of Rights}

6. 1. Licensed Material remains the property of either Licensor or the relevant third party and any rights not explicitly granted herein are expressly reserved.

\section{Warranty}

IN NO EVENT SHALL LICENSOR BE LIABLE TO YOU OR ANY OTHER PARTY OR ANY OTHER PERSON OR FOR ANY SPECIAL, CONSEQUENTIAL, INCIDENTAL OR INDIRECT DAMAGES, HOWEVER CAUSED, ARISING OUT OF OR IN CONNECTION WITH THE DOWNLOADING, VIEWING OR USE OF THE MATERIALS REGARDLESS OF THE FORM OF ACTION, WHETHER FOR BREACH OF CONTRACT, BREACH OF WARRANTY, TORT, NEGLIGENCE, INFRINGEMENT OR OTHERWISE (INCLUDING, WITHOUT LIMITATION, DAMAGES BASED ON LOSS OF PROFITS, DATA, FILES, USE, BUSINESS OPPORTUNITY OR CLAIMS OF THIRD PARTIES), AND

WHETHER OR NOT THE PARTY HAS BEEN ADVISED OF THE POSSIBILITY OF SUCH DAMAGES. THIS LIMITATION SHALL APPLY NOTWITHSTANDING ANY FAILURE OF ESSENTIAL PURPOSE OF ANY LIMITED REMEDY PROVIDED HEREIN.

\section{Limitations}

8. 1. BOOKS ONLY:Where 'reuse in a dissertation/thesis' has been selected the following terms apply: Print rights of the final author's accepted manuscript (for clarity, NOT the published version) for up to 100 copies, electronic rights for use only on a personal website or institutional repository as defined by the Sherpa guideline 
(www.sherpa.ac.uk/romeo/).

8. 2. For content reuse requests that qualify for permission under the STM Permissions Guidelines, which may be updated from time to time, the STM Permissions Guidelines supersede the terms and conditions contained in this licence.

\section{Termination and Cancellation}

9. 1. Licences will expire after the period shown in Clause 3 (above).

9. 2. Licensee reserves the right to terminate the Licence in the event that payment is not received in full or if there has been a breach of this agreement by you.

\section{Appendix 1 - Acknowledgements:}

For Journal Content:

Reprinted by permission from [the Licensor]: [Journal Publisher (e.g. Nature/Springer/Palgrave)] [JOURNAL NAME] [REFERENCE CITATION (Article name, Author(s) Name), [COPYRIGHT] (year of publication)

For Advance Online Publication papers:

Reprinted by permission from [the Licensor]: [Journal Publisher (e.g. Nature/Springer/Palgrave)] [JOURNAL NAME] [REFERENCE CITATION (Article name, Author(s) Name), [COPYRIGHT] (year of publication), advance online publication, day month year (doi: 10.1038/sj.[JOURNAL ACRONYM].)

For Adaptations/Translations:

Adapted/Translated by permission from [the Licensor]: [Journal Publisher (e.g. Nature/Springer/Palgrave)] [JOURNAL NAME] [REFERENCE CITATION (Article name, Author(s) Name), [COPYRIGHT] (year of publication)

\section{Note: For any republication from the British Journal of Cancer, the following} credit line style applies:

Reprinted/adapted/translated by permission from [the Licensor]: on behalf of Cancer Research UK: : [Journal Publisher (e.g. Nature/Springer/Palgrave)] [JOURNAL NAME] [REFERENCE CITATION (Article name, Author(s) Name), [COPYRIGHT] (year of publication)

For Advance Online Publication papers:

Reprinted by permission from The [the Licensor]: on behalf of Cancer Research UK: [Journal Publisher (e.g. Nature/Springer/Palgrave)] [JOURNAL NAME] [REFERENCE CITATION (Article name, Author(s) Name), [COPYRIGHT] (year of publication), advance online publication, day month year (doi: 10.1038/sj. [JOURNAL ACRONYM])

\section{For Book content:}

Reprinted/adapted by permission from [the Licensor]: [Book Publisher (e.g. Palgrave Macmillan, Springer etc) [Book Title] by [Book author(s)]

[COPYRIGHT] (year of publication) 


\section{Other Conditions:}

Version 1.3

Questions? customercare@copyright.com or +1-855-239-3415 (toll free in the US) or +1-978-646-2777. 